\author{
Universidade de Brasília \\ Instituto de Ciências Exatas \\ Departamento de Ciência da Computação
}

\title{
Composição Algoritmica de Fugas ao Estilo de J. S. Bach
}

\author{
José Marcos Alves Menezes
}

Monografia apresentada como requisito parcial para conclusão do Bacharelado em Ciência da Computação

Orientador

Prof. Dr. Aluizio Arcela

Brasília

2008 
Universidade de Brasília - UnB

Instituto de Ciências Exatas

Departamento de Ciência da Computação

Curso de Bacharelado em Ciência da Computação

Coordenador: Prof. Dr. Guilherme Albuquerque Pinto

Banca examinadora composta por:

Prof. Dr. Aluizio Arcela (Orientador) - CIC/UnB

Prof. Dr. Márcio da Costa Pereira Brandão - CIC/UnB

Prof. Dr. Homero Luiz Píccolo - CIC/UnB

\section{CIP - Catalogação Internacional na Publicação}

José Marcos Alves Menezes.

Composição Algorítmica de Fugas ao Estilo de J. S. Bach/ José Marcos Alves Menezes. Brasília : UnB, 2008.

95 p. : il. ; $29,5 \mathrm{~cm}$.

Monografia (Graduação) - Universidade de Brasília, Brasília, 2008.

1. Composição algorítmica, 2. Fuga, 3. Bach,

4. Linguagens para notação musical

CDU 004

Endereço: Universidade de Brasília

Campus Universitário Darcy Ribeiro - Asa Norte

CEP 70910-900

Brasília - DF - Brasil 

Universidade de Brasília
Instituto de Ciências Exatas
Departamento de Ciência da Computação

\title{
Composição Algoritmica de Fugas ao Estilo de J. S. Bach
}

\author{
José Marcos Alves Menezes \\ Monografia apresentada como requisito parcial \\ para conclusão do Bacharelado em Ciência da Computação
}

\author{
Prof. Dr. Aluizio Arcela (Orientador) \\ $\mathrm{CIC} / \mathrm{UnB}$
}
Prof. Dr. Márcio da Costa Pereira Brandão Prof. Dr. Homero Luiz Píccolo $\mathrm{CIC} / \mathrm{UnB}$ $\mathrm{CIC} / \mathrm{UnB}$

Prof. Dr. Guilherme Albuquerque Pinto Coordenador do Bacharelado em Ciência da Computação

Brasília, 27 de junho de 2008 


\section{Dedicatória}

Dedico este trabalho ao meu orientador Aluizio, minha principal referência, que sempre me incentivou a nunca desistir e me mostrou outras possibilidades musicais. 


\section{Agradecimentos}

Meus sinceros agradecimentos a Eliza, Yuri, Lehilton, Ígor e Daniel,meus companheiros de jornada, por sempre me acompanhar nesses cinco árduos e longos anos. 


\section{Resumo}

O presente trabalho implementa a geração computacional automática de fugas, baseada no estilo de compor de J. S. Bach, por crescimento melódico, a partir de transformações melódicas sobre um tema dado, chamado de sujeito da fuga.

A fuga é codificada como um script em uma linguagem de notação musical bastante eficiente (LilyPond).

A partir desse script, utilizando-se o interpretador dessa linguagem, pode-se obter uma representação sônica - por arquivos MIDI - ou a partitura gráfica em PostScript da fuga gerada.

Palavras-chave: Composição algorítmica, Fuga, Bach, Linguagens para notação musical 


\section{Abstract}

This project implements the automatic computational generation of fugues, based on the composing style of J. S. Bach, by melodic growth, using melodic transformations on a given theme, called fugue subject.

The fugue is codified as a script using a very efficient musical notation language called LilyPond.

From this script, using this language interpreter, we are able to have a sonic representation - through MIDI files - or a grafic score in PostScript of the generated fugue.

Keywords: Algorithmic composition, Fugue, Bach, Music notation languages 


\section{Sumário}

$\begin{array}{ll}\text { Lista de Figuras } & 10\end{array}$

$\begin{array}{ll}\text { Lista de Códigos } & 10\end{array}$

$\begin{array}{lll}\text { Capítulo } 1 \text { Introdução } & 13\end{array}$

$\begin{array}{lll}\text { Capitulo } 2 \text { Anatomia da Fuga } & 15\end{array}$

$\begin{array}{ll}\text { Capítulo } 3 \text { Notação Musical } & 17\end{array}$

3.1 Notas . . . . . . . . . . . . . . . . 17

3.2 Altura . . . . . . . . . . . . . . . 18

3.3 Duração . . . . . . . . . . . . . . . . . 18

3.4 Símbolos . . . . . . . . . . . . . . . 19

3.4 .1 Pausas . . . . . . . . . . . . . . 19

3.4 .2 Ligaduras . . . . . . . . . . . . . . . . 19

3.4 .3 Ponto de aumento . . . . . . . . . . . . . 19

3.5 Sobre a linguagem LiLyPond . . . . . . . . . . . . . . . 19

3.5.1 O formato .ly . . . . . . . . . . . 20

3.5.2 Comandos . . . . . . . . . . . . 20

3.5.3 Exemplo de código no formado .ly . . . . . . . . . 21

Capítulo 4 Transformações Melódicas 23

4.1 Resposta . . . . . . . . . . . . . . . 24

4.2 Contra-sujeitos . . . . . . . . . . . . . 25

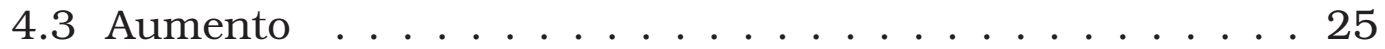

4.4 Diminuição . . . . . . . . . . . . . . . . . 25

4.5 Retrógrado . . . . . . . . . . . . . . . 25

4.6 Transformações inversas . . . . . . . . . . . . . 25

Capítulo 5 Algoritmo do Programa FugueMaker 27

5.1 Propriedades do sujeito . . . . . . . . . . . 27

5.2 O algoritmo . . . . . . . . . . . . . . 28

5.3 Considerações . . . . . . . . . . . . . . 28

Capítulo 6 Implementação das Classe do Programa FugueMaker 29

6.1 Implementação da Classe Constantes . . . . . . . . . 29

6.2 Implementação da Classe Arquivo . . . . . . . . . . . . 30

6.3 Implementação da Classe Arquivo_tily . . . . . . . . . . 33 
6.4 Implementação da Classe TocadorMidi . . . . . . . . . . . 34

6.5 Implementação da Classe FuncoesAuxiliares . . . . . . 38

6.6 Implementação da Classe PartesDaFuga . . . . . . . . . 45

52

6.8 Implementação da Classe GeraFuga . . . . . . . . . . . . 63

6.9 Implementação da Classe Janela . . . . . . . . . . . . . 73

6.9 .1 Interface Gráfica . . . . . . . . . . . . . . 78

6.10 Implementação da Classe ProgramaFinal . . . . . . . . 79

Capitulo 7 Resultados Obtidos $\quad \mathbf{8 0}$

7.1 Exemplo 1: O Cravo Bem Temperado, Fuga I em Dó Maior

(BWV 846) . . . . . . . . . . . . . . . . 81

7.1.1 Sujeito ( entrada do programa ) . . . . . . . 8 81

7.1 .2 Fuga ( saída do programa ) . . . . . . . . . . 82

7.1.3 Partitura . . . . . . . . . . . . . . 82

7.2 Exemplo 2: O Cravo Bem Temperado, Fuga II em Dó

Menor (BWV 847) . . . . . . . . . . . . . . . . . 84

7.2.1 Sujeito ( entrada do programa ) . . . . . . . . 84

7.2 .2 Fuga ( saída do programa ) . . . . . . . . . 85

7.2 .3 Partitura . . . . . . . . . . . . . 85

7.3 Exemplo 3: A Arte da Fuga, Contrapunctus I em Ré Menor

(BWV 1080) . . . . . . . . . . . . . . . 87

7.3.1 Sujeito ( entrada do programa ) . . . . . . . 87

7.3 .2 Fuga ( saída do programa ) . . . . . . . . . 88

7.3.3 Partitura . . . . . . . . . . . . . 888

7.4 Exemplo 4: Tema do Desenho Animado "Os Simpsons"

7.4.1 Sujeito ( entrada do programa ) . . . . . . . . . . 990

7.4.2 Fuga ( saída do programa ) . . . . . . . . . . 91

7.4 .3 Partitura .................. 91

Capítulo 8 Conclusões e Trabalhos Futuros 94 


\section{Lista de Figuras}

3.1 Nomenclatura das notas . . . . . . . . . . . . 17

3.2 Notação de bemóis e sustenidos . . . . . . . . . . . . 17

3.3 Altura das notas . . . . . . . . . . . . . . . 18

3.4 Duração das notas . . . . . . . . . . . . . . . 18

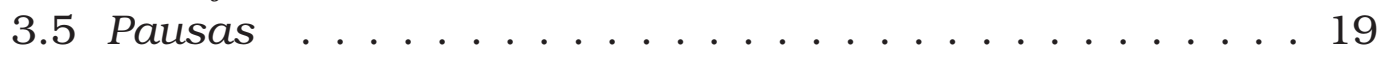

3.6 Ligadura . . . . . . . . . . . . . . . . . . . . . 19

3.7 Ponto de Aumento . . . . . . . . . . . . . . . . . . . 19

6.1 Interface Gráfica . . . . . . . . . . . . . . . 78

7.1 Sujeito da Fuga . . . . . . . . . . . . . . 81

7.2 Partitura ...................... . . 83

7.3 Continuação da Partitura . . . . . . . . . . . . . . 84

7.4 Sujeito da Fuga . . . . . . . . . . . . . . . 84

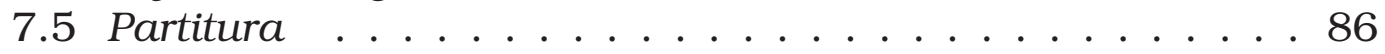

7.6 Continuação da Partitura . . . . . . . . . . . . . . 87

7.7 Sujeito da Fuga . . . . . . . . . . . . . . . . . 87

7.8 Partitura . . . . . . . . . . . . . . . . . 89

7.9 Continuação da Partitura . . . . . . . . . . . . . . 90

7.10 Sujeito da Fuga . . . . . . . . . . . . . . . 990

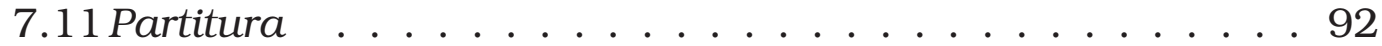

7.12 Continuação da Partitura . . . . . . . . . . . . . . 93 


\section{Lista de Códigos}

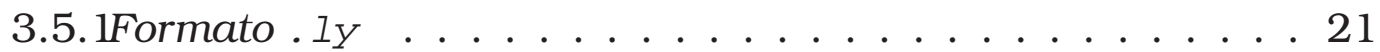

3.5.2Continuação do formato . Iy . . . . . . . . . . . 22

6.1.1Implementação da Classe Constantes . . . . . . . . . . 30

6.2.1Implementação do método de abertura de arquivos . . . . . 31

6.2.2Implementação do método de gravação de arquivos . . . . . 32

6.3. 1Códigos dos instrumentos musicais utilizados . . . . . . . . 33

6.3.2Texto para geração do arquivo . mid . . . . . . . . . . . . . 34

6.3.3Variável que guarda o texto do arquivo .ly a ser gerado . . . 34

6.3.4Implementação do método para adicionar texto à variável

arquivoprincipal . . . . . . . . . . . . . 34

6.4.1Implementação da Classe TocadorMidi . . . . . . . . . . 35

6.4.2Continuação da implementação da Classe TocadorMidi . . 36

6.4.3Continuação da implementação da Classe TocadorMidi . . 37

6.5. Implementação do método get Literal () . . . . . . . . . 38

6.5.2Implementação da método get TempoNota () . . . . . . . . . 39

6.5.3implementação do método get NumCompassos () . . . . . . . 40

6.5.4Implementação do método get Compassoscheios () . . . . . 40

6.5.5mplementação do método getValorPreencherCompasso () 40

6.5.6implementação do método getPosicaoNota() . . . . . . . . 41

6.5.7mplementação do método calcula Inversao() . . . . . . . 42

6.5.8mplementação do método imprime () . . . . . . . . . . . . . 42

6.5.9implementação do método modificaUltimaNota () . . . . . 43

6.5.10nplementação do método retiraultimaNota () . . . . . . 43

6.5. 1Implementação do método copialista() . . . . . . . . . . 44

6.5. 1Enplementação do método completaCompausas () . . . . . 44

6.5. 113nplementação do método retornaMaiorValor() . . . . . 45

6.6. 1Arraylist com as Partes da Fuga . . . . . . . . . . . . . . 45

6.6.2Implementação do método setSu jeito() . . . . . . . . . 46

6.6.3mplementação do método set Resposta () . . . . . . . . . . 46

6.6.4Implementação do método set ContraSujeito_1 () . . . . . 47

6.6.5mplementação do método set ContraSujeito_2() . . . . . 48

6.6.6Implementação do método setFuncInversaContraSujeito_1 () 50

6.6. Tmplementação do método set FuncInversaContraSu jeito_2() 51

6.6.8Implementação do método setPartesDaFuga() . . . . . . . 52

6.7. 1Arraylist com as Transformações Melódicas . . . . . . . 52

6.7.2Implementação do método normal iza Token () . . . . . . . . 53

6.7.3Continuação da implementação do método norma l i za Token () 54 
6.7.4Implementação do método transpoetoken() . . . . . . . . 55

6.7.5mplementação do método pausificaToken() . . . . . . . . 56

6.7.6Implementação do método aumenta Token () . . . . . . . . . 57

6.7.7mplementação do método diminui Token () . . . . . . . . . 58

6.7.8mplementação do método inverteToken() . . . . . . . . . 60

6.7.9Continuação da implementação do método inverteToken () 61

6.7.10nplementação do método set Inversao () . . . . . . . . . . 61

6.7.11mplementação do método set Ret rogrado() . . . . . . . . 62

6.7. 1Enplementação do método set Trans formacoesAlgebricas () 63

6.8.1Variáveis da Classe GeraFuga . . . . . . . . . . . . . . . 64

6.8.2Implementação dos métodos adicionarVoz . . . . . . . . 64

6.8.3implementação do método setFugaPrimeiraParte() . . . 65

6.8.4Continuação da implementação do método set FugaPrimei raParte () 66

6.8.5Continuação da Implementação do método set FugaPrimei raParte () 67

6.8.6Continuação da Implementação do método set FugaPrimeiraParte () 68

6.8.7Implementação do método setFugaSegundaParte() . . . . 69

6.8.8Implementação do método completarFugaCompausas () . . 70

6.8.9Continuação da implementação do método completarFugaCompausas () 71

6.8. 1Oontinuação da implementação do método complet arFugaComPausas () 72

6.8. 1Implementação do método set TextoVozes () . . . . . . . . 73

6.9. Implementação do método gerarfuga () . . . . . . . . . . . 74

6.9.2Continuação da implementação do método gerarFuga () . . 75

6.9.3mplementação do método compi larFuga () . . . . . . . . . 76

6.9.4Implementação do método tocarfuga() . . . . . . . . . . 77

6.10 Implementação da Classe ProgramaFinal . . . . . . . . 79

7.1.1Arquivo gerado pelo programa . . . . . . . . . . . . 82

7.2.1Arquivo gerado pelo programa . . . . . . . . . . 85

7.3.1Arquivo gerado pelo programa . . . . . . . . . . 88

7.4.1Arquivo gerado pelo programa . . . . . . . . . . . 9 91 


\section{Capítulo 1}

\section{Introdução}

O presente trabalho aborda a composição algorítmica[9] de fugas, ao estilo de J. S. Bach ${ }^{1}$, implementando um programa que realiza o trabalho que um compositor teria para compô-las.

A fuga é considerada por muitos como o mais matemático tipo de composição, principalmente por tratar-se de uma forma musical, ou antes, um roteiro a ser seguido, com várias partes que podem ser combinadas entre si, dependendo para isso somente da inventividade do compositor. Por esse motivo, de ser um "roteiro a ser seguido", um algoritmo, a fuga tem esse grau de abstração tipicamente matemático. Um computador, assim, poderia substituir o homem na tarefa artística[4] de elaborar uma fuga.

Uma fuga é uma composição tipicamente monotemática em que um tema musical (sujeito) é apresentado e desenvolvido, elaborado, variado em toda a extensão da peça[6]. Mesmo não sendo uma regra rígida, todo o material da fuga é derivado do sujeito.

Internamente, a construção da fuga leva em consideração as transformações que seu sujeito pode ter e, externamente, as possiveis concatenações dessas transformações[6].

Essas transformações do sujeito, que em música dá-se o nome de desenvolvimento, são, em última análise, funções que levam o sujeito de um domínio para uma contra-domínio, tendo uma determinada imagem como resultado. Essa analogia de música com matemática norteia todo este trabalho e possibilita, dessa maneira, a implementação de um programa que possa compor satisfatoriamente, computando e concatenando essas transformações.

Levando-se em consideração esses aspectos, a fuga se apresenta como uma forma de arte musical se não de todo, pelo menos em parte computável[3].

Os capítulos que se seguem abordam a constituição de uma fuga; a notação musical utilizada; a analogia do desenvolvolvimento temático com transformações melódicas; o algoritmo desenvolvido e as classe

\footnotetext{
${ }^{1}$ Compositor alemão que aprimorou e consolidou a forma fuga, sendo considerado por muitos o maior compositor desse estilo, levando a forma às últimas consequências.
} 
implementadas na linguagem JAVA; alguns resultados obtidos e, por fim, a conclusão a que se chegou. 


\section{Capítulo 2}

\section{Anatomia da Fuga}

Fuga, do latim fugare (perseguir) ou fugere (fugir)[8] é um um tipo contrapontístico de composição musical em que o sujeito ${ }^{1}$ é apresentado por uma voz isoladamente e, em seguida, é novamente apresentado, em outra tonalidade, por uma segunda voz, enquanto a primeira segue fazendo um contraponto, e assim sucessivamente, por outras vozes, dependendo de seu número[10].

Geralmente uma fuga apresenta de três a cinco vozes, sendo raro, mas não impossível o uso de somente duas ou mais de seis[10]. O termo vozes também pode ser denotado por partes, e não deve ser confundido com vozes humanas. Voz é uma linha melódica da fuga, sendo que um instrumento qualquer pode representá-la e/ou tocá-la.

A fuga é composta por três partes: a exposição, o desenvolvimento e a conclusão.

A exposição é o início da fuga, em que o sujeito será exposto por todas as vozes. É a parte da composição que define a fuga como tal, pois o desenvolvimento e a conclusão podem apresentar diversas formas, combinações, aparências. A exposição tem uma forma fixa, onde cada voz deve expor o sujeito uma vez, necessariamente, enquanto as outras vozes seguem fazendo algum tipo de contraponto.

O tema é chamado de sujeito[8] e apresenta algum interesse rítmico e/ou melódico que será desenvolvido posteriormente e é apresentado na tônica pela primeira voz. Qualquer voz pode iniciar a fuga, mas o sujeito deve, estritamente, na exposição, ser apresentado em todas as vozes.

Ao terminar a declaração do sujeito, a segunda voz entra com a resposta, enquanto a primeira voz faz um contraponto com ela, chamado de contra-sujeito. A resposta é uma imitação do sujeito em outra tonalidade, geralmente a dominante, ocasionalmente a subdominante. A resposta pode ser tonal ou real. Se real, são mantidos, literalmente, os intervalos do sujeito na nova tonalidade; se tonal, são feitas alterações para que fique adequada à nova tonalidade[8].

O contra-sujeito, como visto anteriormente, é um contraponto que

\footnotetext{
${ }^{1}$ Tema da fuga.
} 
irá acompanhar o sujeito em suas várias declarações, com exceção da primeira, em que o sujeito aparece desacompanhado.

Em uma fuga a três vozes, na exposição ocorrem as entradas sujeito - resposta - sujeito, necessariamente.

A parte central da fuga é chamada de desenvolvimento,onde o sujeito, como o próprio nome sugere, será desenvolvido, elaborado, variado, utilizando-se para isso seus motivos (fragmentos) rítmicos e melódicos.

Episódios são transições modulantes entre uma exposição e outra do sujeito, exposição aqui tomada com o sentido de reexposição temática e não a parte inicial da fuga. Usam de motivos do sujeito em sua composição. Episódios também podem ser chamados de divertimento.

Entra as várias possibilidades de técnicas composicionais, as mais usadas no desenvolvimento de uma fuga são :

- Inversões: os intervalos das notas do sujeito são invertidos, ou seja, o que era ascendente torna-se descendente e vice-versa.

- Movimento retrógrado: o sujeito é declarado de trás pra frente[7].

- Aumento e diminuição: os valores rítmicos das notas do sujeito sofrem um acréscimo ou decréscimo em seus valores, tornandose mais rápidos ou mais lentos [7].

- Seqüências: padrões rítmicos e melódicos que se repetem em cadeia, geralmente umas três vezes.

- Modulações: mudanças de tonalidade ou de modo (maior-menor).

- Entradas falsas: somente o início do sujeito aparece, dando a impressão de que ele será declarado totalmente.

Não é obrigatório que uma fuga apresente todas as técnicas acima elencadas, podendo, entretanto, apresentar uma combinação dessas técnicas [8].

Por fim, a conclusão pode apresentar um pedal (uma nota longa), geralmente a tônica ou dominante, no baixo (voz mais grave), que soa enquanto as demais vozes encerram a fuga, ou uma recapitulação do sujeito e uma coda $a^{2}$, com uma cadência final, no tom da tônica ${ }^{3}$, concluindo, assim, a composição.

\footnotetext{
${ }^{2}$ Cauda. Finalização de uma peça musical.

${ }^{3}$ Tonalidade em que a peça está escrita.
} 


\section{Capítulo 3}

\section{Notação Musical}

\subsection{Notas}

As notas são grafadas como na notação germânica, ou seja, com letras do alfabeto latino. Assim, como correspondência tem-se:

$$
\begin{aligned}
& \text { dó }=\mathrm{c} \\
& \text { ré }=\mathrm{d} \\
& \mathrm{mi}=\mathrm{e} \\
& \text { fá }=\mathrm{f} \\
& \mathrm{sol}=\mathrm{g} \\
& \text { lá }=\mathrm{a} \\
& \mathrm{si}=\mathrm{b}
\end{aligned}
$$

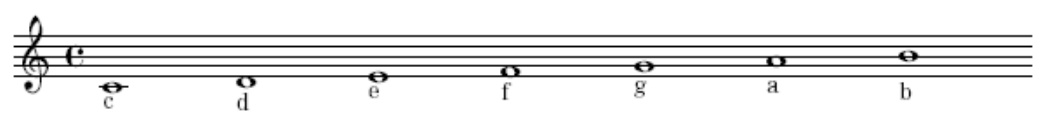

Figura 3.1: Nomenclatura das notas

Os sustenidos e bemóis ${ }^{1}$ são representados como "is"e "es", respectivamente, e são escritos imediatamente após as notas, sem espaços [1].

Duplos bemóis ou sustenidos ${ }^{2}$ são grafados com "isis"ou "eses”[1].

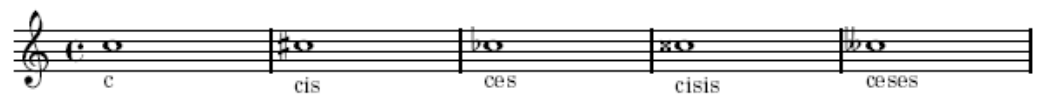

Figura 3.2: Notação de bemóis e sustenidos

\footnotetext{
${ }^{1}$ Os sustenidos e os bemóis são alterações ascendentes e descendentes, respectivamente, nas notas em que são aplicadas. Essas alterações elevam ou diminuem a frequência da nota em um semitom.

${ }^{2}$ Elevam ou diminuem a nota em que está aplicado em um tom.
} 


\subsection{Altura}

A altura de uma nota é a percepção psicológica do fenômeno físico que denomina-se frequência [2]. Notas com o mesmo nome podem estar em oitavas diferentes. Assim,para diferenciá-las, as oitavas são especificadas colocando-se apóstrofo ("”) ou vírgula (",") após as notas, sendo que cada apóstrofo indica uma oitava superior à central e, cada virgula, uma inferior [1].

A oitava central é desprovida desses símbolos, e corresponde à do dó 2 do piano, ou seia. o dó do segundo espaco na clave de fá na quarta

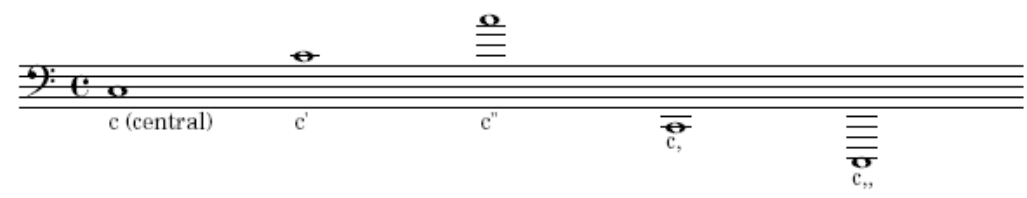

Figura 3.3: Altura das notas

\subsection{Duração}

O duração de cada nota é representada por um número, que é equivalente a alguma figura musical [1]. Assim tem-se, como correspondência:

- 1 = semi-breve

- 2 = mínima

- 4 = semínima

- 8 = colcheia

- 16 = semi-colcheia

- 32 = fusa

- 64 = semi-fusa

O número indicativo de duração deve ser colocado após o nome da nota e altura. A linguagem LilyPond permite a omissão dos tempos da nota, adotando para as notas sem número o último valor que porventura tenha aparecido, ou ' 4 ', como default. Mas adotou-se no presente trabalho a indicação de duração para cada nota.

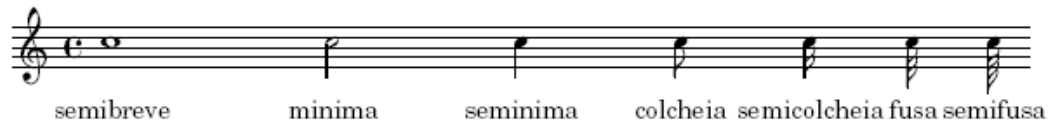

Figura 3.4: Duração das notas 


\subsection{Simbolos}

\subsubsection{Pausas}

As pausas são indicadas com a letra 'r' (rest), adicionadas pelo número indicativo de duração de tempo [1].

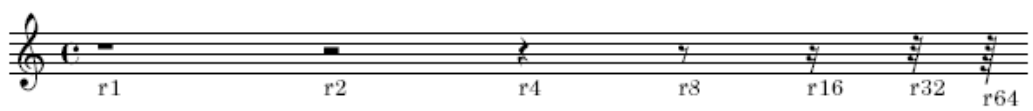

Figura 3.5: Pausas

\subsubsection{Ligaduras}

As ligaduras são indicadas com a o símbolo ( ) [1].

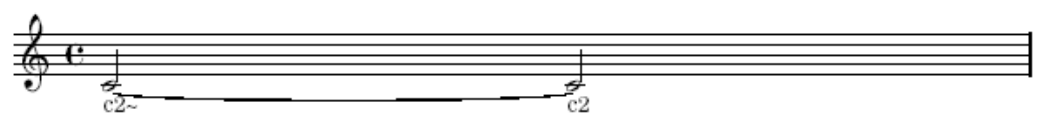

Figura 3.6: Ligadura

\subsubsection{Ponto de aumento}

Os pontos de aumento são indicados com ponto simples (.) ou ponto duplo (..) [1].

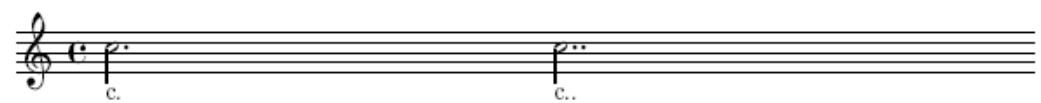

Figura 3.7: Ponto de Aumento

\subsection{Sobre a linguagem LiLyPond}

LilyPond é uma linguagem poderosa para notação musical. Permite uma vasta representação de símbolos musicais e extra-musicais, além de possuir um interpretador que permite a geração gráfica de partituras (em PostScript) e possibilita, também, a geração de um arquivo MIDI com a representação sônica da partitura em questão [1]. 


\subsubsection{O formato .1y}

Para que o interpretador da linguagem LilyPond funcione corretamente, a música deve ser escrita em um arquivo texto, como o formato apropriado, possuindo a extensão .ly.

Somente alguns aspectos da sintaxe da linguagem LilyPond foram usados, mas foram suficientes para poder-se compilar o arquivo gerado pelo programa gerador de fugas e ter como saída a partitura em .pdf e o áudio em .mid.

Para as notas, tem-se que as mesmas devem estar entre chaves ( )[1]. Assim, foi usada uma facilidade da sintaxe LilyPond que tem seu funcionamento análogo às atribuições de linguagens de programação, ou seja, pode-se atribuir valores a uma variável e depois usá-la. Assim, as vozes foram definidas como variáveis e as notas geradas pelo programa gerador de fugas foram atribuídas a elas, para clareza do código gerado.

Como exemplo tem-se:

Soprano $=\ldots$ notas $\ldots$

Contralto $=\ldots$ notas $\ldots$

Tenor $=\ldots$ notas $\ldots$

\subsubsection{Comandos}

O comando \s core é o responsável por criar a partitura . Ele "junta"as partes criadas. Dentro dele são adicionados os outros comandos. É análogo à função main de algumas linguagens de programação.

O comando \midi permite a geração de um arquivo MIDI no momento da compilação do arquivo .ly.

Instrumentos podem ser adicionados ao código das vozes para uma maior variedade na execução da música gerada. Esses instrumentos são adicionados pelo comando \ set Staff.midiInstrument = "nome do instrumento".

O arquivo MIDI gerado com esse código fará com que a voz a que foi adicionado esse código seja executada com o timbre desse instrumento. Quando não há adição desse comando, por default o instrumento para as vozes será o piano.

O interpretador também escolhe, por default, um andamento para a execução do arquivo MIDI, assim, para modificar esse valor deve-se adicionar ao código o comando tempoWholesPerMinute $=$ ( $l_{\mathrm{y}}$ :make-moment $\mathrm{X} \mathrm{Y}$ ), onde $\mathrm{X}$ corresponde a quantos $\mathrm{Y}$ devem haver em um minuto $\mathrm{e}$ $\mathrm{Y}$ corresponderia a alguma figura musical.

O comando $\backslash$ clef (clave) adiciona a clave ${ }^{3}$ selecionada à voz. As claves usadas foram treble, clave de sol, e bass, clave de fá na quarta linha.

\footnotetext{
${ }^{3}$ Claves são símbolos colocados no início das partituras para indicar em qual oitava as notas estão escritas.
} 


\subsubsection{Exemplo de código no formado .ly}

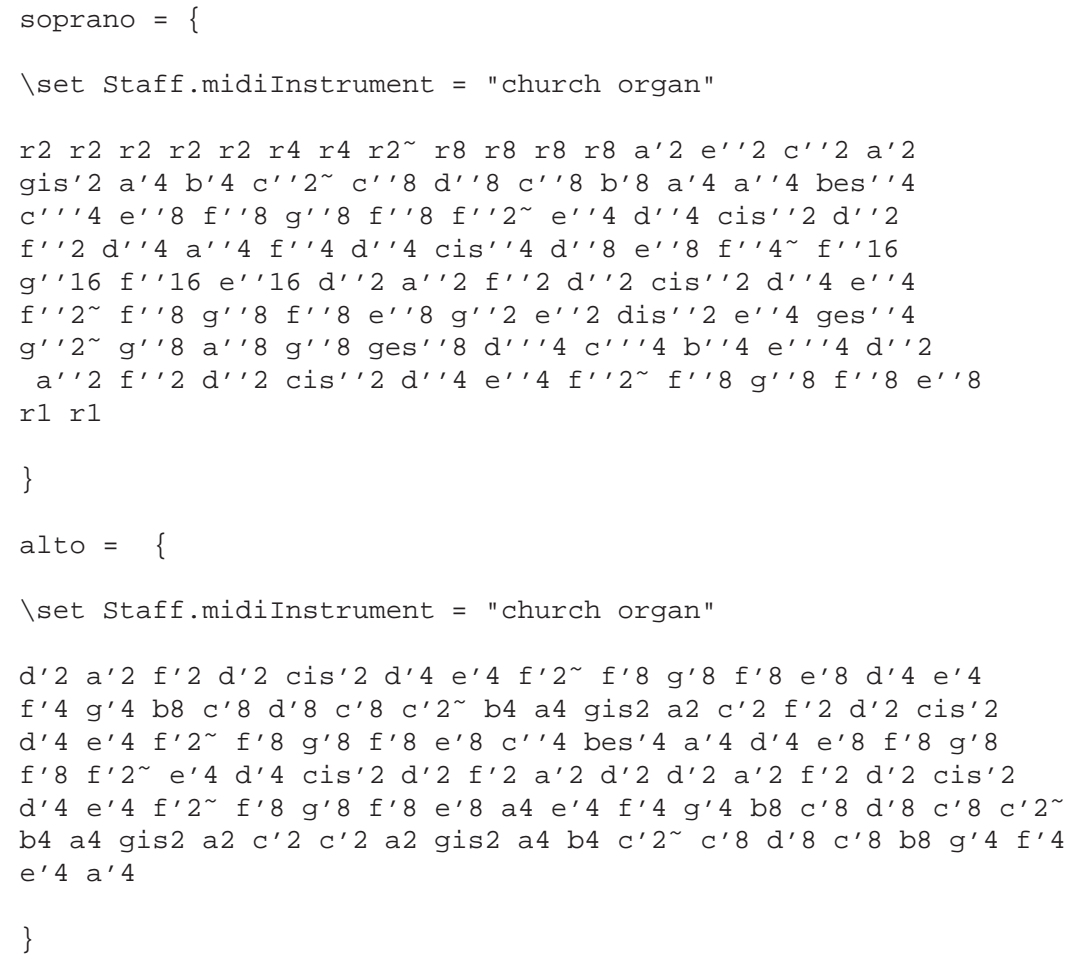

Código 3.5.1: Formato . Iy 


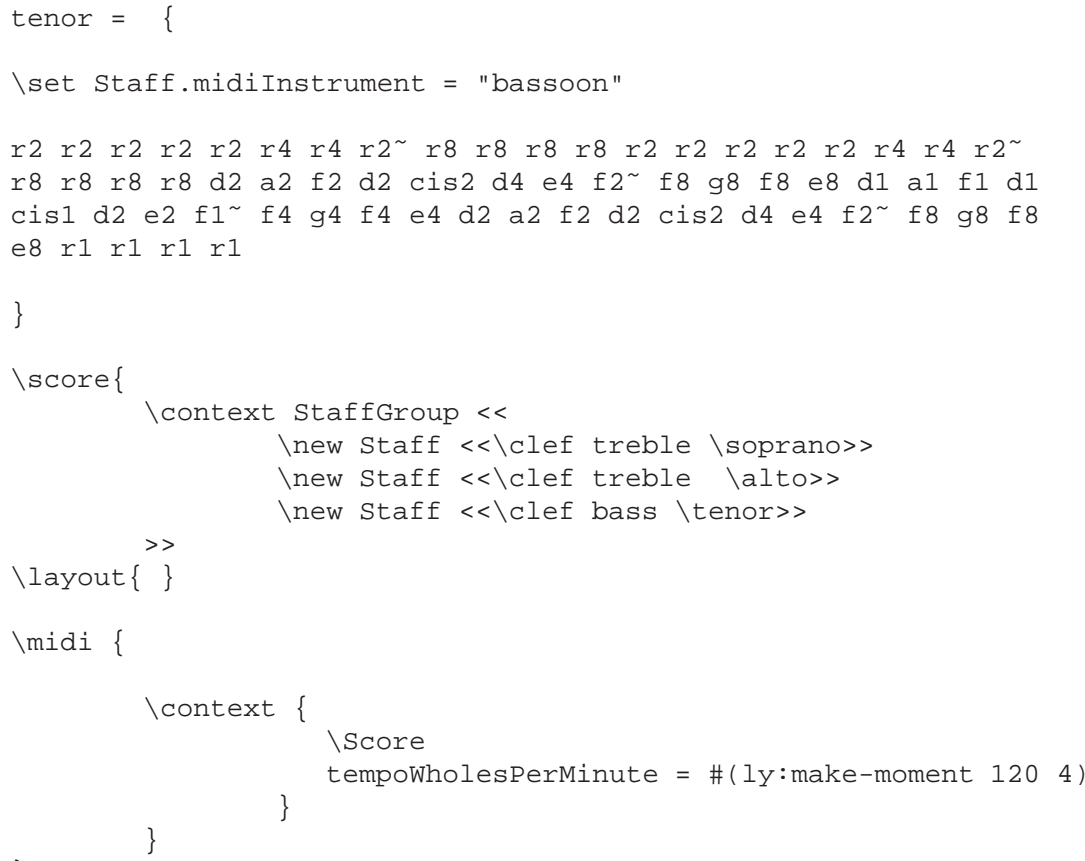

Código 3.5.2: Continuação do formato . $I_{y}$ 


\section{Capítulo 4}

\section{Transformações Melódicas}

A fuga é uma forma musical extremamente matemática. Uma das possíveis razões para isso talvez seja devido aos momentos temporais das entradas das vozes, que devem estar perfeitamente alinhados. Um outro motivo para esta constatação pode ser devido às transformações que o sujeito sofre ao longo da composição.

Notas musicais podem ser representadas de diversas maneiras possíveis, mas sempre levam em consideração suas três características fundamentais : altura, duração e intensidade.

Em composições musicais é muito comum encontrar-se apenas a notação de altura e duração [5], ficando a intensidade a cargo do intérprete que toca a música. Aqui neste trabalho não foi diferente, a intensidade não foi abordada, por tratar-se de aspecto menos tradicional e observado na composição da fuga.

Com os outros dois parâmetros, altura e duração, é possível toda uma gama de transformações que o sujeito pode sofrer.

No aspecto da duração, as notas podem ser encurtadas ou aumentadas, dilatando ou diminuindo sua duração. Simples multiplicações e divisões são suficientes para acarretar tal transformação. Em tese, o tempo pode ser aumentado ou diminuído em qualquer razão, mas em música o mais comum é a duração ser dobrada ou dividida ao meio, e as fugas usam frequentemente esse tipo de transformação.

Quanto à altura de uma nota, que é o número que representa o valor de sua freqüência, basta multiplicar-se por uma razão para obtermos outra nota, diferente da primeira,ou seja, modula-se essa nota nessa razão.

Pode-se concluir, assim, que as notas podem ser entendidas como tuplas numéricas, e, no caso em questão, entendidas como um par de números, um indicando a freqüência da nota e outro indicando sua duração.

Para fazer-se a transposição das notas num intervalo qualquer, basta multiplicar-se a freqüência da mesma pelo valor da razão do intervalo desejado. Mas para isso seria necessário ter-se esse valor de freqüência para cada nota, o que seria inviável pela notação utilizada. Se assim fosse, cada nota seria representada por um número, indica- 
tivo de sua frequência, e não pelos doze nomes que atribuí-se a elas.

Mas essa notação para a representação das notas, qual seja, a utilização de uma cadeia de caracteres com seus respectivos nomes em notação germânica (c, d,e...), permite uma abordagem em aritmética modular para as mesmas, já que pode-se associar um número inteiro a cada nota, e tendo somente 12 notas, pode-se fazer operações mod $12 \mathrm{com}$ as mesmas, pois elas sempre se repetem na mesma ordem. Assim, tem-se para o presente trabalho a seguinte associação [1]:

$$
\begin{aligned}
& \mathrm{c}=0 \\
& \text { cis-des }=1 \\
& \mathrm{~d}=2 \\
& \text { dis-ees }=3 \\
& \mathrm{e}=4 \\
& \mathrm{f}=5 \\
& \text { fis-ges }=6 \\
& \mathrm{~g}=7 \\
& \text { gis-aes }=8 \\
& \mathrm{a}=9 \\
& \text { ais-bes }=10 \\
& \mathrm{~b}=11
\end{aligned}
$$

Um array que guarde essas notas, nessa ordem, tem a vantagem de o índice de cada posição ser o valor que as representa.

As operações em aritmética modular tem a propriedade de sempre retornar o nome da nota, independente da oitava na qual esteja, simplificando assim a multiplicação das notas por uma razão qualquer, que faria o papel das transposições.

O cálculo das oitavas é feito através de somas e subtrações dos apóstrofos e vírgulas, que representam em qual oitava a nota está.

As transformações melódicas mais imediatas são as transposições, em que um trecho musical tem suas freqüencias multiplicadas (ou divididas) por uma razão específica.

\subsection{Resposta}

A resposta, numa fuga, é a transformação que leva o sujeito, no tom da tônica ${ }^{1}$, ao tom da dominante ${ }^{2}$ ou quinto grau. Todas as notas do sujeito são transpostas, ou seja, multiplicadas, pela razão do quinto grau.

Para isso, basta somar ao valor do índice que representa a nota o valor 7 , que corresponde ao quinto grau, tendo assim a transposição ao tom da dominante. Uma operação em aritmética modular (mod 12) deve ser feita para que a soma desses valores não ultrapasse a extensão

\footnotetext{
${ }^{1}$ Tonalidade em que a peça musical está escrita.

${ }^{2}$ Tonalidade do quinto grau da escala na qual a peça está escrita.
} 
do array que guarda os valores das notas, e devido a circularidade dessa representação, retorne a nota correta.

\subsection{Contra-sujeitos}

Os sujeitos das fugas utilizados neste trabalho nunca preenchem o último compasso em que aparecem, por terminarem em um tempo forte do mesmo. Assim, o contra-sujeito, que se inicia imediatamente após a apresentação do sujeito, deve completar os tempos faltantes. Para isso, utilizaram-se as últimas notas do sujeito em movimento retrógrado, ou seja, de trás para frente, e, para não se depender do valor da duração dessas notas, que poderia não completar esse último compasso, seus valores de duração foram modificados para se tornarem semínimas.

Completado esse último compasso, o contra-sujeito 1 foi elaborado com as notas da resposta em movimento retrógrado, de tal forma que estivesse concatenado com a mesma, apresentada por outra voz.

O contra-sujeito 2 foi construído com as notas do contra-sujeito 1 em movimento retrógrado. Como o tamanho do contra-sujeito 1 é menor que o do sujeito, precisa-se, no fim da construção, preencher o contra-sujeito 2 com mais algumas notas, retiradas do sujeito, em movimento retrógrado e com a duração modificada para semínima.

As funções inversas dessas transformações melódicas tentam reverter seu processo de construção, numa tentativa de se obter as partes de que se originaram. No caso do contra-sujeito 1, a resposta, e no caso do contra-sujeito 2, o contra-sujeito 1 .

\subsection{Aumento}

As notas do sujeito tem o valor de suas durações duplicadas.

\subsection{Diminuição}

As notas do sujeito tem suas durações divididas pela metade.

\subsection{Retrógrado}

As notas do sujeito são armazenadas de trás para frente.

\subsection{Transformações inversas}

Somente o sujeito não possui transformação inversa, por ser o gerador de toda a fuga. Assim, as partes da fuga e as transformações 
melódicas, como foram definidos, possuem uma transformação inversa, podendo, a partir dos mesmos, obter-se a parte que os gerou. 


\section{Capítulo 5}

\section{Algoritmo do Programa FugueMaker}

\subsection{Propriedades do sujeito}

A única entrada para o programa gerador de fugas é um arquivo texto contendo a representação musical de um sujeito qualquer.Mas, para o correto funcionamento do programa, esse sujeito tem que apresentar certas características, ou seja, ter uma boa construção. A composição de uma fuga deve levar em consideração a estrutura do sujeito, pois nem todos são aptos a tal empreitada.[10]

A boa construção do sujeito significa que o mesmo deve ser em algum compasso binário ou quaternário; não apresentar tempos terciários internamente, tais como tercinas e quiálteras; terminar sempre em tempo forte, ou seja, no primeiro de compassos binários ou primeiro e terceiro de compassos quaternários.

O uso de compassos binários ou quaternários se deve ao fato de tornar o cálculo das partes da fuga mais fácil e suas entradas no tempo e tamanhos ficarem mais simples de se lidar.

Tempos terciários não são incomuns em fugas, mas, também, exigiriam cálculos mais elaborados e complexos, que necessitariam de mais tempo em sua elaboração.

$\mathrm{O}$ aspecto de sempre terminar o sujeito em um tempo forte foi constatado a partir de observações em fugas bachianas [5]. Não se pode afirmar tal fato como uma lei, devido ser impossível e inorpotuno para o presente trabalho analisar a totalidade de fugas do compositor alemão, mas tomando algumas peças do Cravo Bem Temperado e da Arte da Fuga como guias, levou-se isso em consideração para a escolha dos sujeitos utilizados no presente trabalho. Esse fato observado tornou mais fácil o cálculo do momento de entrada dos sujeitos. 


\subsection{O algoritmo}

A entrada deve ser um arquivo texto com a cadeia de caracteres representando o sujeito da fuga.

A partir dessa entrada são geradas as partes da fuga: sujeito, reposta, contra-sujeito 1 e 2 e suas inversas.

O sujeito, agora, é passado como parâmetro, em um ArryList, para o módulo que gerará as transformações melódicas do mesmo: aumento, diminuição, pausas e retrógrado.

Todas essas operações são auxiliadas por funções implementadas em outras classes.

Essas partes, uma vez geradas, devem ser concatenadas corretamente. A classe responsável por essa concatenação vai adicionando as partes e as transformações melódicas correspondentes a cada voz ao arquivo de saída, e, na medida em que faz isso, utilizando-se de uma pilha, empilha a transformações inversas das mesmas,para posterior desempilhamento.

Uma vez acrescentadas as partes e as transformações melódicas ao arquivo de saída, de tal maneira que a forma da fuga seja obedecida, passa-se ao desempilhamento da aplicação das funções inversas, até que as pilhas de cada voz estejam vazias.

Através da interface gráfica, também são passados valores para que a execução da fuga, através do arquivo MIDI gerado, seja mais variada. Esses valores, códigos da linguagem LilyPond, são adicionados ao arquivo de saída.

Terminado esse processo, o arquivo com a representação da fuga está gerado.

Faz-se uma chamada externa ao programa LilyPond para a compilação do arquivo com a fuga, gerando um arquivo .pdf, com a partitura e outro arquivo .mid, para sua execução.

\subsection{Considerações}

Esse algoritmo, da forma como foi implementado, garante que a exposição da fuga seja exatamente como sua definição, ou seja, que cada voz exponha o sujeito uma vez. Terminada a exposição, a parte do desenvolvimento da fuga, menos rígida, foi construída adicionando-se uma transformação melódica a cada voz, e, em seguida, desempilhando as funções inversas empilhadas.

Não foi implementada a conclusão da fuga. 


\section{Capítulo 6}

\section{Implementação das Classe do Programa FugueMaker}

Foi usada a tecnologia Java para a implementação do programa FugueMaker devido às facilidades que propicia no uso de classes já implementadas, exigindo somente o aprendizado das mesmas. Os pacotes gráficos e sônicos que também já existem liberam o programador para se ater somente aos aspectos relevantes de seu projeto.

\subsection{Implementação da Classe Constantes}

Contém as constantes que representam os intervalos de transposição, as oitavas, se acima ou abaixo, e os arrays representando as escalas. 


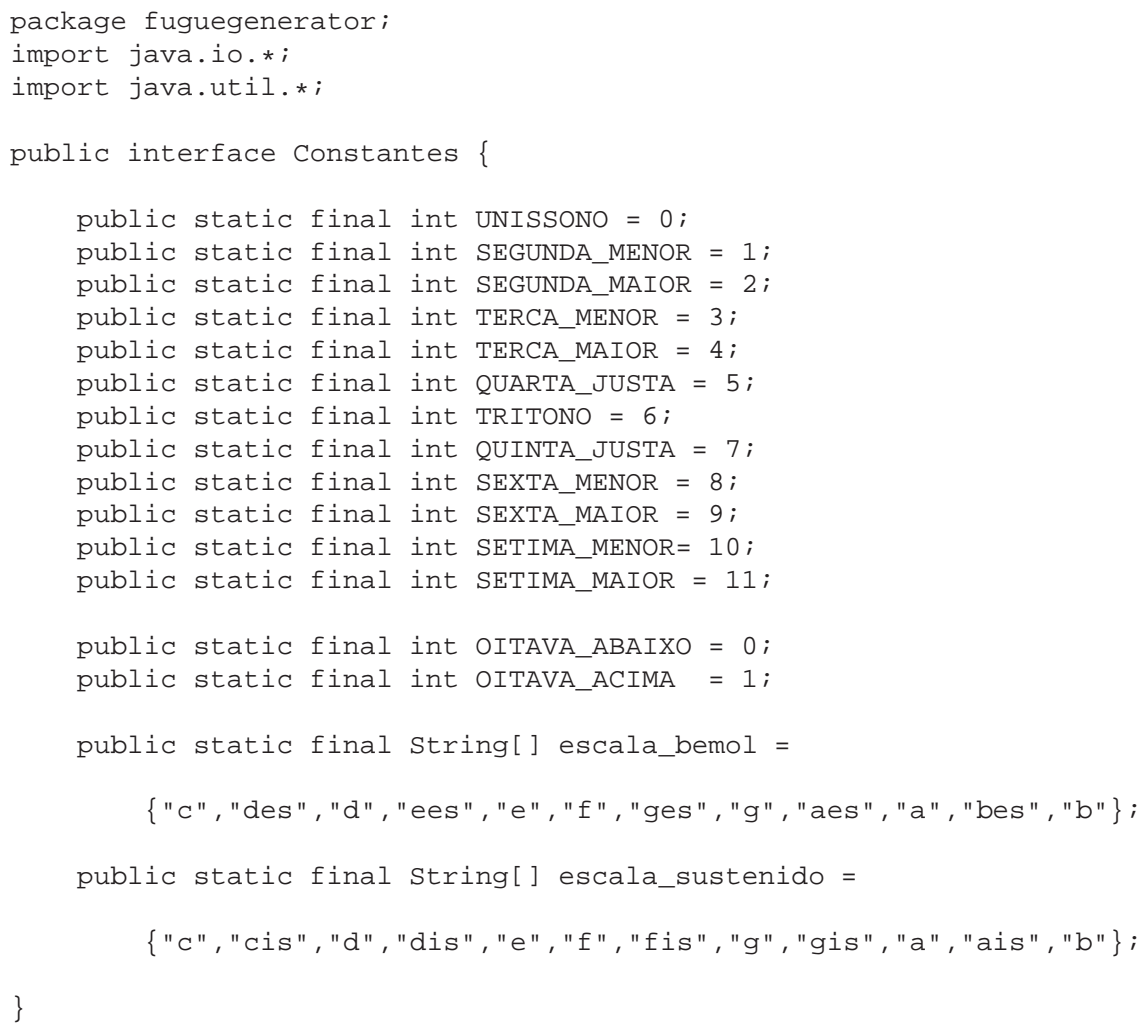

Código 6.1.1: Implementação da Classe Constantes

\subsection{Implementação da Classe Arquivo}

Esta classe possui as funções para abrir e gravar arquivos. 


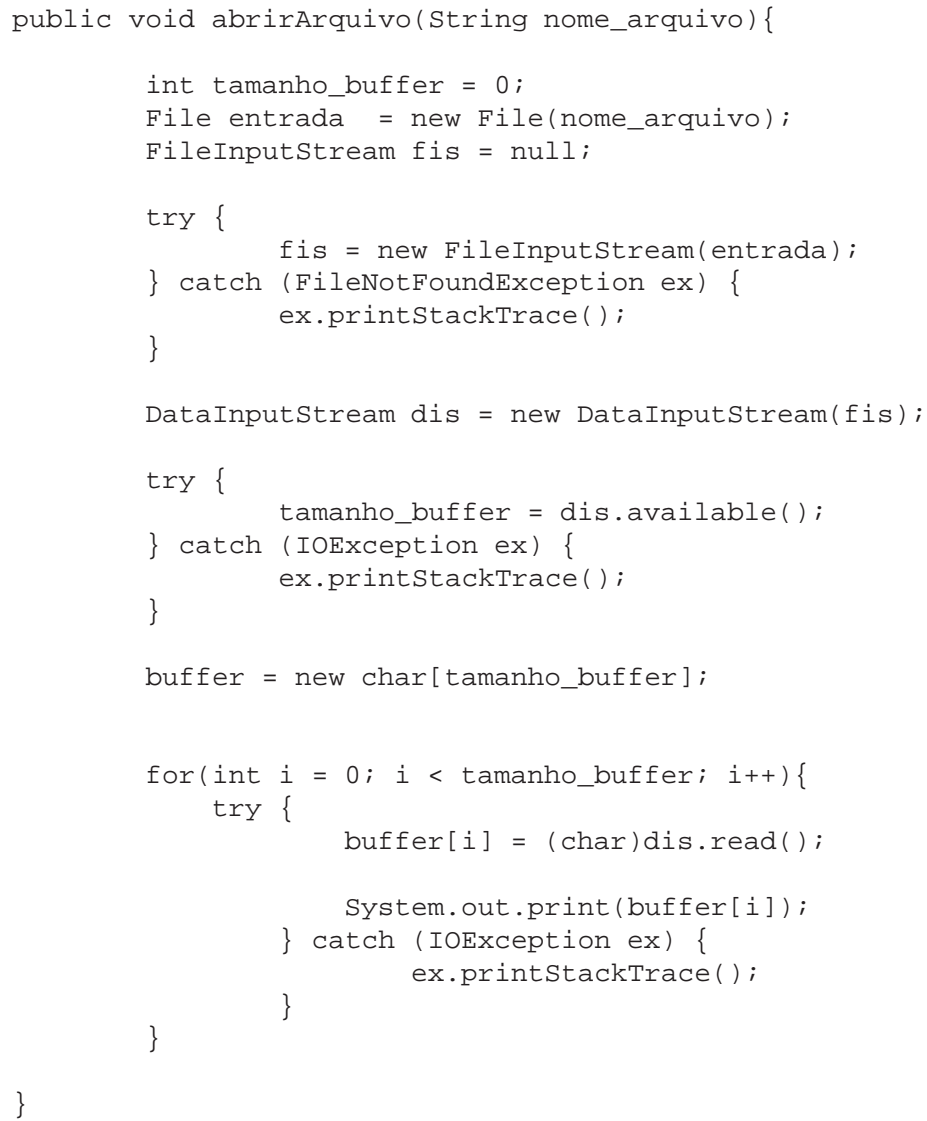

Código 6.2.1: Implementação do método de abertura de arquivos 


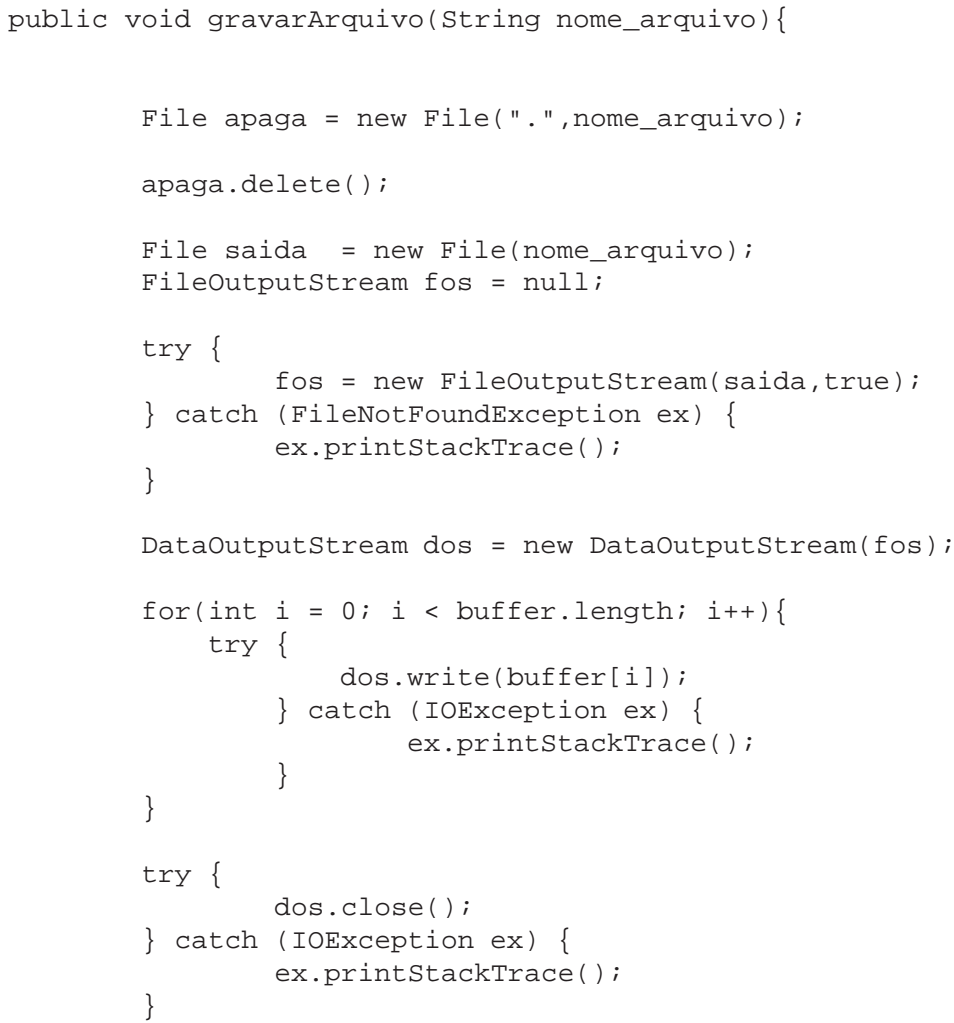

Código 6.2.2: Implementação do método de gravação de arquivos 


\subsection{Implementação da Classe Arquivo_Lily}

Classe para gerar a partitura no formato LilyPond.

Apresenta os códigos dos instrumentos musicais, para que o arquivo .mid execute a fuga com o timbre escolhido associado a cada voZ.

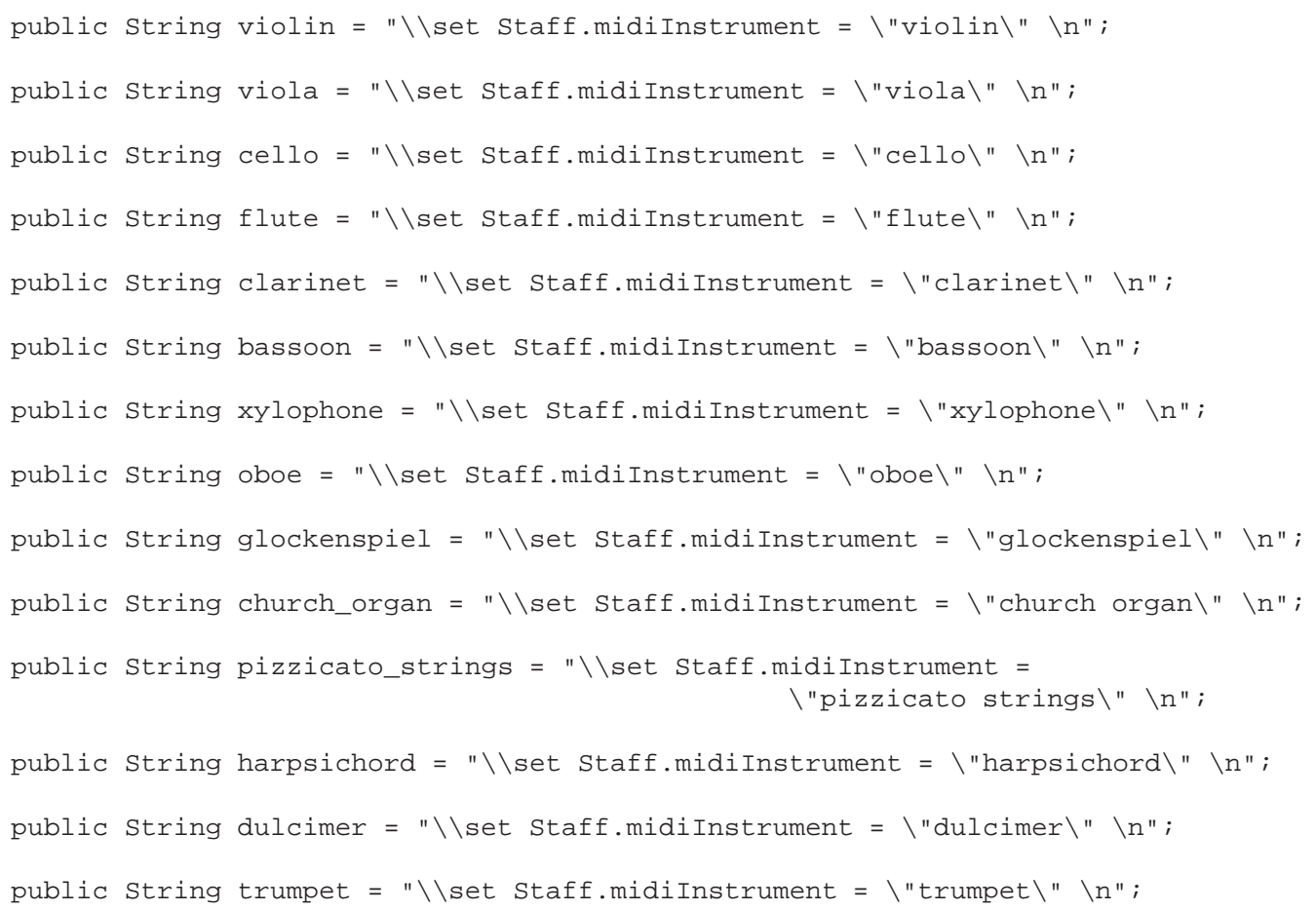

Código 6.3.1: Códigos dos instrumentos musicais utilizados 


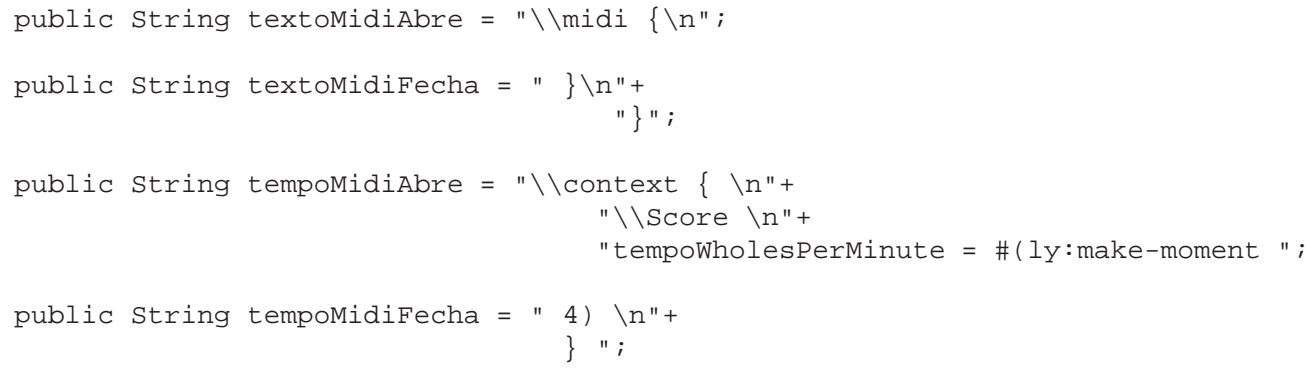

Código 6.3.2: Texto para geração do arquivo .mid

Possui uma variável (arquivoprincipal) na qual toda inserção de código vai sendo colocada através do método adicionarTexto (String s).

1 private String arquivoprincipal = new String();

Código 6.3.3: Variável que guarda o texto do arquivo ly a ser gerado

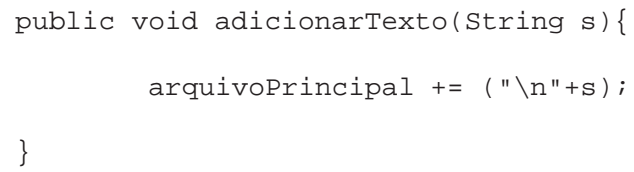

Código 6.3.4: Implementação do método para adicionar texto à variável arquivoPrincipal

\subsection{Implementação da Classe TocadorMidi}

Classe criada para tocar o arquivo .mid. De simples implementação, somente abre o arquivo .mid e o toca e/ou pára a execução que porventura esteja em andamento. 


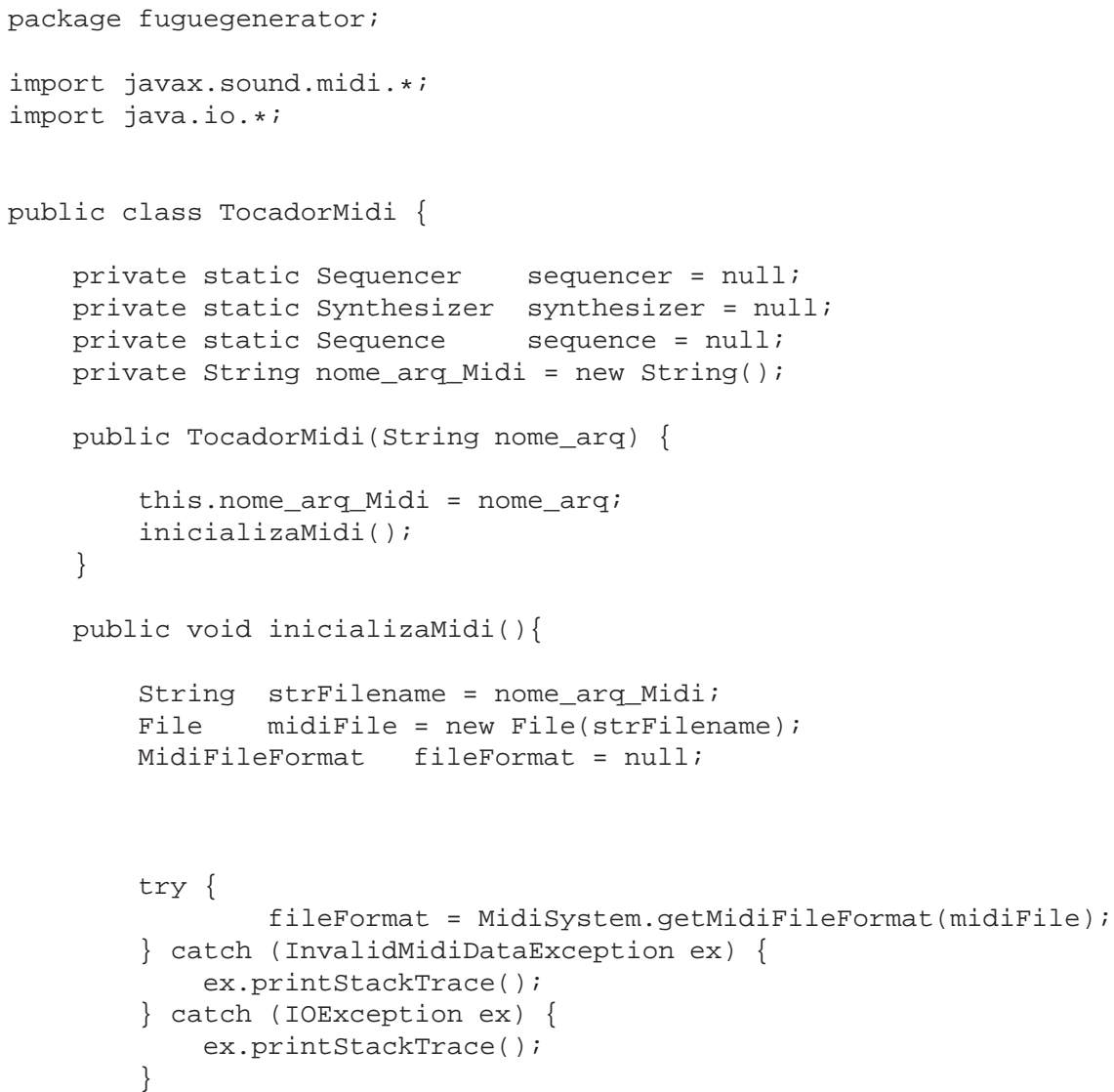

Código 6.4.1: Implementação da Classe TocadorMi di 
try

\{

sequence $=$ MidiSystem.get Sequence (midiFile);

\}

catch (InvalidMidiDataException e)

\{

e.printStackTrace ();

system.exit (1);

catch (IOException e)

\{

e.printStackTrace ();

System.exit (1)

try

\{

sequencer $=$ MidiSystem.getSequencer ();

catch (MidiUnavailableException e)

\{

e.printStackTrace ();

system.exit (1);

try

\{

sequencer.open ();

catch (MidiUnavailableException e)

\{

e.printStackTrace ();

System.exit (1);

\}

Código 6.4.2: Continuação da implementação da Classe TocadorMi di 


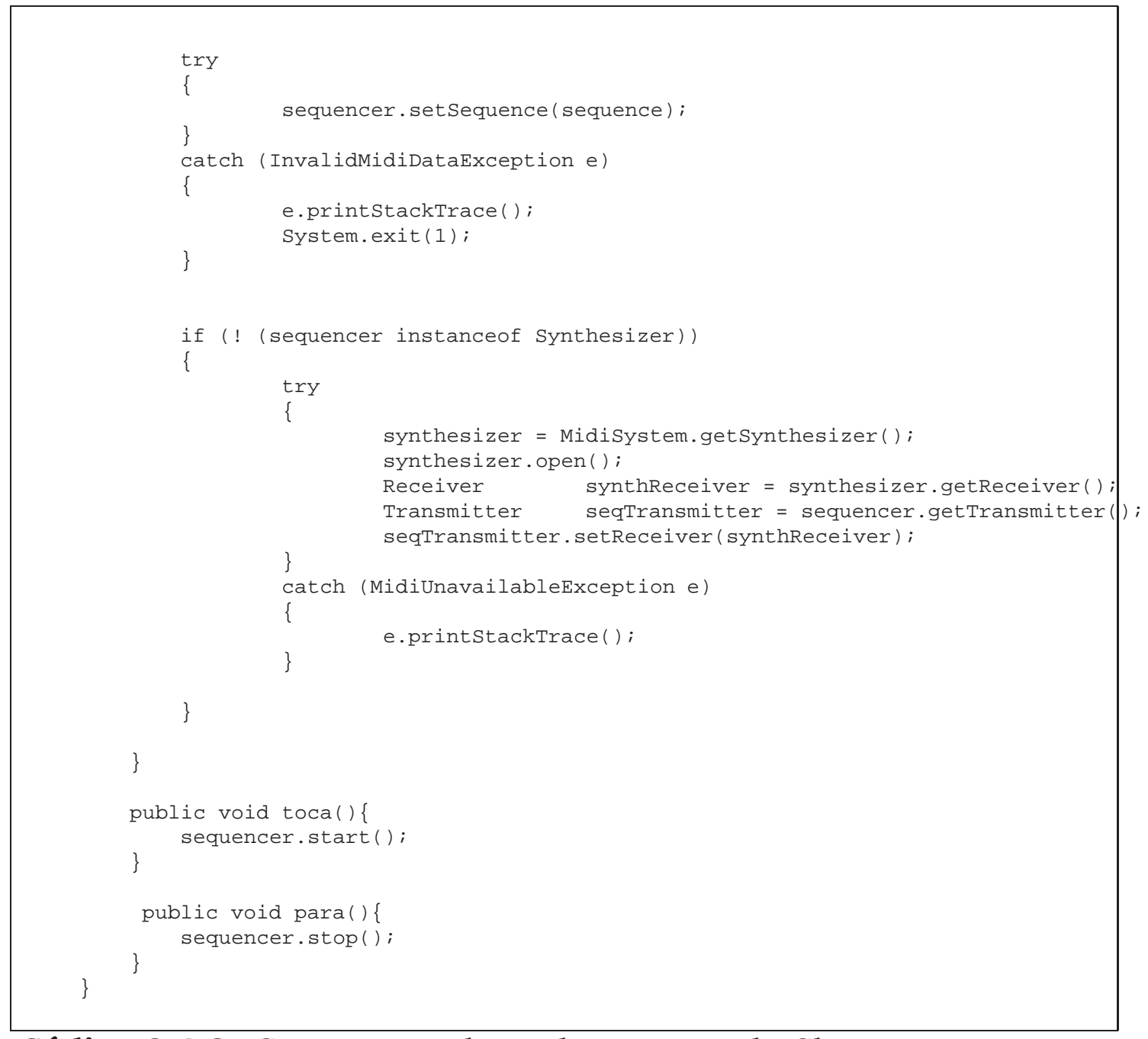

Código 6.4.3: Continuação da implementação da Classe TocadorMi di 


\subsection{Implementação da Classe FuncoesAuxiliares}

Esta classe possui os métodos para auxiliar todos os processos envolvidos na geração da fuga.

O método getLiteral (String s) retorna a cadeia de caracteres que representa a nota que foi passada como parâmetro, sem qualquer símbolo adicional ou número indicativo de duração.

O método get TempoNota (String s) retorna o valor numérico da duração da nota passada como parâmetro.

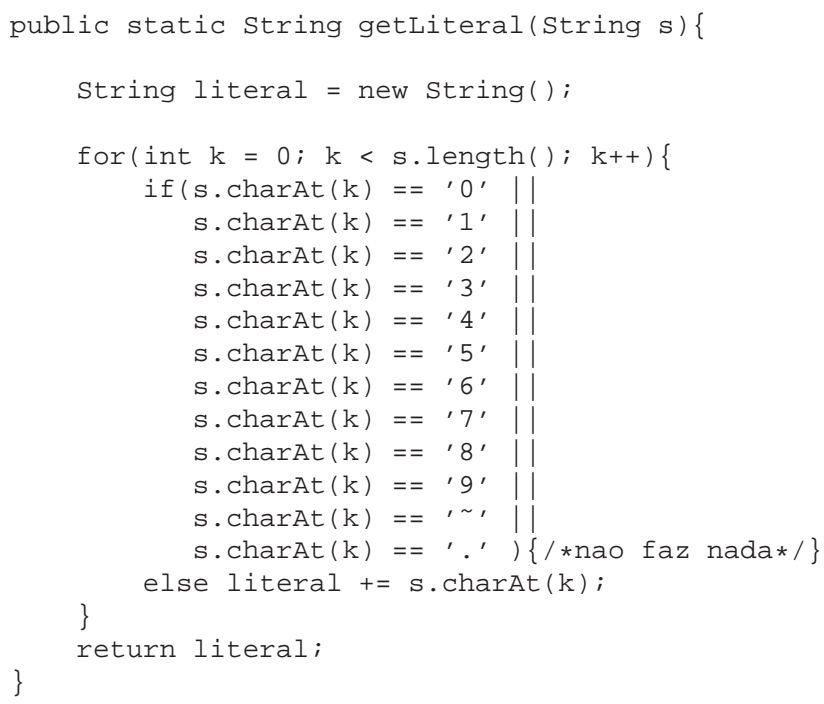

Código 6.5.1: Implementação do método get Litera I () 
public static double getTempoNota (String s) \{

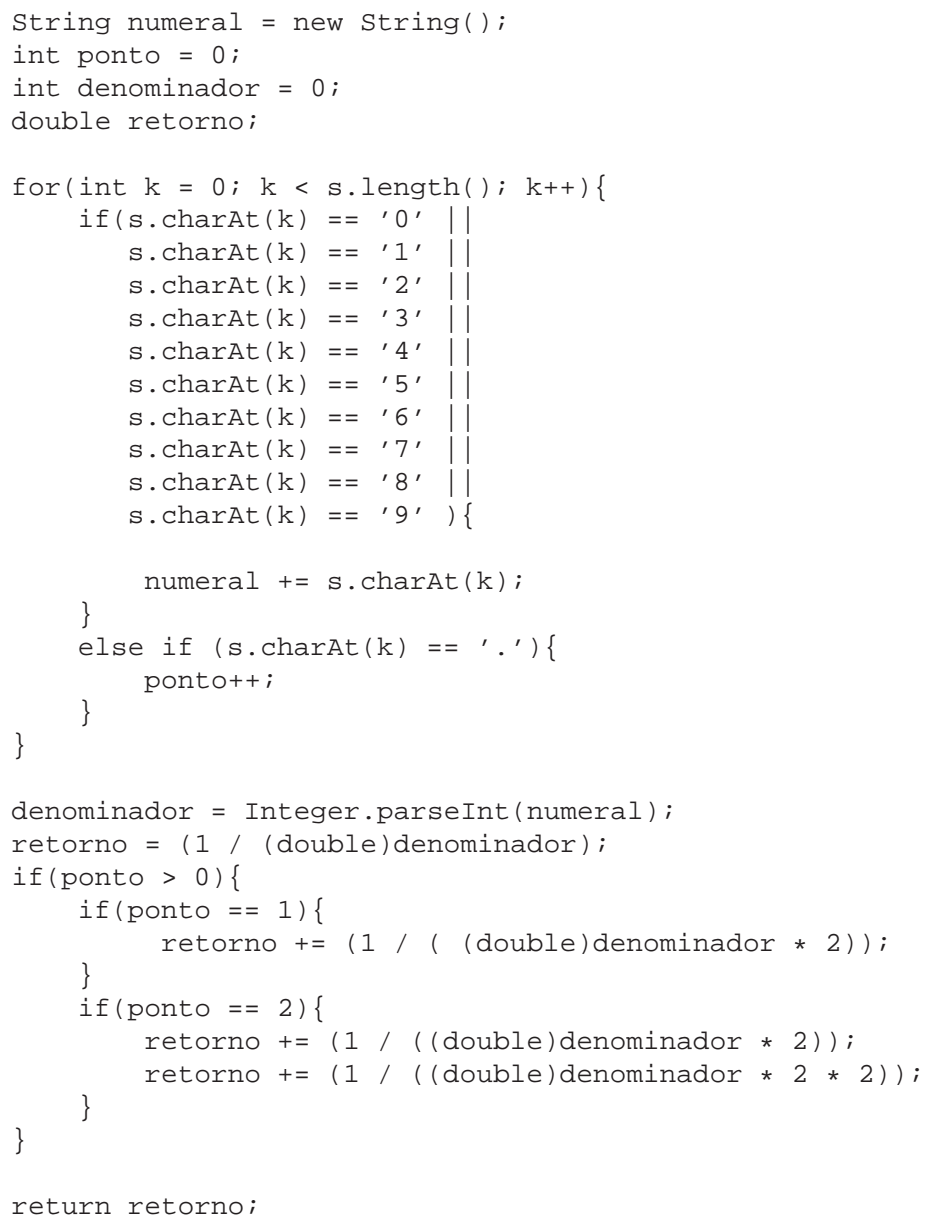

Código 6.5.2: Implementação da método get TempoNota ()

Os métodos get NumCompassos (ArrayList 1), getCompassosCheios (Arraylist 1) e getValorPreencherCompasso (ArrayList 1) retornam o número de compassos com a parte fracionária, se o último compasso não estiver completo; o número de compassos cheios efetivamente, ou seja, sem a parte fracionária; e o valor de duração que falta para preencher o último compasso, se incompleto, dos ArrayList de entrada, respectivamente. 


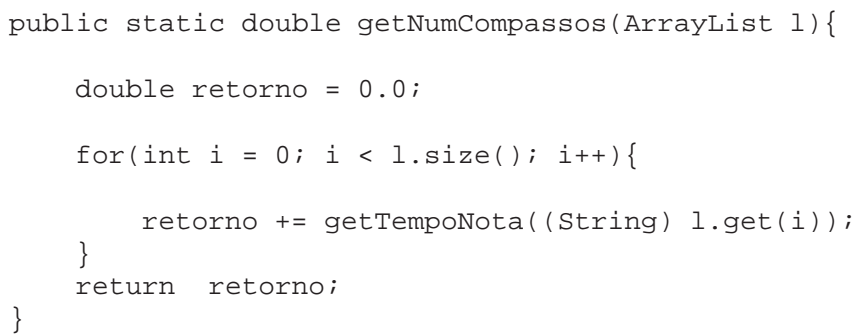

Código 6.5.3: Implementação do método getNumCompassos ()

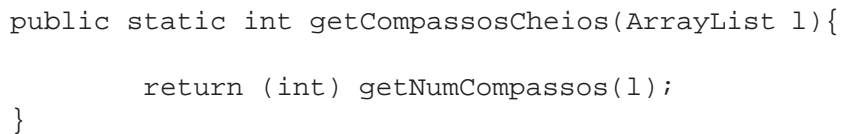

Código 6.5.4: Implementação do método get CompassosCheios ()

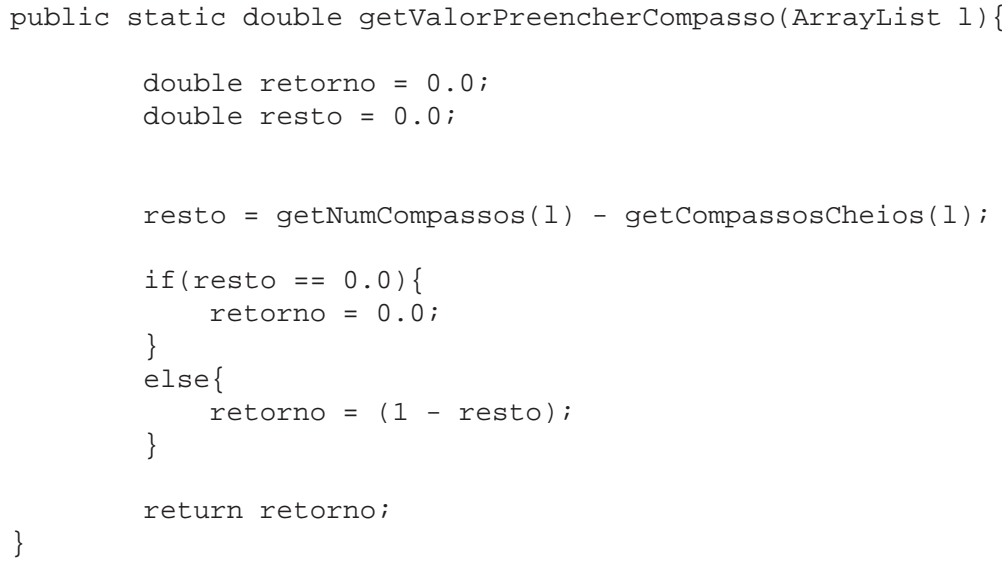

Código 6.5.5: Implementação do método get Va l orPreencherCompasso ()

O método getPosicaoNota (String s) retorna o valor numérico da posição da nota passada como parâmetro na escala, ou seja, o índice do array que representa a escala que está na classe Constantes. 


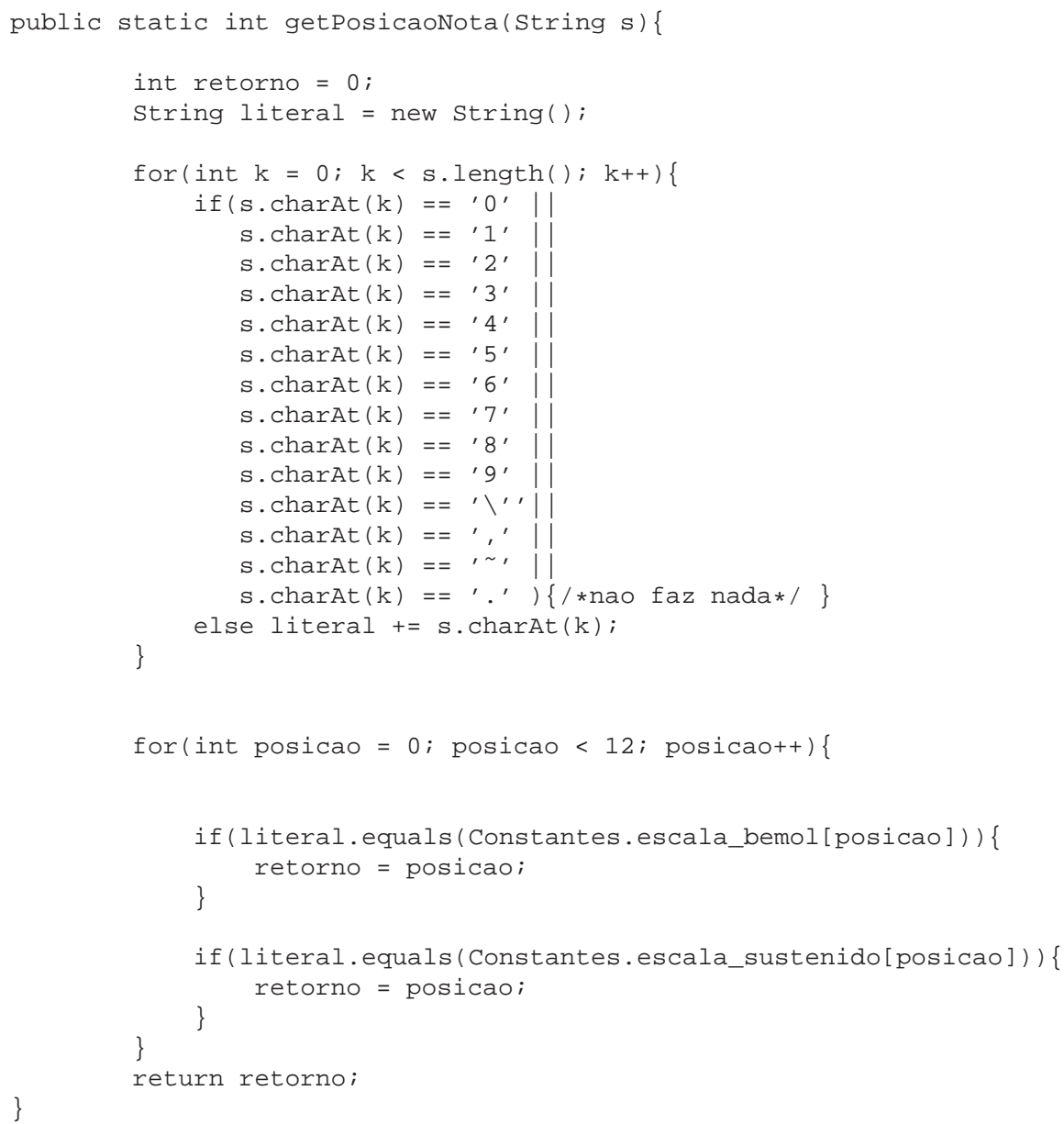

Código 6.5.6: Implementação do método getPosicaoNota ()

O método calculaInversao (int a, int b) recebe como parâmetros a posição de duas notas e calcula a inversão da segunda em relação à primeira, ou seja, retorna o índice da nota invertida na escala, ou de bemóis ou de sustenidos, da classe Constantes, na qual esteja. 


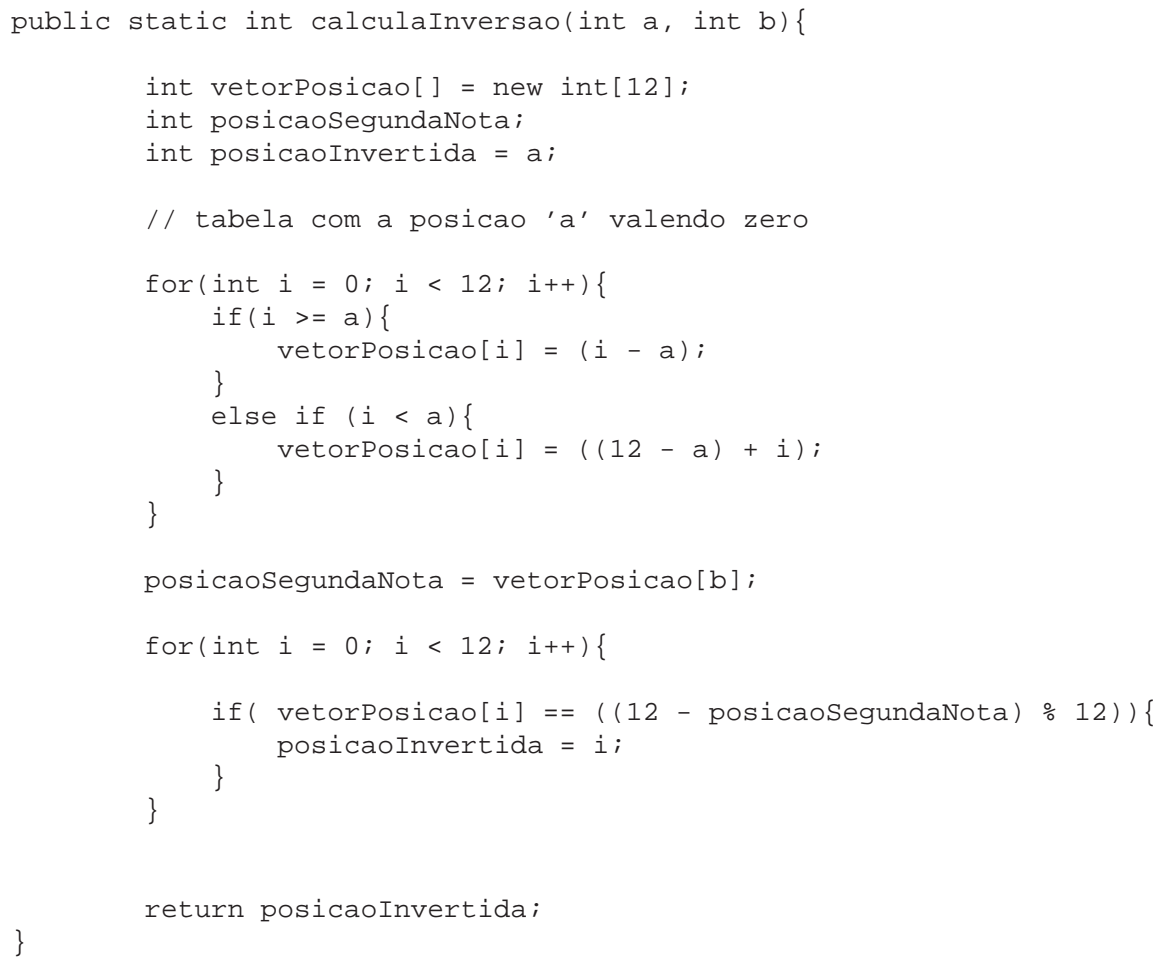

Código 6.5.7: Implementação do método cal cula Inversao()

O métodoo imprime (Arraylist 1) imprime em tela as strings contidas no Arraylist de entrada.

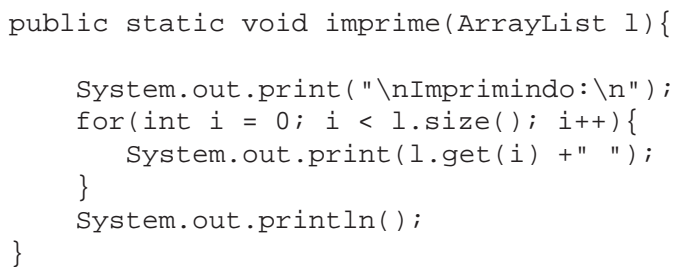

Código 6.5.8: Implementação do método imprime()

O método modificaUltimaNota (ArrayList 1) altera o valor numérico do tempo da última nota para 4 , ou seja, transformando-a em uma semínima. 
public static void modificaultimaNota (Arraylist 1) \{

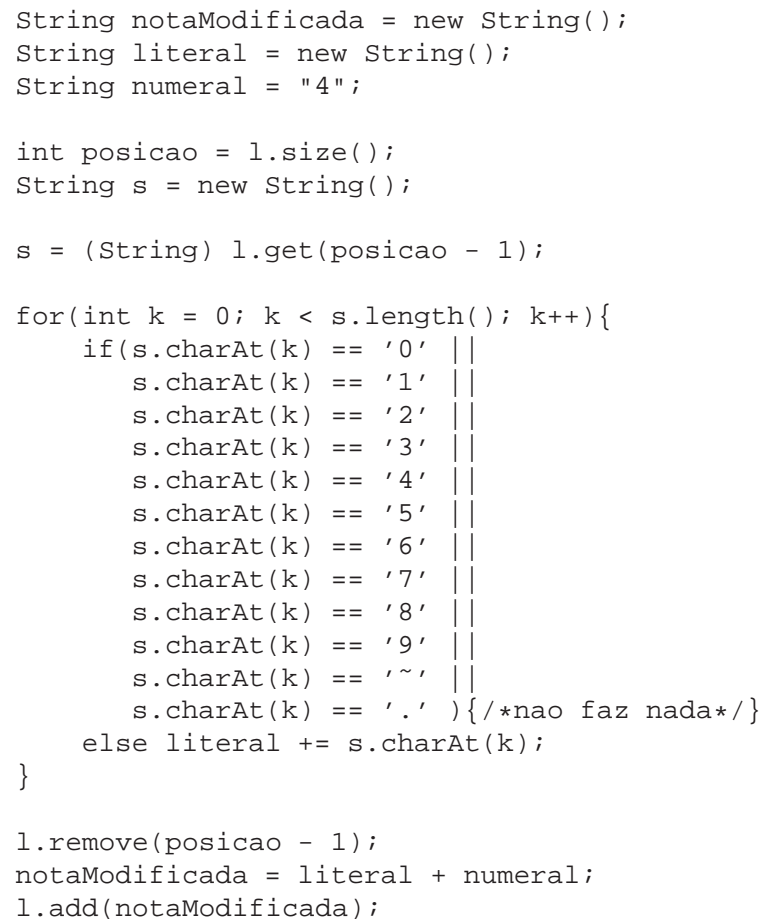

Código 6.5.9: Implementação do método modi ficaUltimaNota ()

O método retiraultimaNota (ArrayList 1), como o nome sugere, retira a última nota do ArrayList passado.

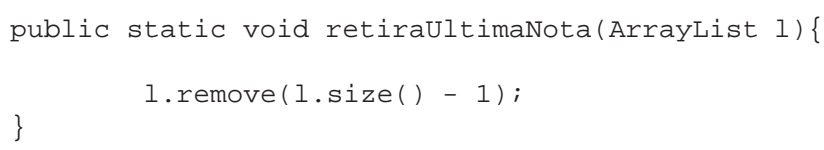

Código 6.5.10: Implementação do método retirault imaNota ()

O método copialista (ArrayList 1) retorna um ArrayList idêntico ao passado como parâmetro. 


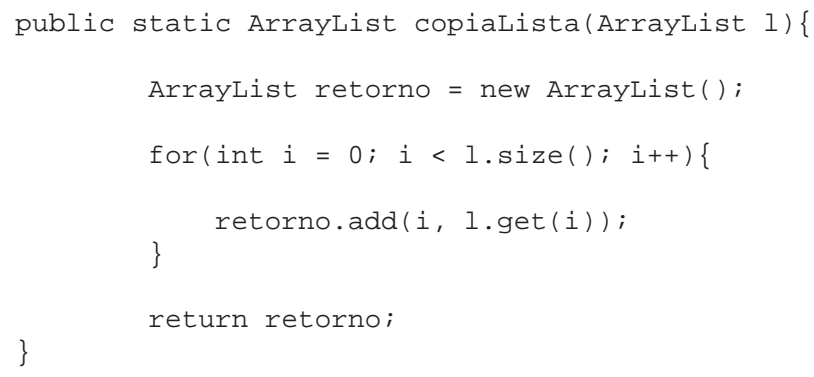

Código 6.5.11: Implementação do método copiaLista()

O método completaComPausas (ArrayList 1) completa o ArrayList passado com pausa até que seu último compasso esteja completo.

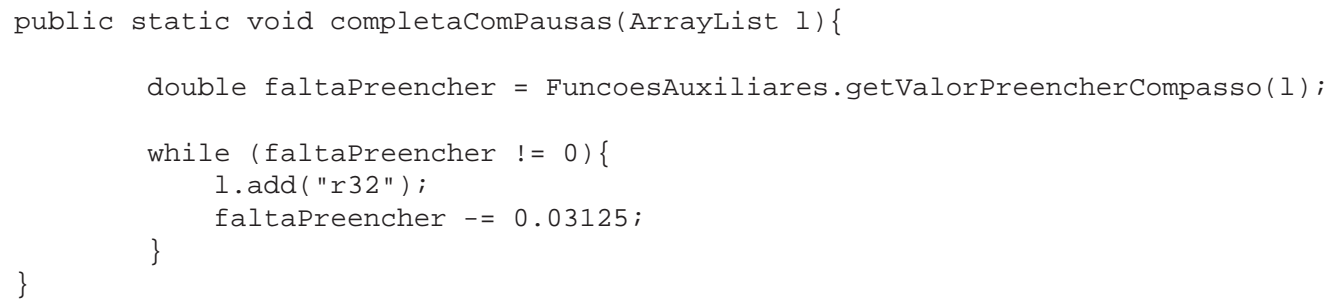

Código 6.5.12: Implementação do método completaCompausas ()

O método retornaMaiorValor (double a, double b, double c) retorna o maior valor dos três argumentos passados. 
public static double retornamaiorvalor(double a, double b, double c) \{

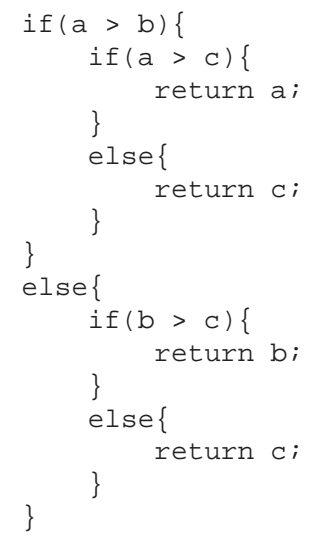

Código 6.5.13: Implementação do método retornaMaiorValor ()

\subsection{Implementação da Classe PartesDaFuga}

Classe que contém as principais partes da fuga: sujeito, resposta, contra-sujeito 1, contra-sujeito 2 e as inversões dos contra-sujeito 1 e 2. Essas partes foram implementadas com Arraylist, onde cada posição do array corresponde a uma nota, ou melhor, à string que a representa.

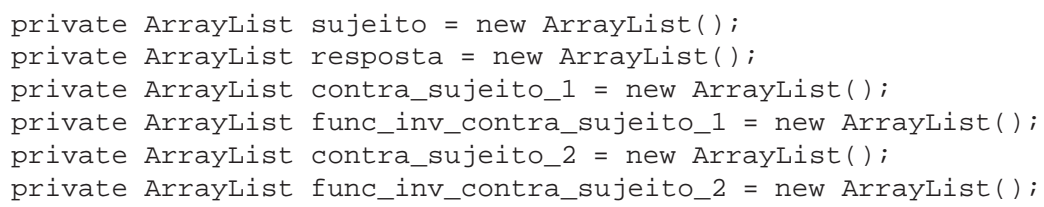

Código 6.6.1: Arraylist com as Partes da Fuga

O método setSujeito(char[] buffer) recebe os caracteres lidos do arquivo de entrada com a representação do sujeito e coloca cada nota em uma posição do Arraylist que o representa. A última nota do sujeito é modificada para que tenha como tempo o número 4 , ou seja, para que seja uma semínima. 
public void setsujeito(char[] buffer) \{

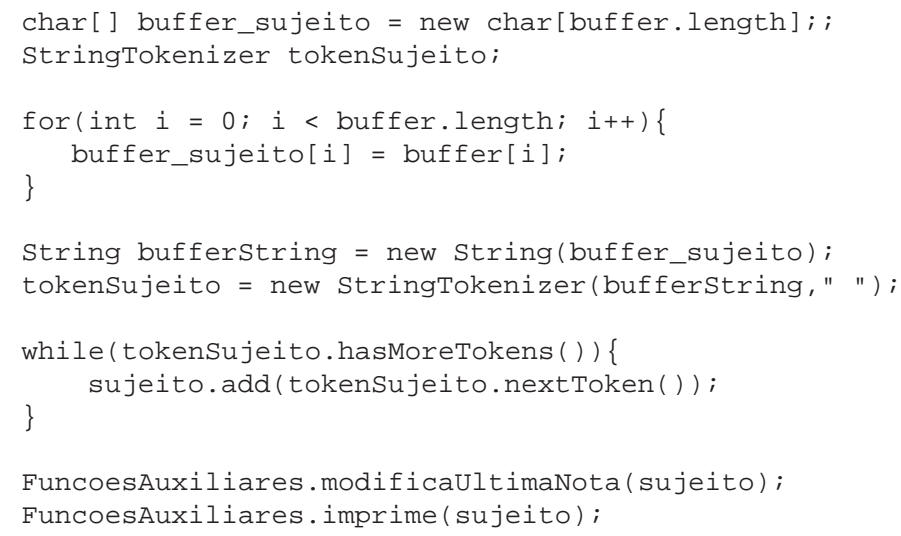

Código 6.6.2: Implementação do método setSu jeito()

A método setResposta (Arraylist 1) tem como parâmetro um Arraylist, que deve conter as notas do sujeito, que será todo transposto uma quinta justa acima. Retorna um Arraylist contendo essa transposição.

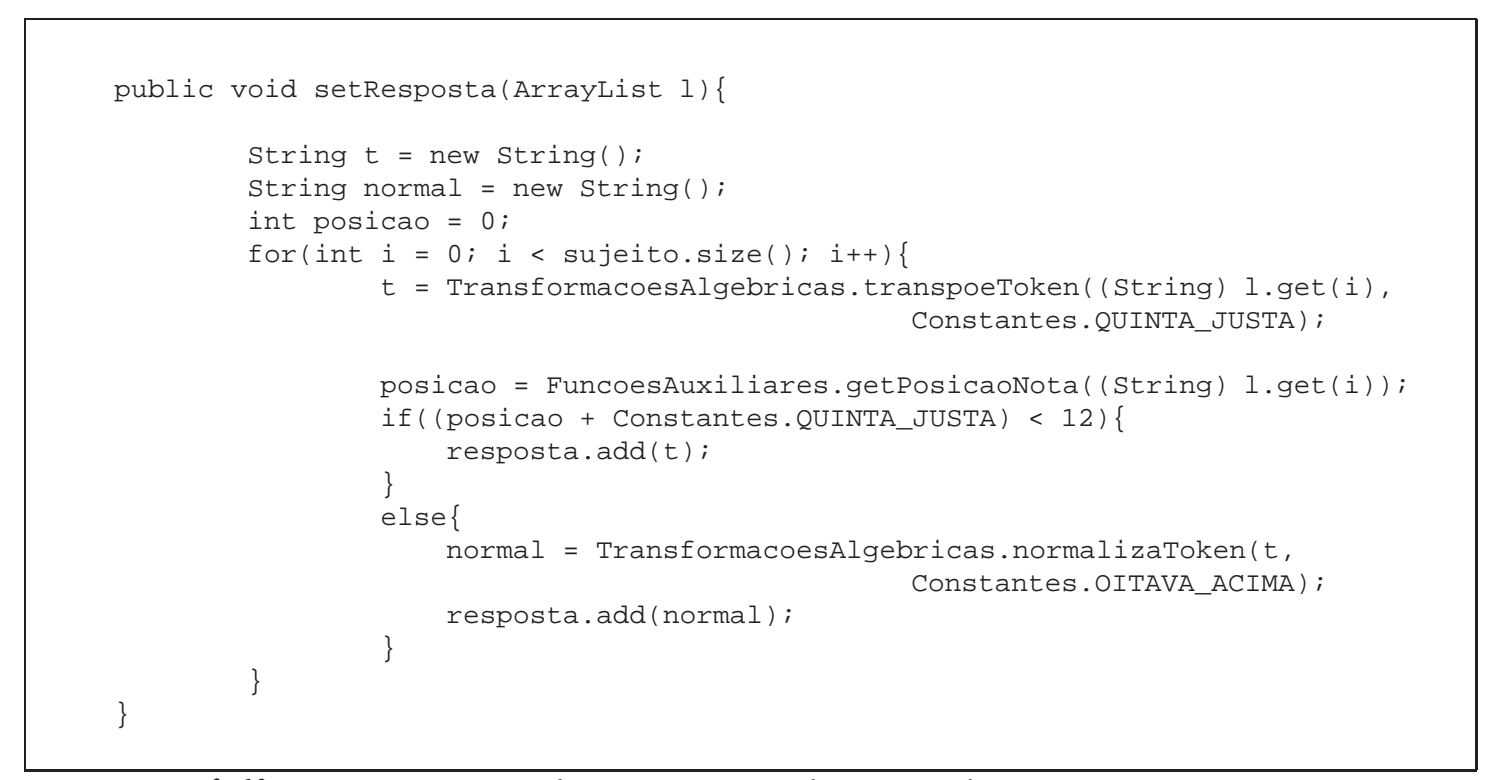

Código 6.6.3: Implementação do método setResposta()

O método setContraSujeito_1 (ArrayList l) tem como parâmetro um Arraylist, que deve conter as notas da resposta. Primeiramente o método coloca no ArrayList de retorno notas que completem o compasso do sujeito, já que este termina em um tempo forte e não fecha um compasso. Essas notas são obtidas a partir do próprio sujeito, em movimento retrógrado. Em seguida, são colocadas as notas do parâmetro de entrada, ou seja, da resposta, em movimento também retrógrado, até que a saída fique do tamanho do mesmo, sem sua 
última nota. Este fato faz com que o contra-sujeito 1 seja menor que o sujeito em 2 semínimas.

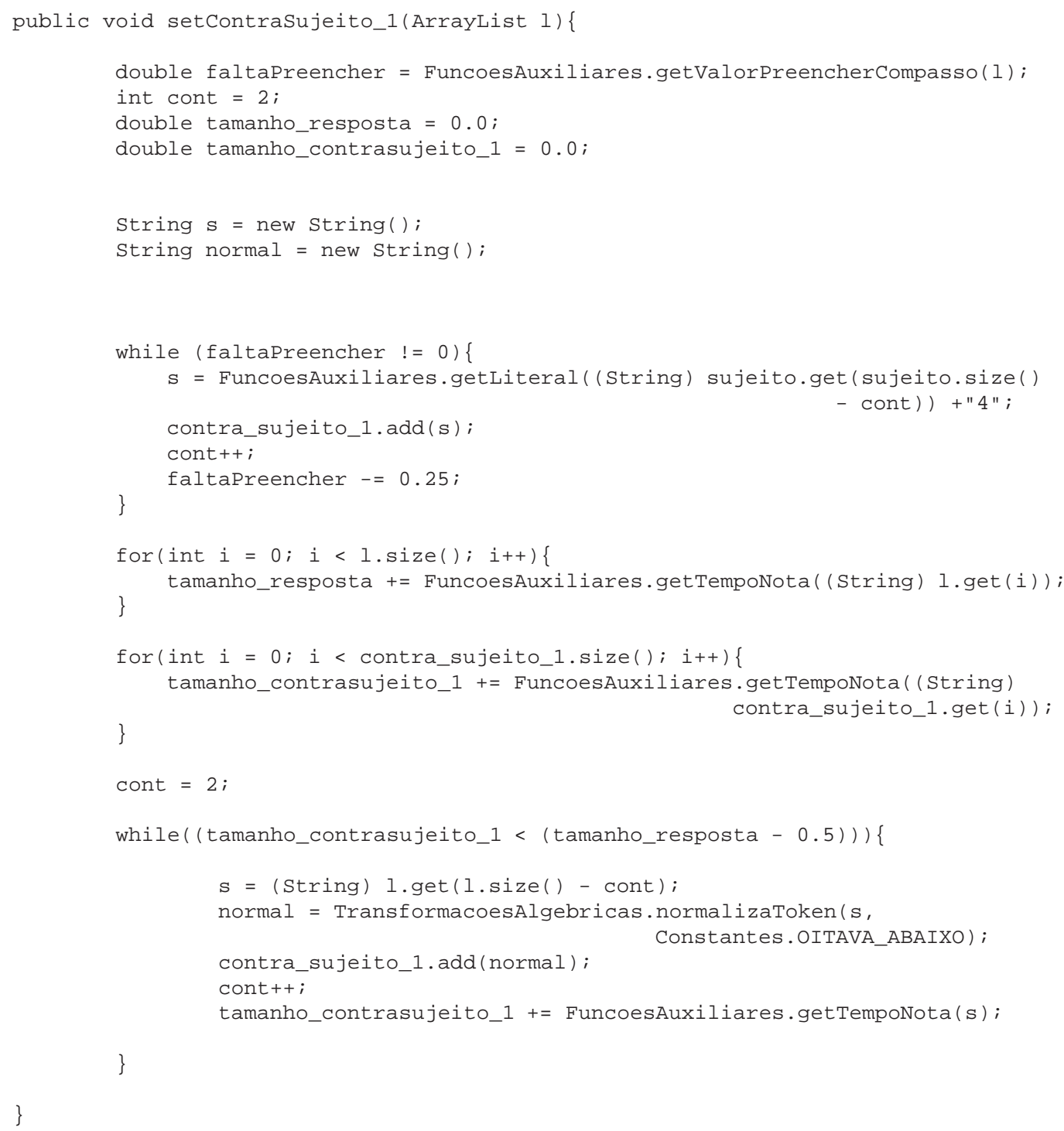

Código 6.6.4: Implementação do método setContraSujeito_1 () 
O método setContraSujeito_2 (ArrayList 1) recebe o ArrayList com as notas do contra-sujeito 1 e as coloca no ArrayList de saída em movimento retrógrado. Como o contra-sujeito 1 é menor que o tamanho do sujeito, há ainda uma complementação do contra-sujeito 2 com notas do sujeito, em movimento retrógrado, até que aquele tenha o tamanho deste.

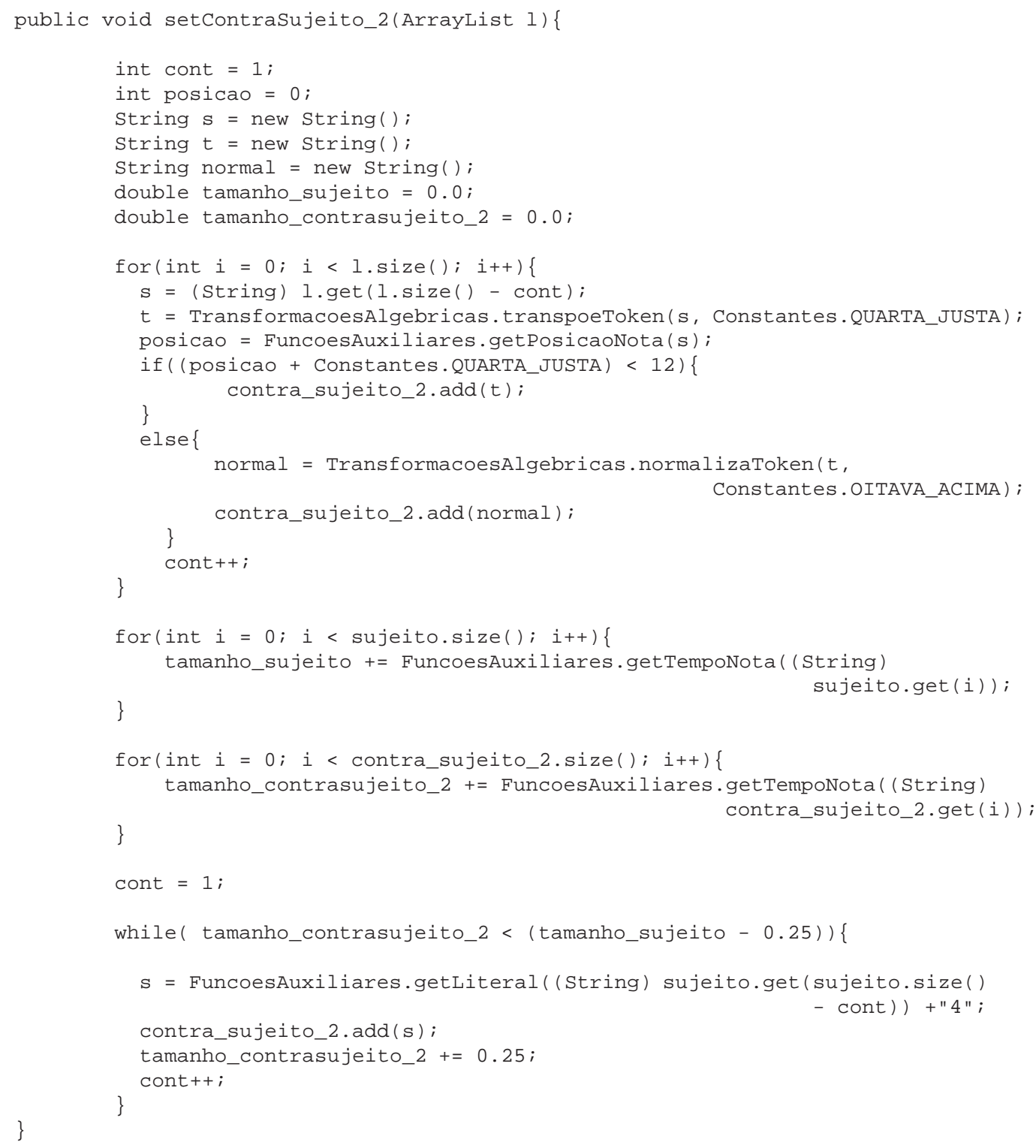

Código 6.6.5: Implementação do método setContraSujeito_2() 
Os métodos setFuncInversaContraSujeito_1 (Arraylist 1) e setFuncInversaContraSujeito_2 (Arraylist l) recebem como entrada o contra-sujeito 1 e o contra-sujeito 2, respectivamente, e tentam reverter o processo de suas criações, retornando suas entradas originais, quais sejam, a resposta e o contra-sujeito 1, nesta ordem. 
public void setFuncInversaContrasujeito_1 (ArrayList 1) \{

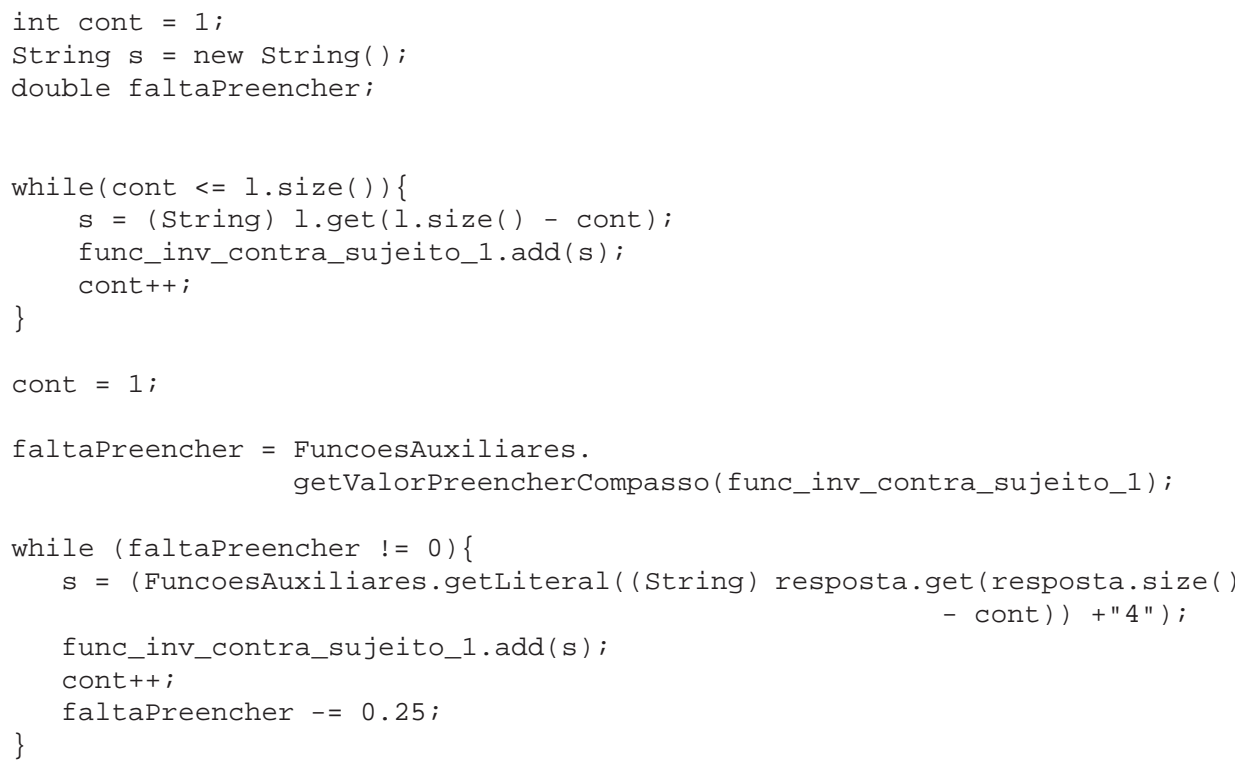

Código 6.6.6: Implementação do método setFuncInversaContraSujeito_1() 


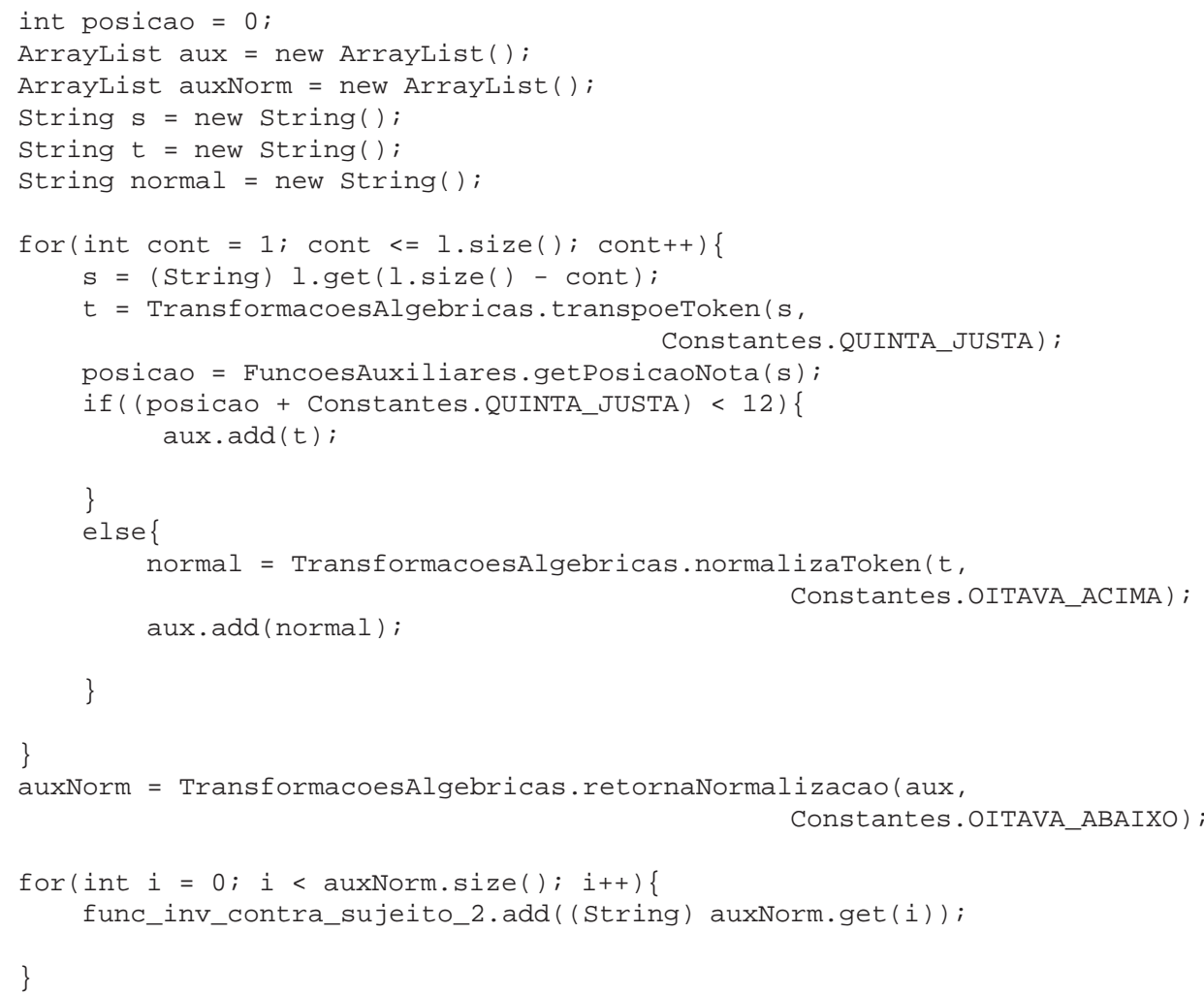

Código 6.6.7: Implementação do método set FuncInversaContraSujei to_2() 
Por fim, o método setPartesDaFuga () inicializa todas os ArrayList desta classe, que tem como entrada o array de char com as notas do sujeito, do qual tudo é derivado.

public void setPartesDaFuga()

setSujeito(buffer_sujeito);

setResposta (sujeito);

setContrasujeito_1(resposta);

setContraSujeito_2(contra_sujeito_1);

setFuncInversaContraSujeito_1 (contra_sujeito_1);

setFuncInversaContraSujeito_2 (contra_sujeito_2);

\}

Código 6.6.8: Implementação do método setPartesDaFuga ()

\subsection{Implementação da Classe TransformacoesAlgebricas}

Classe semelhante à classe PartesdaFuga, pois contém as transformações melódicas do sujeito da fuga: aumento, diminuição, retrógrado e inversão, além das pausas correspondentes às suas notas, armazenadas cada uma em um ArrayList.

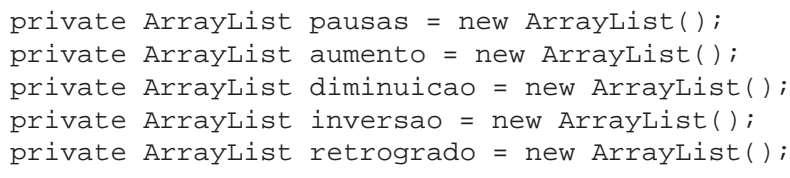

Código 6.7.1: Arraylist com as Transformações Melódicas

O método normalizaToken (String s, int posicao) recebe como parâmetros o token a ser normalizado e a posição para normalização e funciona fazendo com que a string de retorno esteja uma oitava abaixo ou acima da inicial, dependendo do valor da posição. O método trabalha com as vírgulas e apóstrofos que porventura estejam na string. Se a posição é para subir uma oitava, o método acrescenta um apóstrofo ou diminui uma vírgula, da string original; se é para descer uma oitava, o método diminui um apóstrofo ou acrescenta uma vírgula ao token de retorno. Às pausas, que independem de oitavas, não são feitas quaisquer alterações. Para aplicar essa operação a todas as notas de um ArrayList, é utilizada o método retornaNormalizacao (Arraylist 1, int posicao), que retornará um Arraylist com as modificações feitas. 
public static String normalizaToken(String s, int posicao) \{

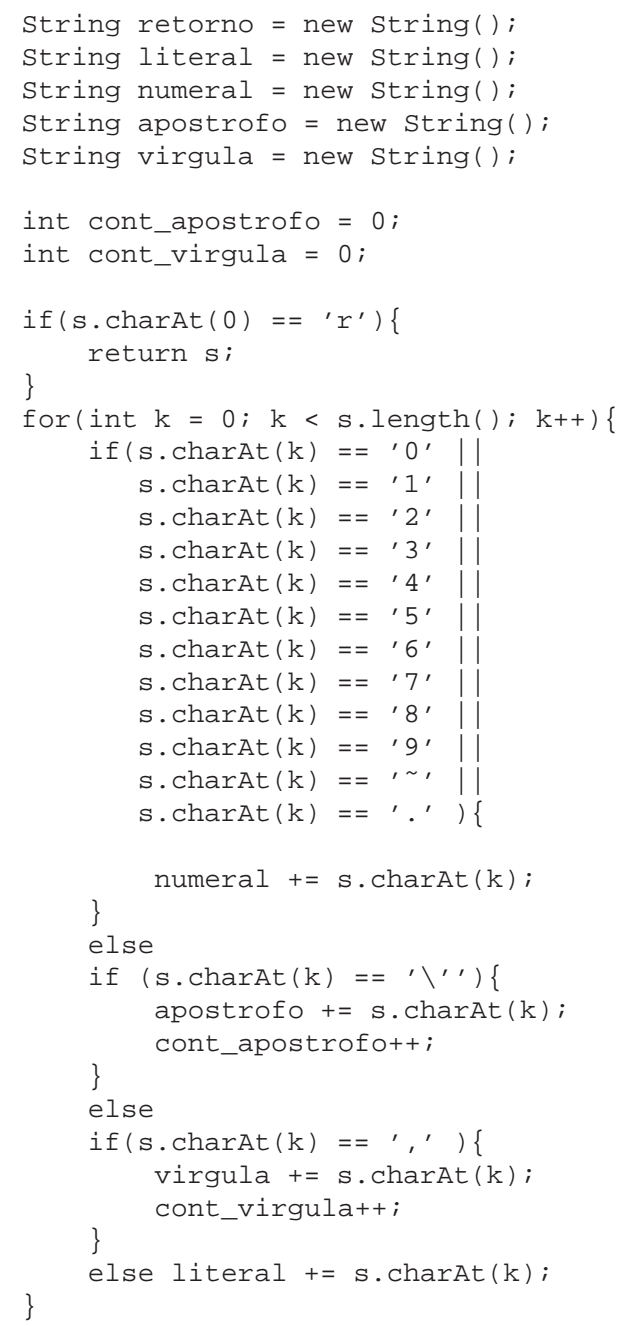

Código 6.7.2: Implementação do método normalizaToken() 


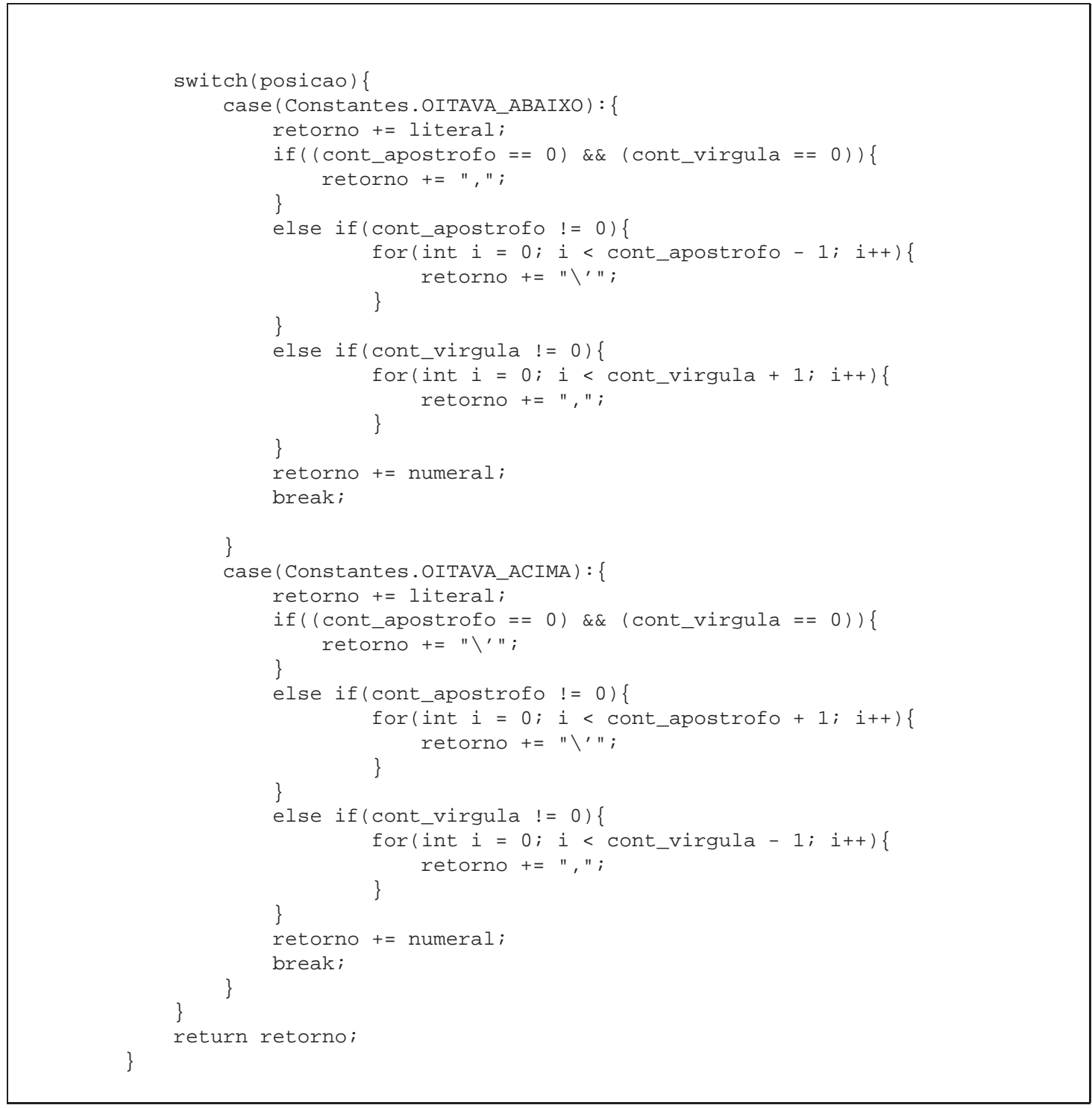

Código 6.7.3: Continuação da implementação do método normalizaToken()

O método transpoeToken (String $s$, int $t$ ) transpõem a nota passada como parâmetro pela posição t. Para isso, depois de localizado em qual escala a nota está, o valor do índice da posição dessa nota nessa escala é somado ao valor de t e é feita a operação em aritmética modular para se achar o índice da posição da nota transposta. 
public static String transpoeToken(String $s$, int $t$ ) \{

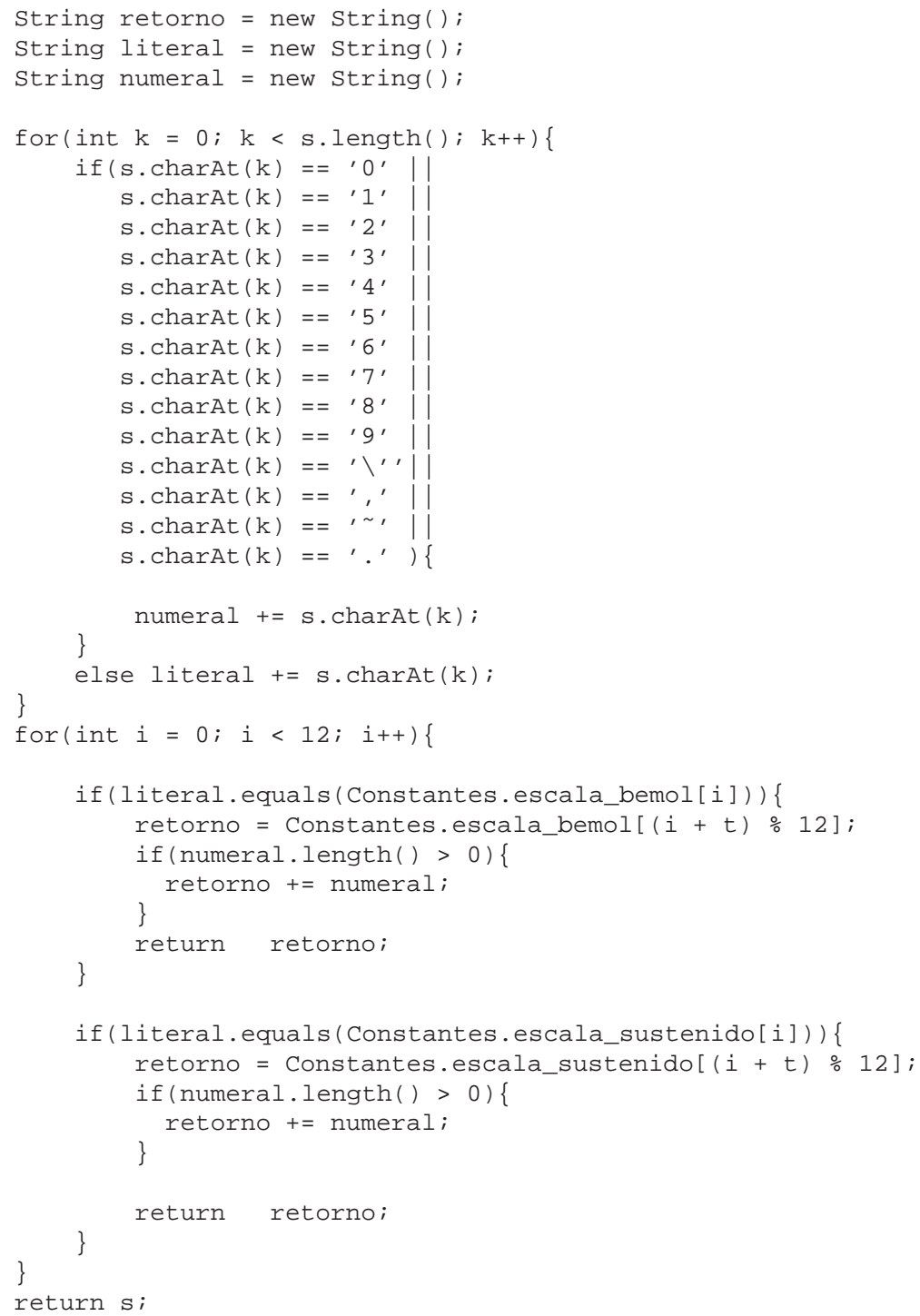

Código 6.7.4: Implementação do método transpoeToken () 
O método pausificaToken (String s) transforma a string de entrada em sua pausa correspondente, ou seja, retorna a pausa que tem o mesmo tamanho, em relação ao tempo, da string. Para que essa transformação seja atribuída à variável pausas da classe, é chamada o método setPausas (ArrayList 1), que tem como entrada o ArrayList com as notas do sujeito.

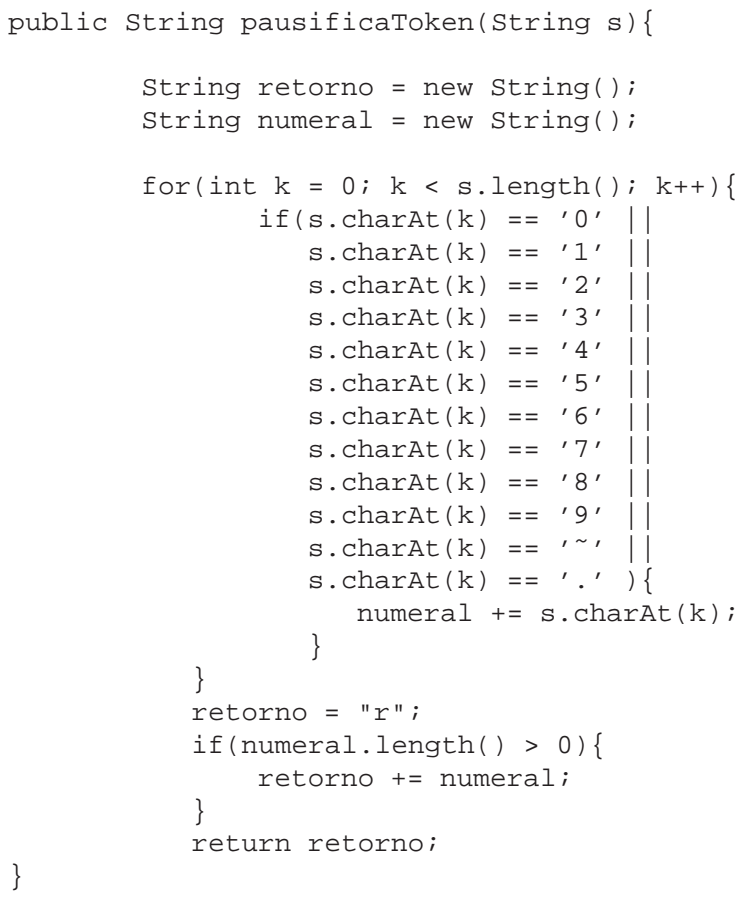

Código 6.7.5: Implementação do método pausificaToken() 
O método aumentaToken (String s) tem como retorno uma string com a duplicação do tempo da string de entrada. Para aplicar essa transformação a um Arraylist, o método setAumento (Arraylist 1) é chamada, e o valor é atribuído à variável aumento da classe.

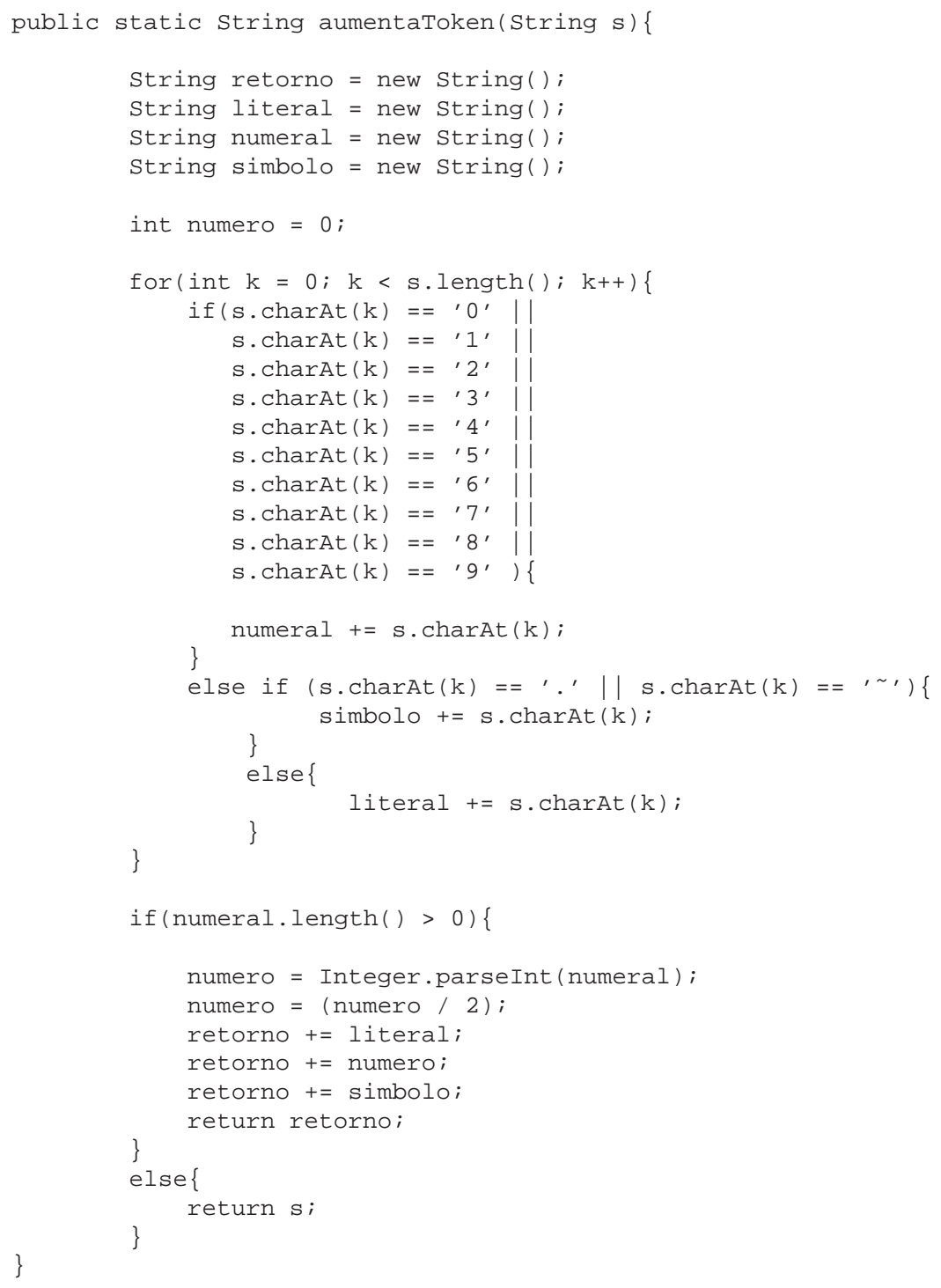

Código 6.7.6: Implementação do método aumenta Token () 
O método diminuiToken (String s) tem como retorno uma string com a metade do tempo da string de entrada. Para aplicar essa transformação a um ArrayList, o método setDiminuicao (ArrayList l) é chamada, e o valor é atribuído à variável diminuicao da classe.

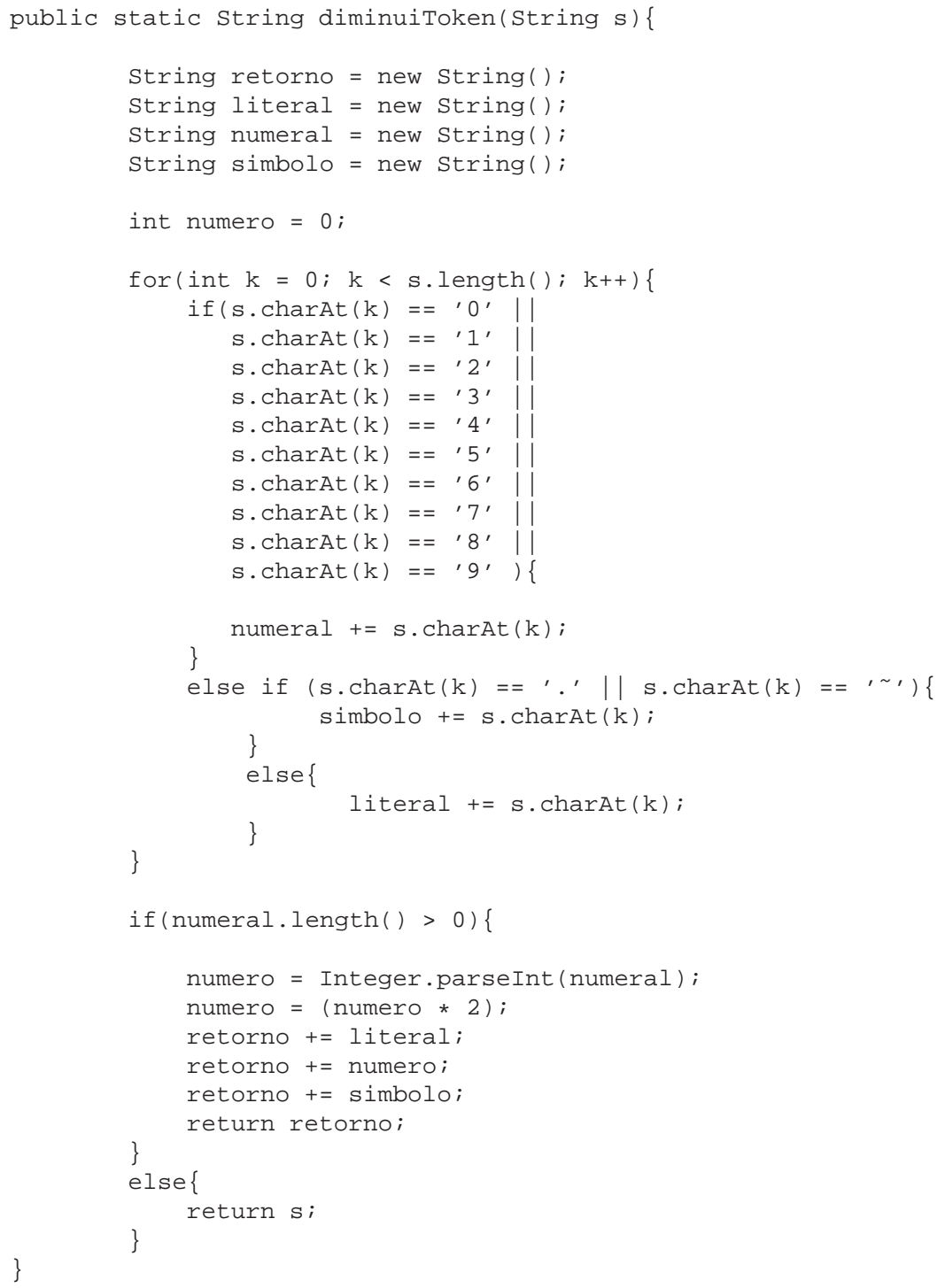

Código 6.7.7: Implementação do método diminui Token () 
O método inverteToken (String $s$, int $t$ ) tem como retorno a string que está na posição t na escala das notas, da classe Constantes, sendo que t é o índice da nota invertida, calculada previamente. Assim, é aparentemente desnecessária a passagem da string s, mas isso é feito para verificar em qual oitava a nota original está e fazer a necessária normalização, se preciso, e também retorna a nova nota com os possíveis símbolos que a nota original apresente. 
public static string inverteToken(String $s$, int $t)\{$

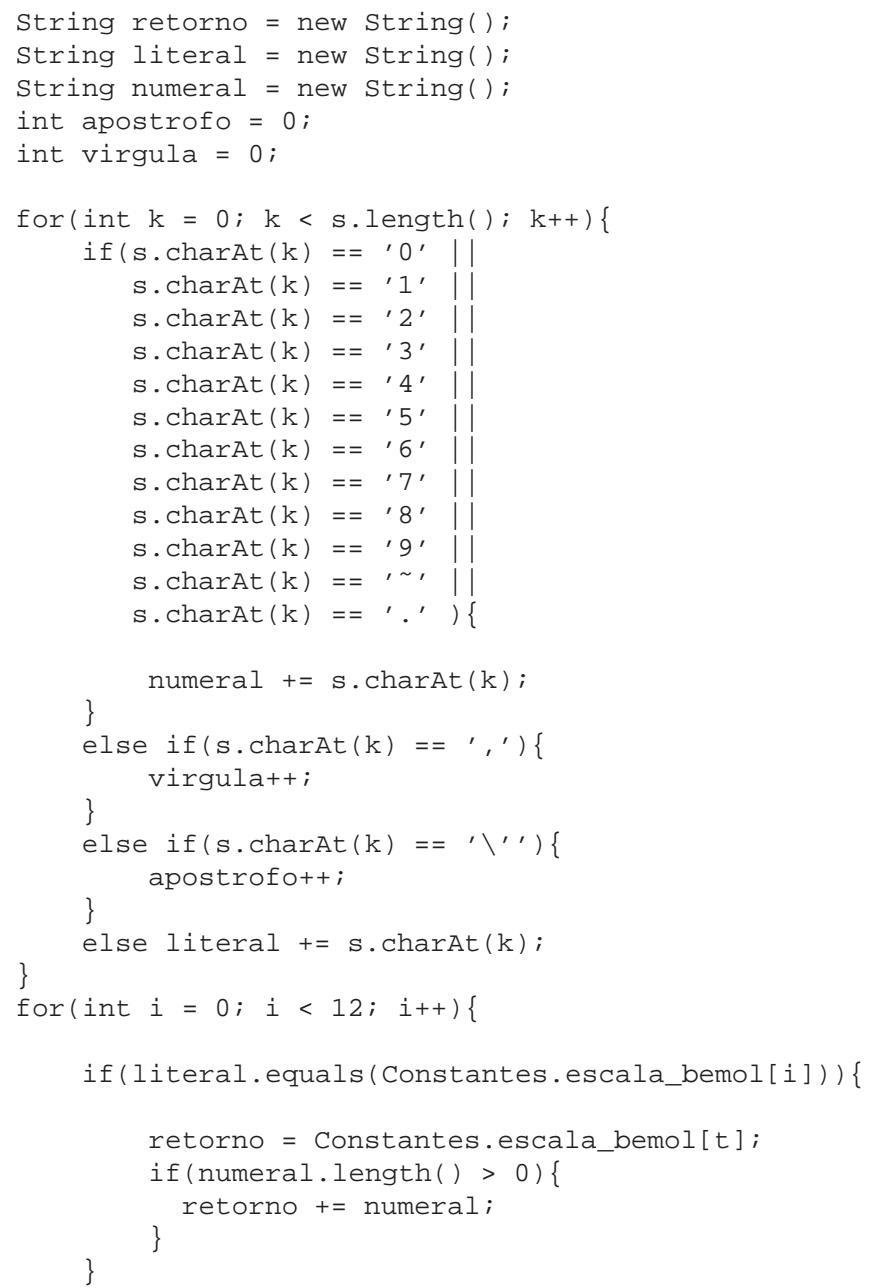

Código 6.7.8: Implementação do método inverteToken () 


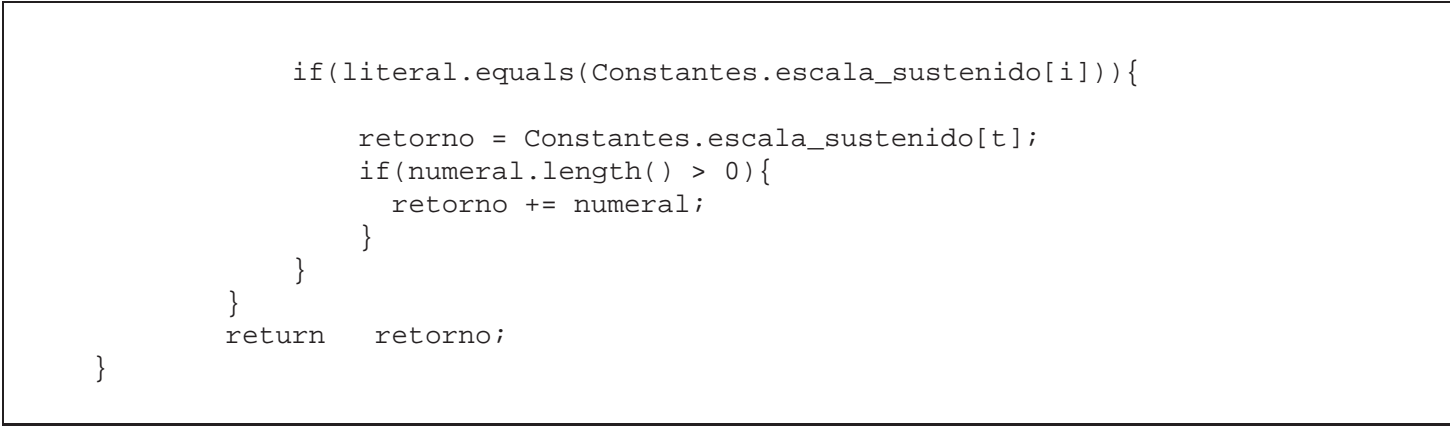

Código 6.7.9: Continuação da implementação do método inverteToken()

O método set Inversao (ArrayList 1) calcula, a partir da primeira nota, que será a base para a inversão, as inversões de todas as restantes do ArrayList passado como parâmetro e adiciona esses valores à variável inversão da classe.

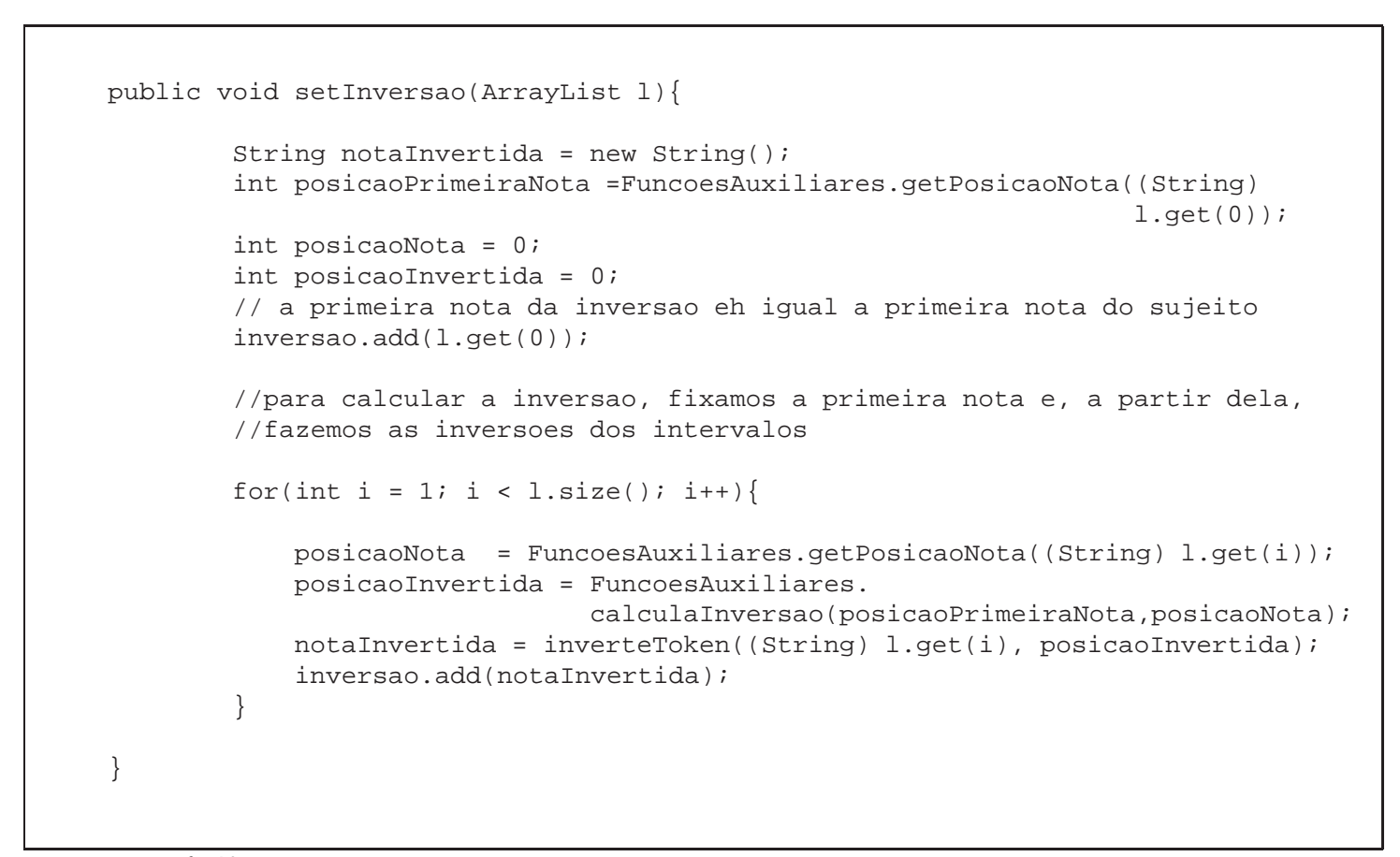

Código 6.7.10: Implementação do método set Inversao() 
O método setRetrogrado (ArrayList 1) inverte as posições do Arraylist passado como parâmetro e atribui esses valores à variável inversão da classe.

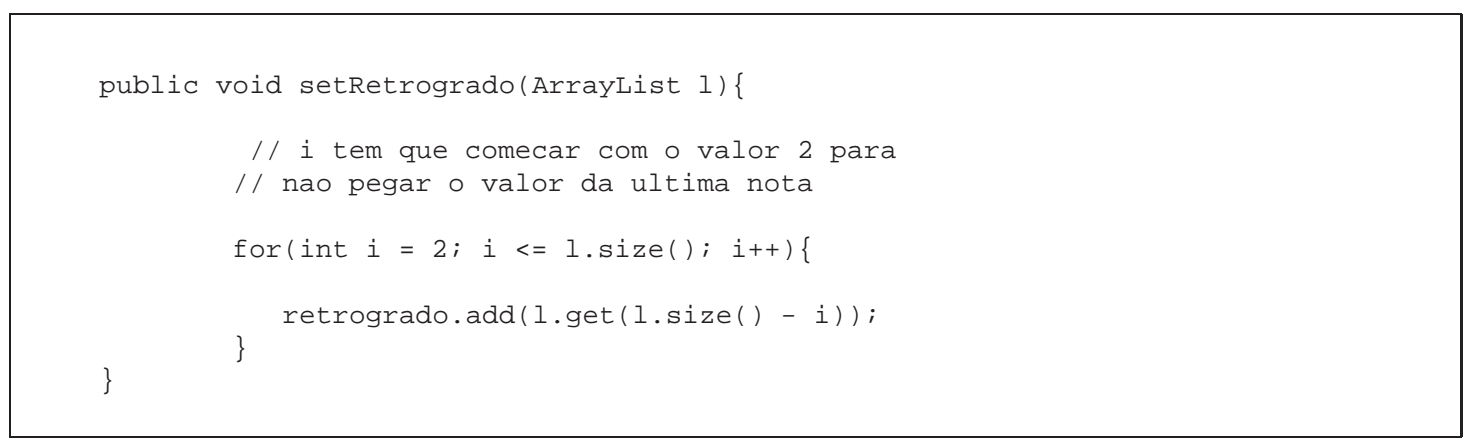

Código 6.7.11: Implementação do método set Ret rogrado () 
O método setTransformacoesAlgebricas (ArrayList l) inicializa todos os ArryList da classe, que tem como entrada o ArrayList contendo as notas do sujeito, ou seja, as transformações melódicas derivam diretamente do sujeito da fuga.

public void setTransformacoesAlgebricas (ArrayList 1) \{

setPausas (1);

setAumento ( 1$)$;

setDiminuicao(1);

setInversao (1):

setRetrogrado (1);

Código 6.7.12: Implementação do método set Trans formacoesAlgebricas ()

\subsection{Implementação da Classe GeraFuga}

É a classe principal do programa gerador de fugas, onde as partes da fuga e as transformações melódicas serão concatenadas, de forma a gerar a fuga.

Os ArrayList voz_1, voz_2 e voz_3 armazenam as notas obtidas na construção das partes da fuga e das transformações melódicas, na ordem em que devem aparecer.

As pilhas pilha_1, pilha_2 e pilha_3 armazenam as transformações inversas das partes da fuga na medida em que estas vão sendo geradas, para posterior desempilhamento na ordem inversa em que foram empilhadas.

Os contadores de tempo contadorTempo_1, contadorTempo_2 e contadorTempo_3 são variáveis numéricas que vão sendo incrementadas dos tempos das notas na medida em que estas são adicionadas nos ArrayList das vozes correspondentes, para o cálculo do tamanho dessas vozes enquanto estão sendo geradas e/ou para uso posterior do valor desse tamanho.

As strings textoVoz_1, textoVoz_2 e textoVoz_3 recebem as strings que foram armazenadas nos ArrayList voz_1, voz_2 e voz_3, respectivamente, para serem acrescentadas no arquivo texto que representará a fuga no formato Lylipond. 


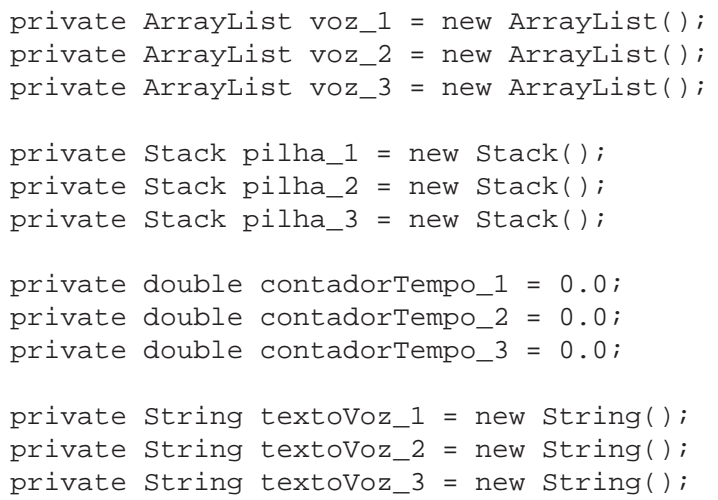

\section{Código 6.8.1: Variáveis da Classe GeraFuga}

Os métodos adicionarVoz1 (ArrayList 1), adicionarVoz2 (ArrayList 1) e adicionarVoz3 (Arraylist 1 ) adicionam o conteúdo das posições do Arraylist passado ao Arraylist da voz correspondente e incrementa o contador dessas vozes com os tempos das notas passadas.

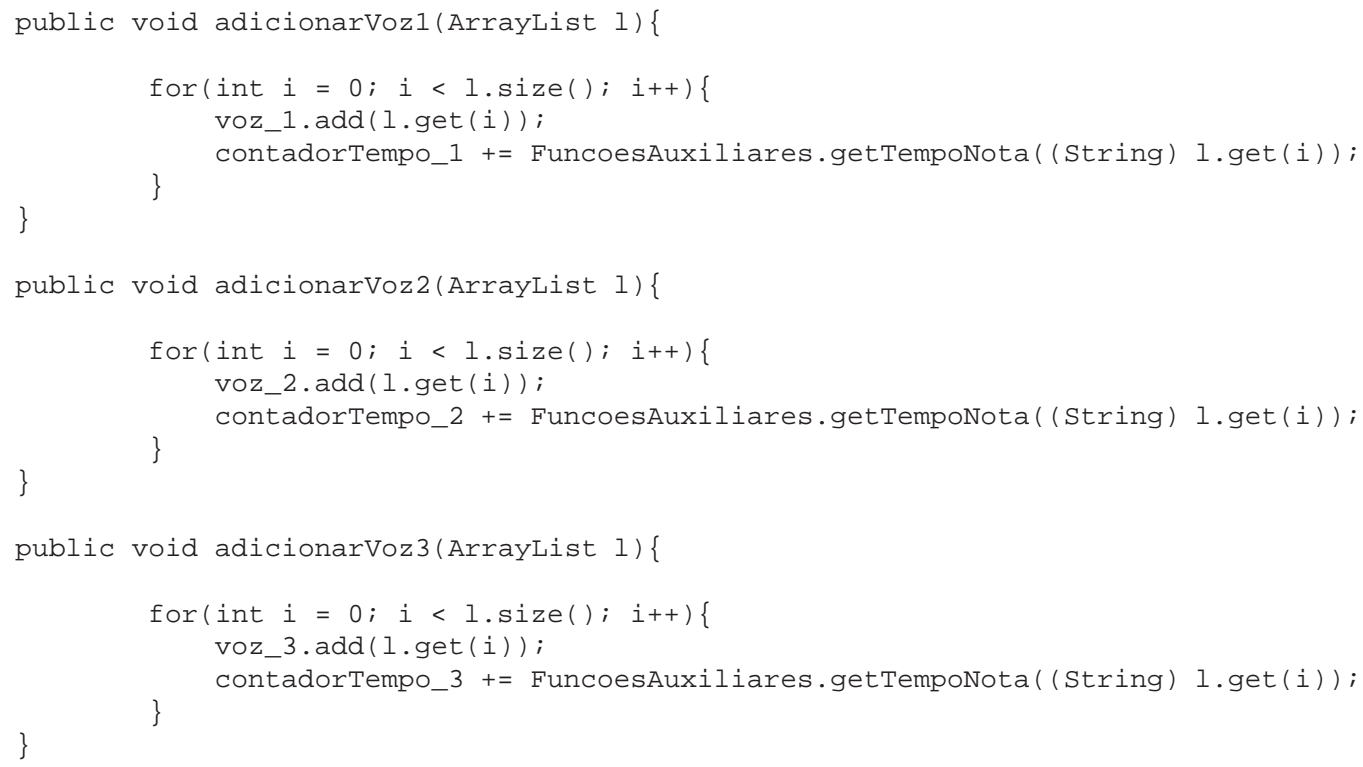

Código 6.8.2: Implementação dos métodos adicionarVoz 
O método setFugaPrimeiraParte() adiciona às vozes correspondentes as partes da fuga e suas transformações melódicas, na ordem correta de aparecimento, e, concomitantemente, empilha os valores obtidos da aplicação da função inversa a essas partes, se são derivações de outras partes da fuga. Como todas as partes que compõem a fuga derivam direta ou indiretamente do sujeito, somente este não possuirá função inversa.

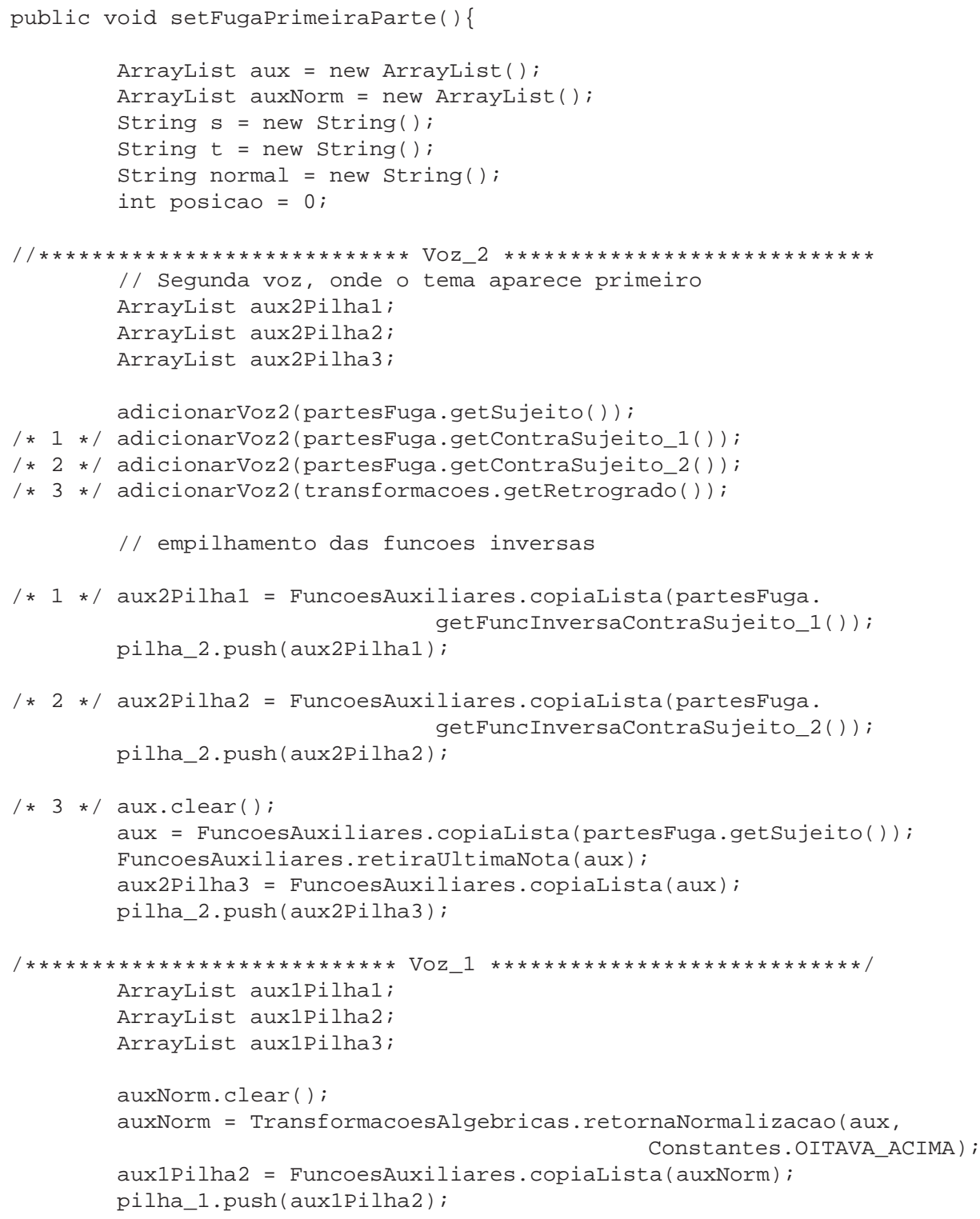

Código 6.8.3: Implementação do método setFugaPrimeiraParte() 
/* $3 \star /$ auxNorm.clear();

auxNorm = TransformacoesAlgebricas.

retornaNormalizacao (partesFuga.getsujeito(), Constantes.OITAVA_ACIMA);

FuncoesAuxiliares.retiraUltimaNota (auxNorm);

aux1Pilha3 = FuncoesAuxiliares.copiaLista (auxNorm);

pilha_1.push (aux1Pilha3);

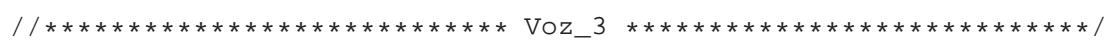

Arraylist aux3Pilhal;

adicionarVoz3 (transformacoes.getPausas ());

adicionarVoz3 (transformacoes.getPausas ());

auxNorm.clear ();

auxNorm = TransformacoesAlgebricas. retornaNormalizacao (partesFuga.getsujeito(), Constantes.OITAVA_ABAIXO);

FuncoesAuxiliares.retiraultimaNota (auxNorm);

adicionarVoz3 (auxNorm);

//a ordem esta invertida para nao ser preciso fazer outra normalizacao

/* $1 * /$ aux3Pilha1 = FuncoesAuxiliares.copiaLista(auxNorm);

pilha_3.push (aux3Pilha1);

/* 1 */ auxNorm.clear();

auxNorm = TransformacoesAlgebricas.

retornaNormalizacao (transformacoes.getAumento (), Constantes.OITAVA_ABAIXO);

adicionarVoz3 (auxNorm);

\}

adicionarVoz1 (transformacoes.getpausas ()) ;

/* 1 */ adicionarVozl (partesFuga.getResposta());

Código 6.8.4: Continuação da implementação do método setFugaPrimeiraParte() 
aux.clear ();

/* $2 * /$ for(int $i=0 ; i<$ partesFuga.getContraSujeito_1().size(); $i++)\{$

$t=$ TransformacoesAlgebricas .

transpoeToken((String) partesFuga.getContraSujeito_1().get(i), Constantes.QUARTA_JUSTA)

posicao = FuncoesAuxiliares.getPosicaoNota( (String)

partesFuga.getContrasujeito_1().get(i)) ;

if ( (posicao + Constantes.QUARTA_JUSTA $)<12)\{$

aux.add $(t)$;

\}

else \{

normal = TransformacoesAlgebricas.normalizaToken $(t$,

Constantes.OITAVA_ACIMA):

\}

\}

auxNorm.clear();

auxNorm = TransformacoesAlgebricas.retornaNormalizacao(aux, Constantes.OITAVA_ACIMA)

adicionarVoz1 (auxNorm);

/* $3 * /$ auxNorm.clear();

auxNorm = TransformacoesAlgebricas.

retornaNormalizacao (transformacoes.getDiminuicao()

adicionarVoz1 (auxNorm) ;

Constantes.OITAVA ACIMA)

/* 1 */ auxNorm.clear();

auxNorm = TransformacoesAlgebricas.

retornaNormalizacao (partesFuga.getsujeito(), Constantes.OITAVA_ACIMA);

FuncoesAuxiliares.retiraUltimaNota (auxNorm);

auxlPilhal = FuncoesAuxiliares.copiaLista (auxNorm);

pilha_1.push (aux1Pilha1);

Código 6.8.5: $\quad$ Continuação da Implementação do método setFugaPrimeiraParte() 
2 aux.clear();

for (int $i=0 ; i$ partesFuga.getFuncInversaContraSujeito_1().size(); i++)

$t=$ TransformacoesAlgebricas.transpoeToken((String) partesFuga.getFuncInversaContraSujeito_1().get (i), Constantes.QUINTA_JUSTA);

posicao = FuncoesAuxiliares.

getPosicaoNota( (String)

partesFuga.getFuncInversaContraSujeito_1().get(i));

if((posicao + Constantes.QUINTA_JUSTA) 12)

aux.add (t);

\}

else \{

normal $=$ TransformacoesAlgebricas.normalizaToken( $t$, Constantes.OITAVA_ACIMA);

aux.add (normal);

\}

Código 6.8.6: Continuação da Implementação do método setFugaPrimeiraParte() 
O método setFugaSegundaParte () apenas desempilha as inversas das transformações e as adiciona às vozes correspondentes.

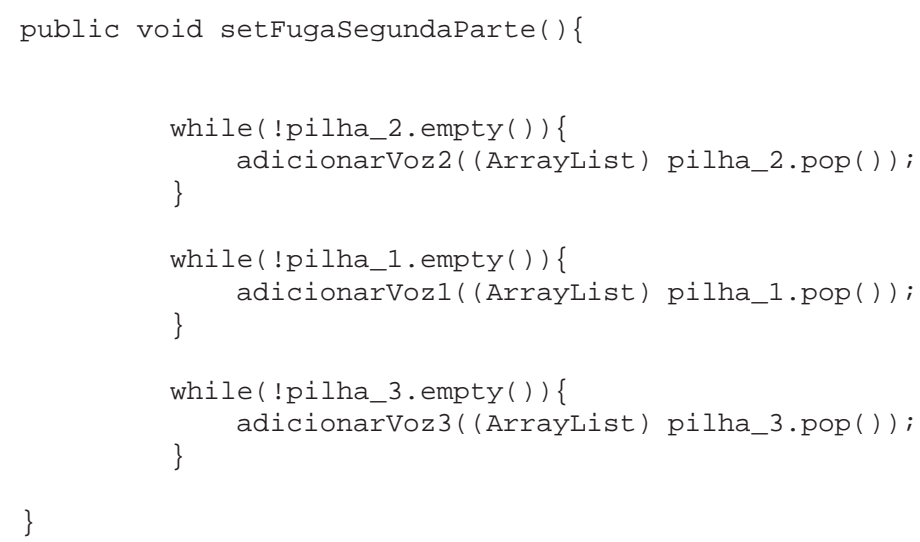

Código 6.8.7: Implementação do método setFugaSegundaParte() 
O método completarFugaCompausas() adiciona pausas às vozes menores até que estejam do mesmo tamanho da maior das três, fechando, assim, de maneira correta a fuga.

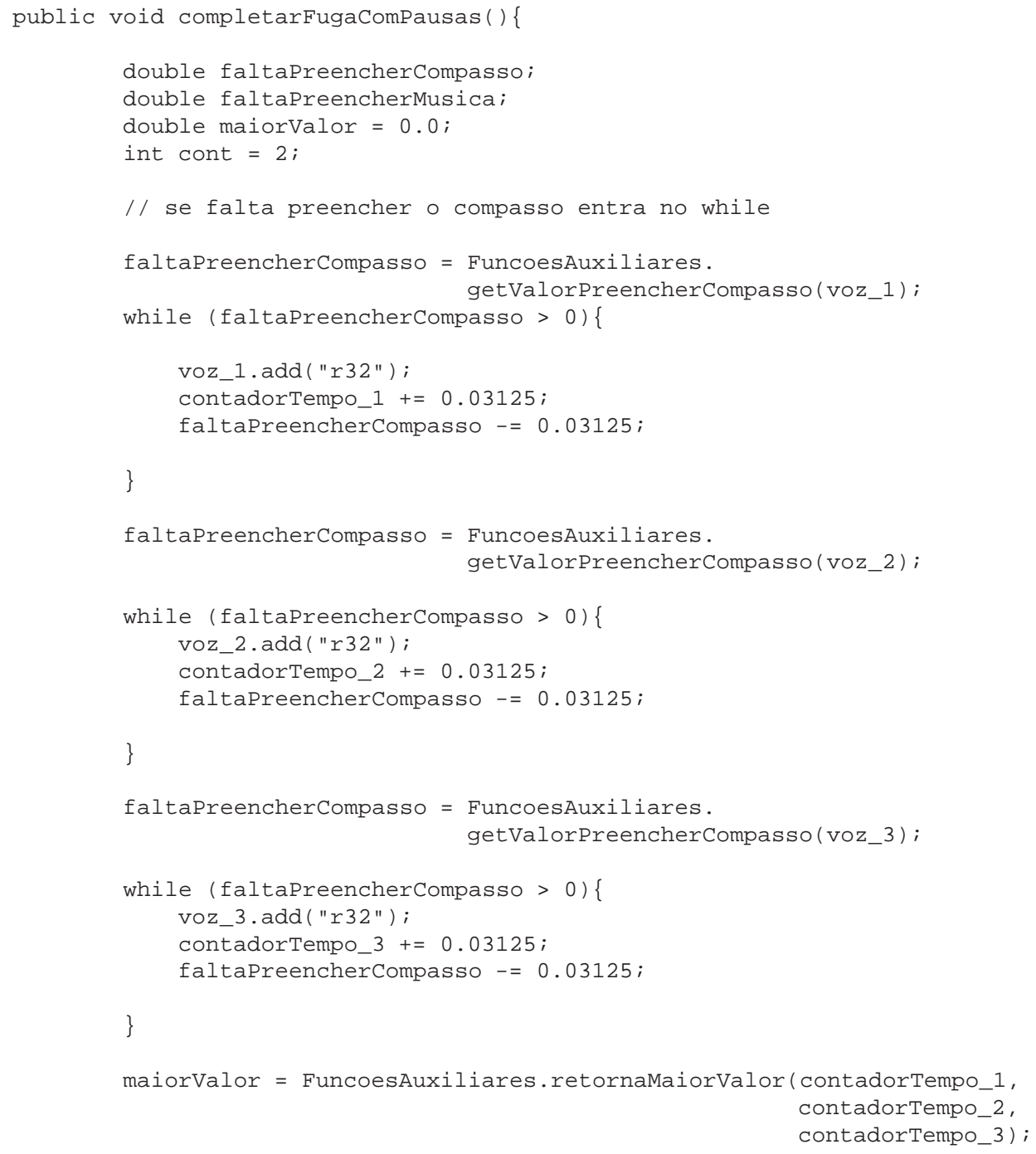

Código 6.8.8: Implementação do método completarFugaComPausas() 


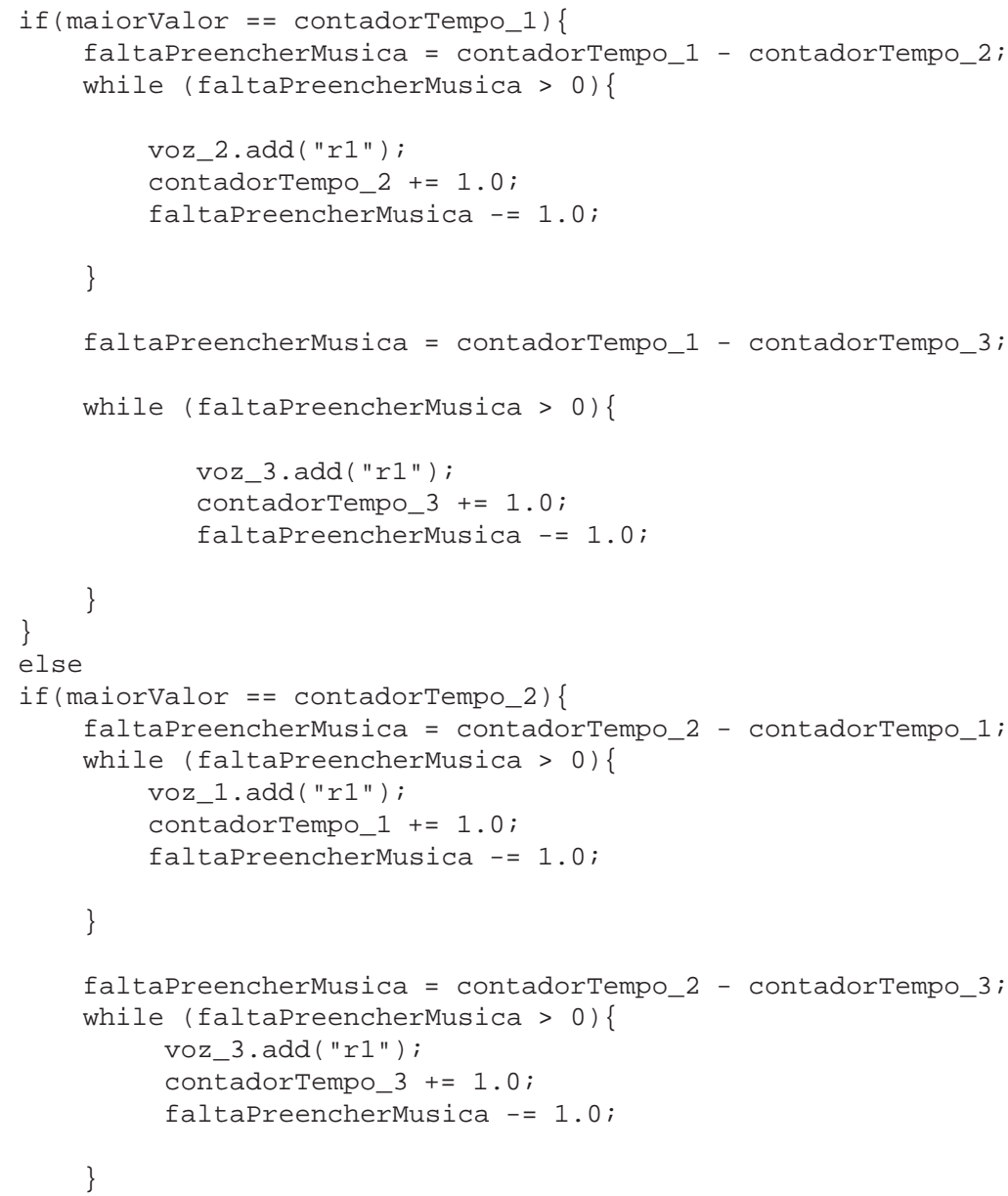

Código 6.8.9: Continuação da implementação do método completarFugaCompausas() 


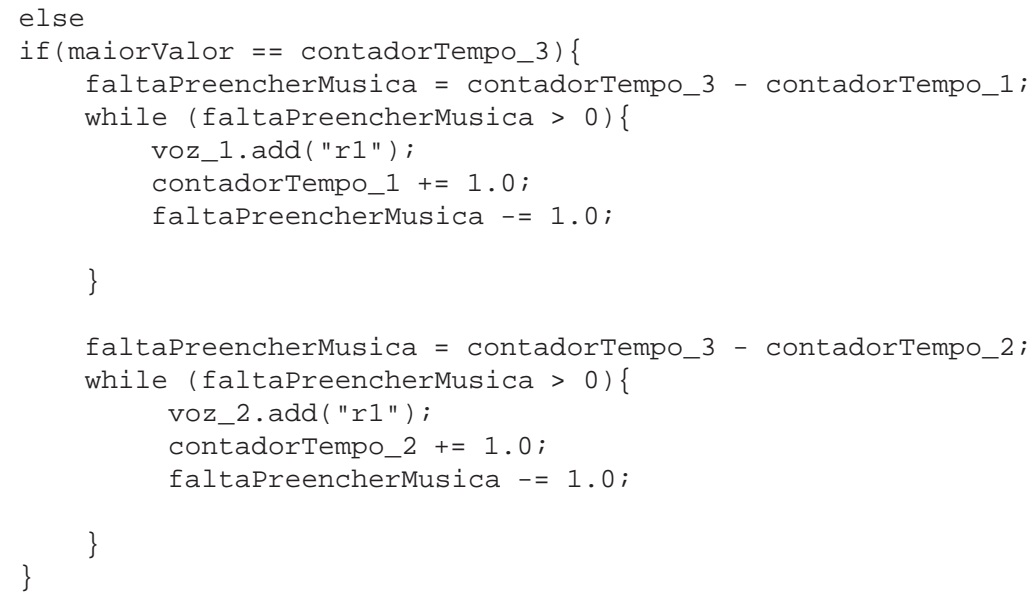

Código 6.8.10: Continuação da implementação do método completarfugaCompausas()

O método set TextoVozes () transfere as strings que estão nas posições dos Arraylist das vozes para as variáveis de texto que as representam e os métodos getVoz_1 (), getVoz_2() e getVoz_3() retornam esses textos armazenados. 


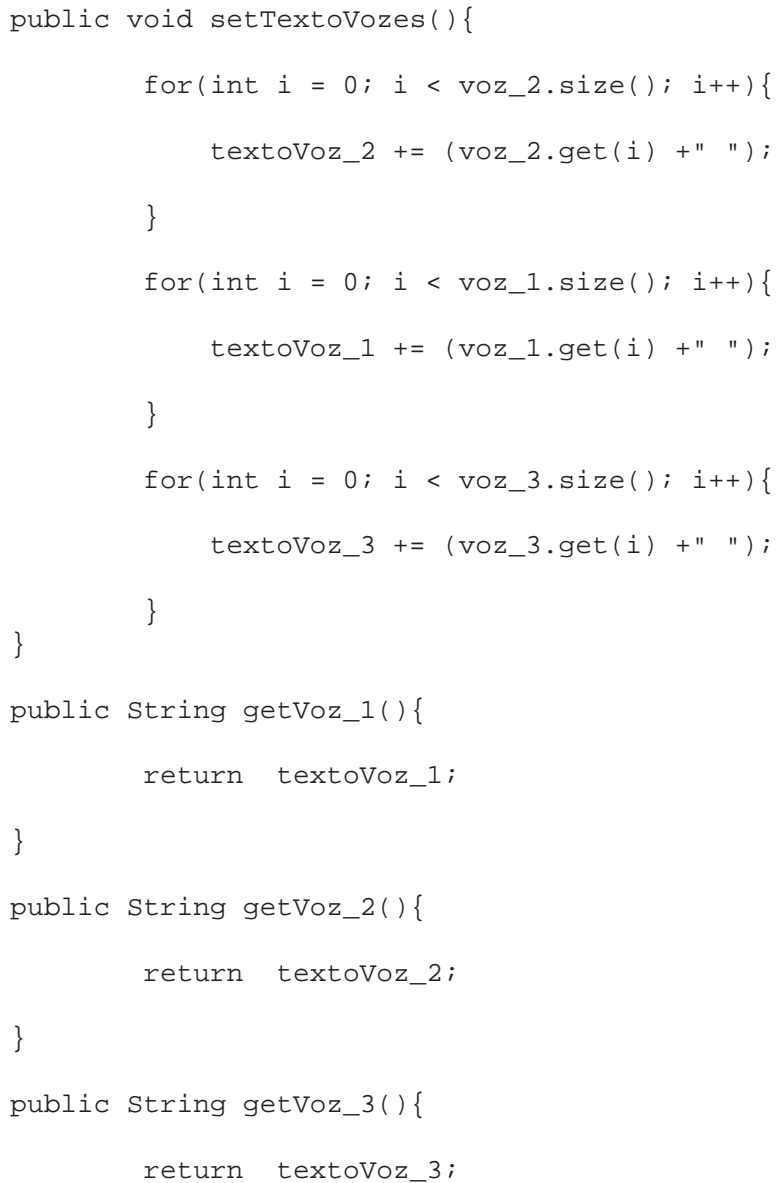

Código 6.8.11: Implementação do método set TextoVozes ()

\subsection{Implementação da Classe Janela}

Esta classe fornece a interface gráfica para facilitar a execução do programa gerador de fugas e adicionar algumas funcionalidades que tornam a música gerada mais palatável ao ouvinte, como a escolha de instrumentos para cada voz e o tempo da execução sônica.

Os instrumentos podem ser aplicados a cada voz separadamente antes da geração do arquivo que será compilado, se isso não for feito, o instrumento default será o piano.

O tempo também deve ser escolhido antes da geração do arquivo, e está em batidas por minuto.

O botão Gerar fuga permite a escolha do arquivo texto que contém o sujeito, a partir do qual a fuga será gerada, e gera o arquivo no formato LilyPond, para posterior compilação. 


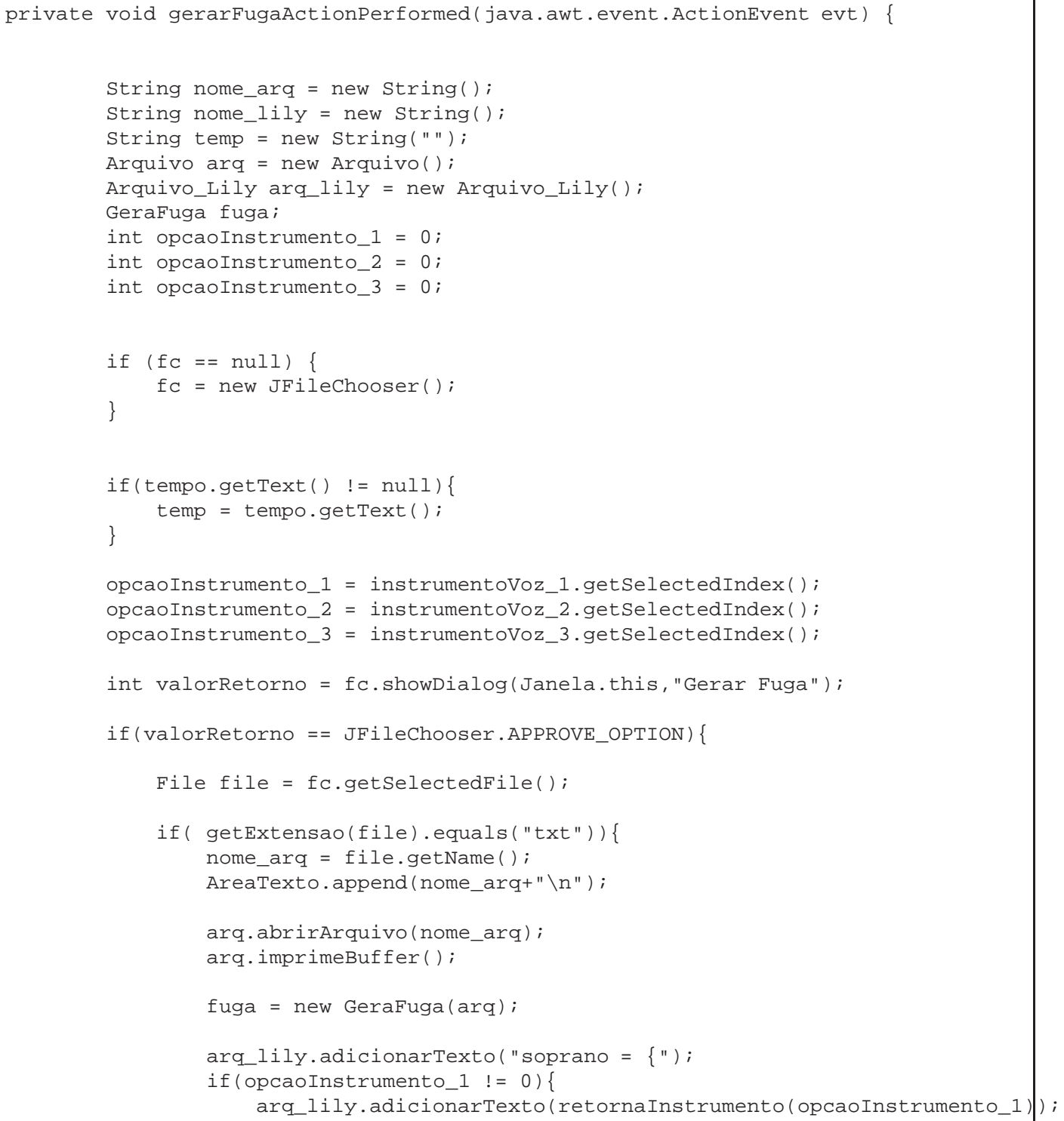

Código 6.9.1: Implementação do método gerarFuga () 
\}

arq_lily.adicionarTexto(fuga.getVoz_1());

arq_lily.adicionarTexto("\}");

arq_lily.adicionarTexto ("alto $=\{\backslash \mathrm{n} ")$;

if (opcaoInstrumento_2 $!=0)\{$

arq_lily.adicionarTexto(retornaInstrumento (opcaoInstrumento_2)); \}

arq_lily.adicionarTexto(fuga.getVoz_2());

arq_lily.adicionarTexto("\}");

arq_lily.adicionarTexto("tenor $=\{")$;

if (opcaoInstrumento_3 $!=0)\{$

arq_lily.adicionarTexto(retornaInstrumento(opcaoInstrumento_3)) ; \}

arq_lily.adicionarTexto(fuga.getVoz_3()) ;

arq_lily.adicionarTexto (" \}") ;

arq_lily.adicionarTexto(arq_lily.fim);

arq_lily.adicionarTexto(arq_lily.textoMidiAbre);

if (! temp.equals (" ")) \{

arq_lily.adicionarTexto(arq_lily.tempoMidiAbre);

arq_lily.adicionarTexto(temp); // colocar aqui o tempo

\}

arq_lily.adicionarTexto(arq_lily.tempoMidiFecha);

arq_lily.adicionarTexto(arq_lily.textoMidiFecha) ;

arq_lily.imprimeTexto();

nome_lily = nome_arq.replaceAll (".txt"," ");

arq_lily.gravarArquivoTexto(nome_lily+".ly") ;

AreaTexto.append (arq_lily.getTexto()) ;

\}

else\{

AreaTexto.append("\n Formato de arquivo invalido $\backslash \mathrm{n} "$ );

\}

\}

else \{

AreaTexto.append(" $\backslash n$ Erro na abertura do arquivo $\backslash n ")$;

\}

fC.setSelectedFile(null);

\}

Código 6.9.2: Continuação da implementação do método gerarFuga() 
O botão Compila fuga faz uma chamada externa ao interpretador LilyPond, que compilará o arquivo gerado pelo programa gerador de fugas e gerará o arquivo .pdf com a partitura que representa a fuga e o arquivo .mid, para tocá-la.

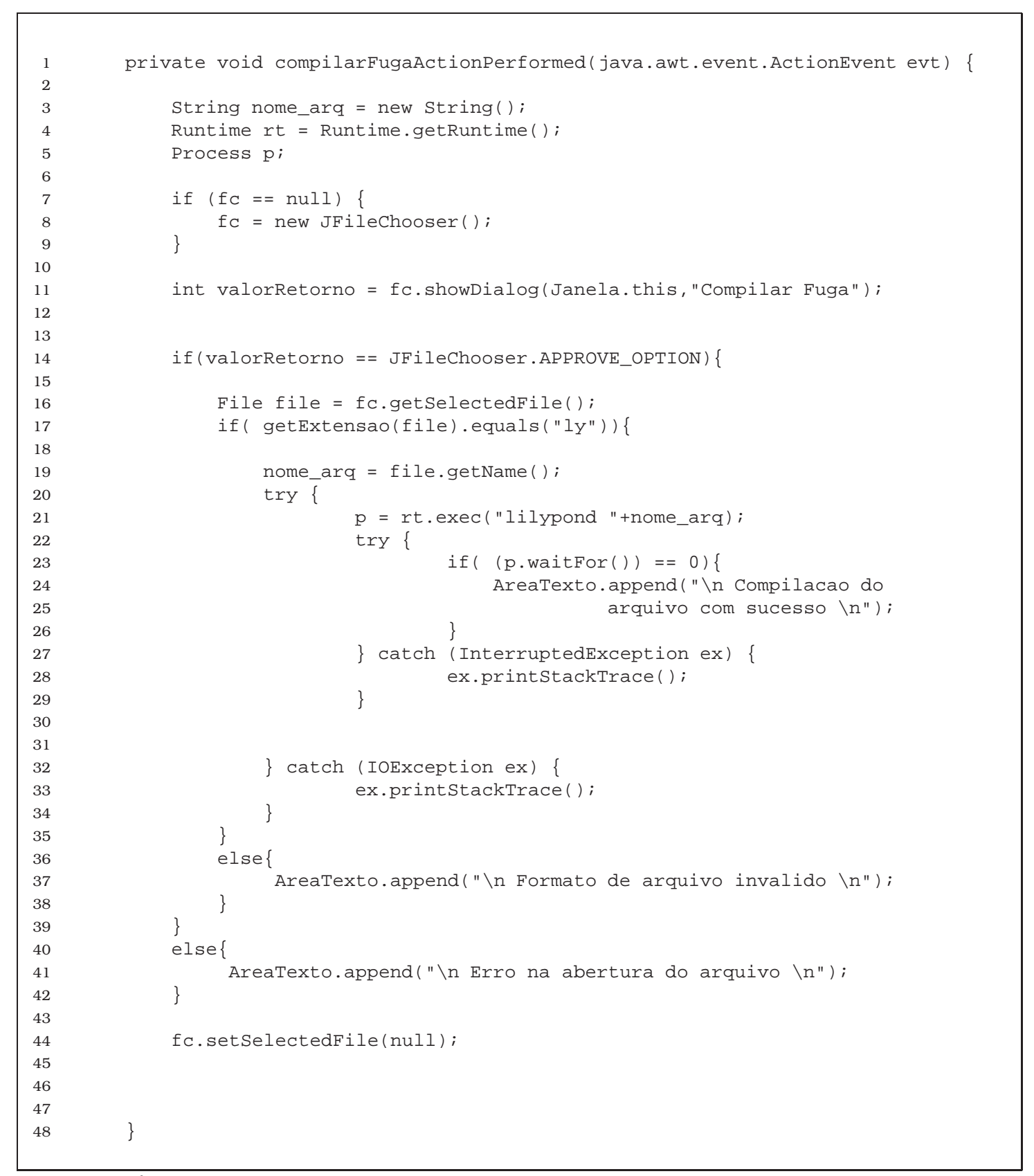

Código 6.9.3: Implementação do método compi larfuga () 
Os botões Tocar fuga e Parar execução são meras adições de funcionalidade, para não ser preciso outro programa externo para executar e parar a execução do arquivo .mid gerado.

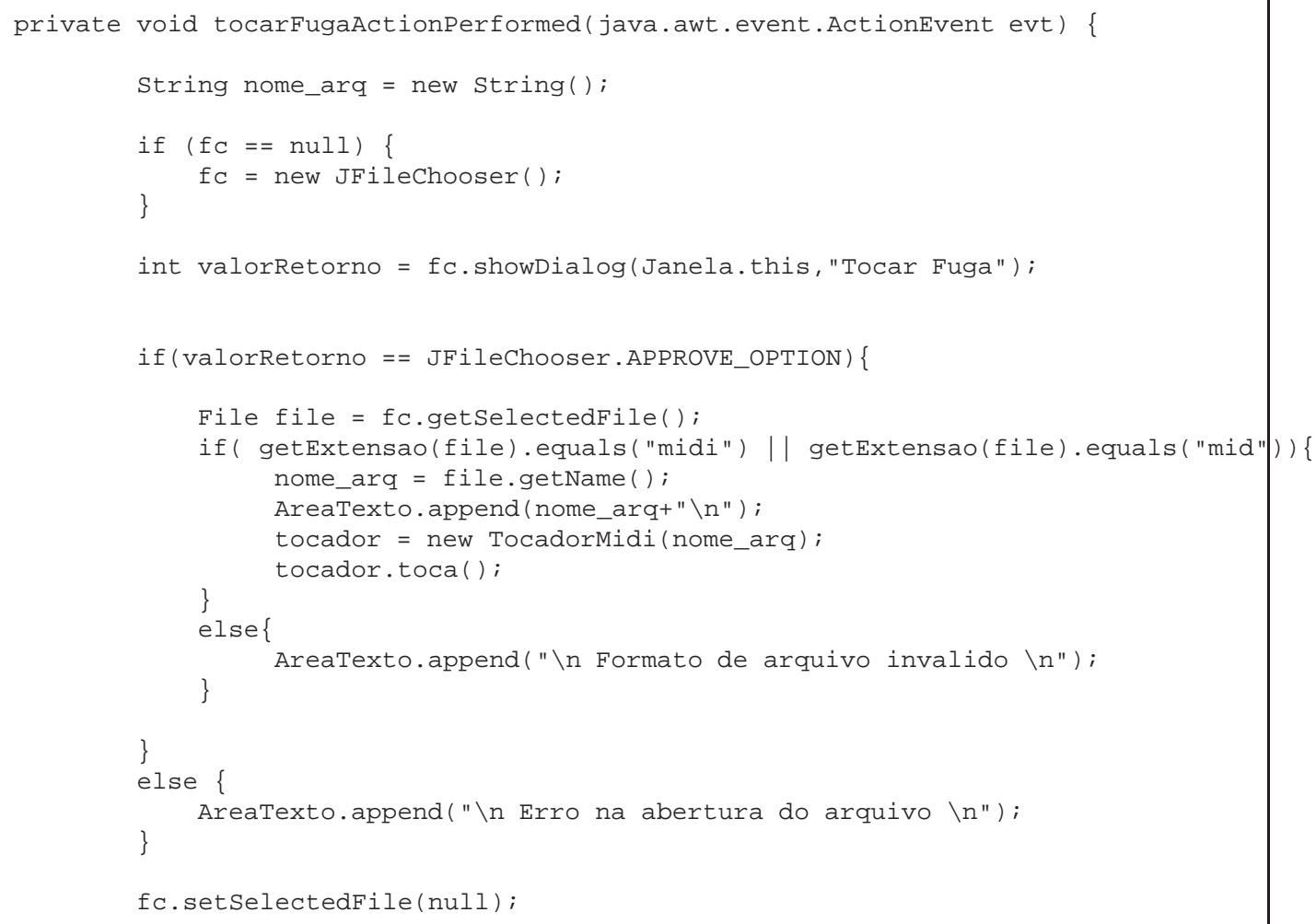

Código 6.9.4: Implementação do método tocarFuga() 


\subsubsection{Interface Gráfica}

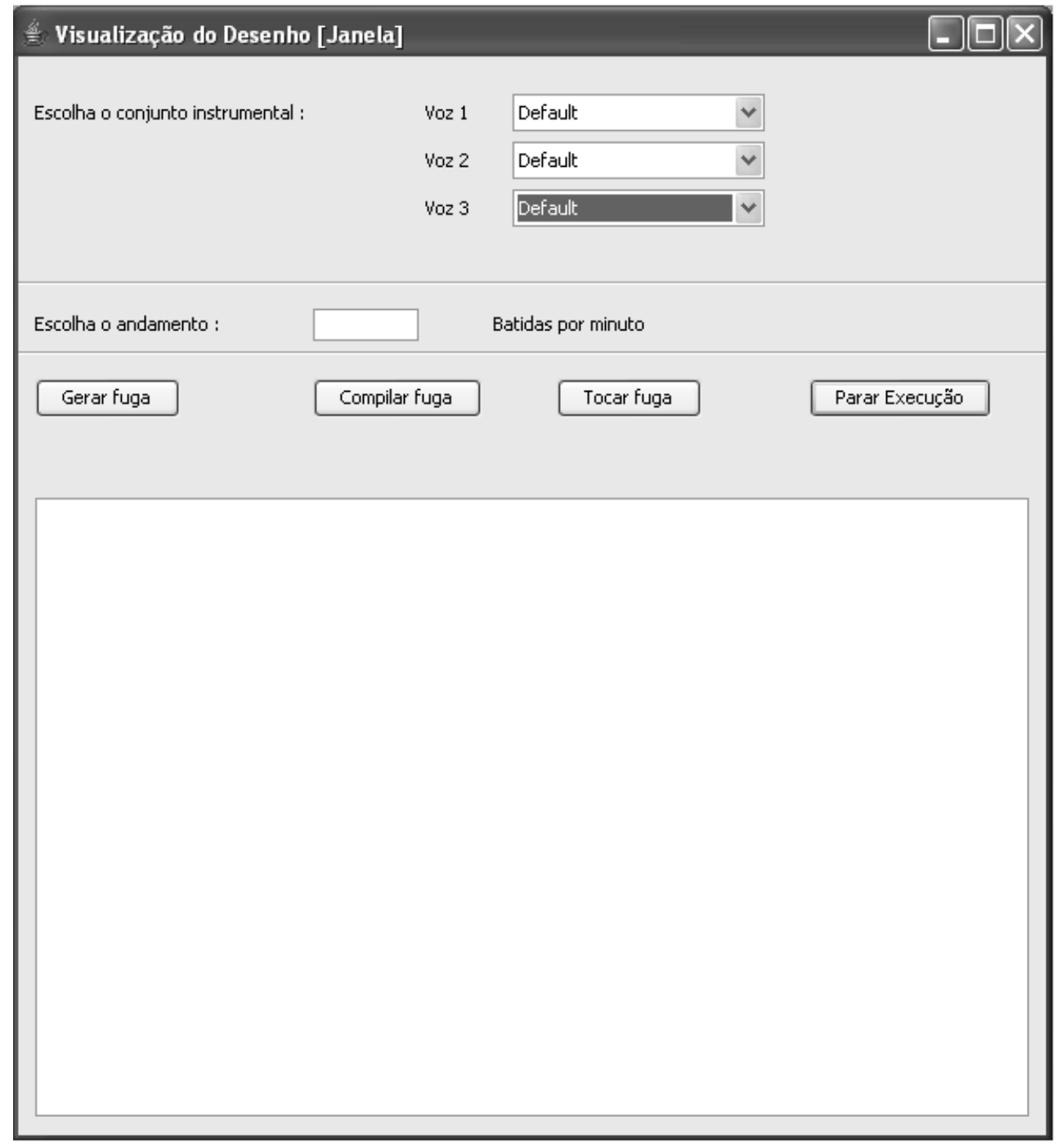

Figura 6.1: Interface Gráfica 


\subsection{Implementação da Classe ProgramaFinal}

Classe principal, que inicializa a execução do programa.

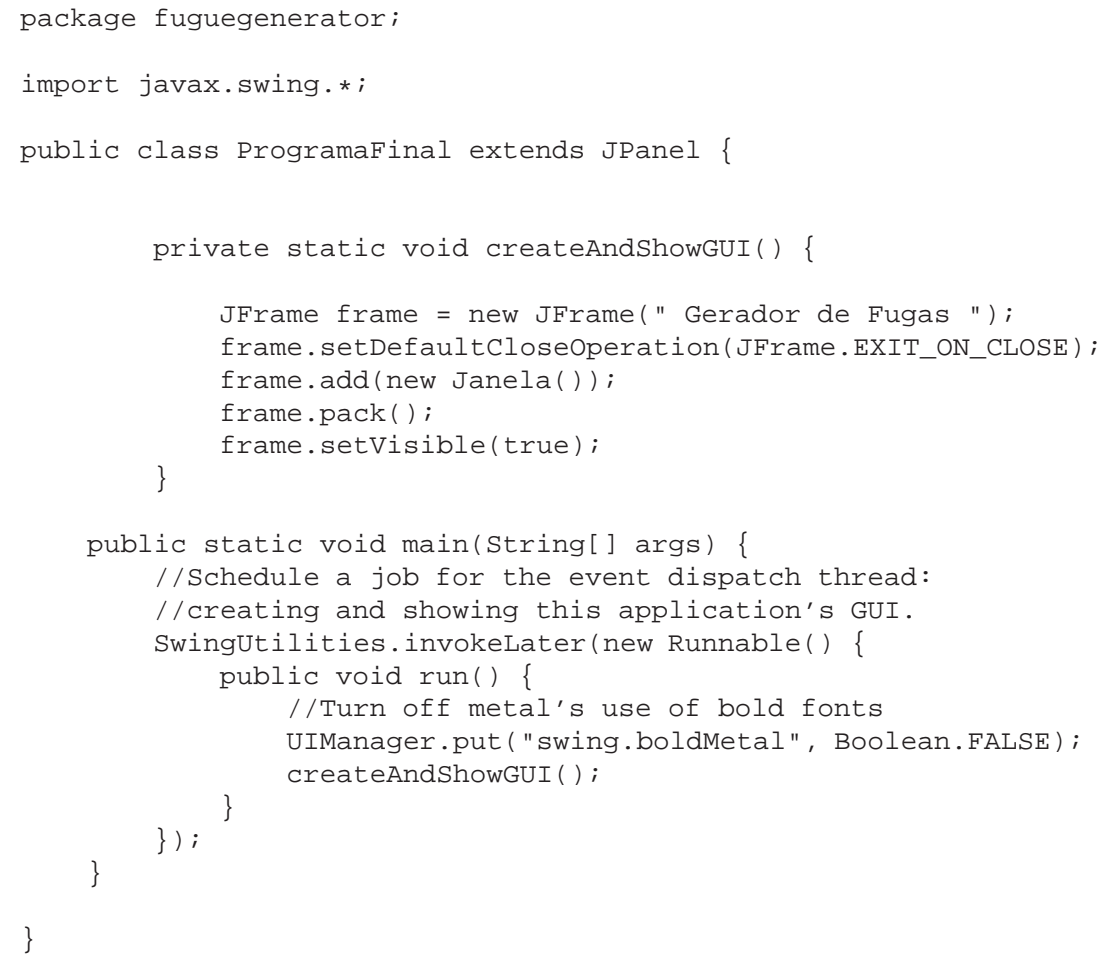

Código 6.10.1: Implementação da Classe ProgramaFinal 


\section{Capítulo 7}

\section{Resultados Obtidos}

Como exemplo para o funcionamento do programa, apresentamos quatro sujeitos, ou entradas, as saídas correspondentes e a partitura que as representa. 


\subsection{Exemplo 1: O Cravo Bem Temperado, Fuga I em Dó Maior (BWV 846)}

\subsubsection{Sujeito ( entrada do programa )}

A notação para este sujeito é:

r8 c'8 d'8 e'8 f'8. g'32 f32 e'8 a'8 d'8 g'8 g'16 a'16 g'16 f'16 e'16

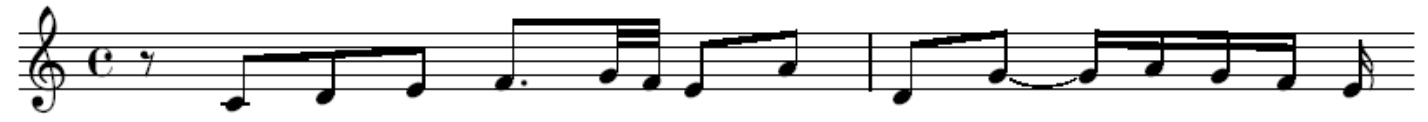

Figura 7.1: Sujeito da Fuga 


\subsubsection{Fuga ( saida do programa )}

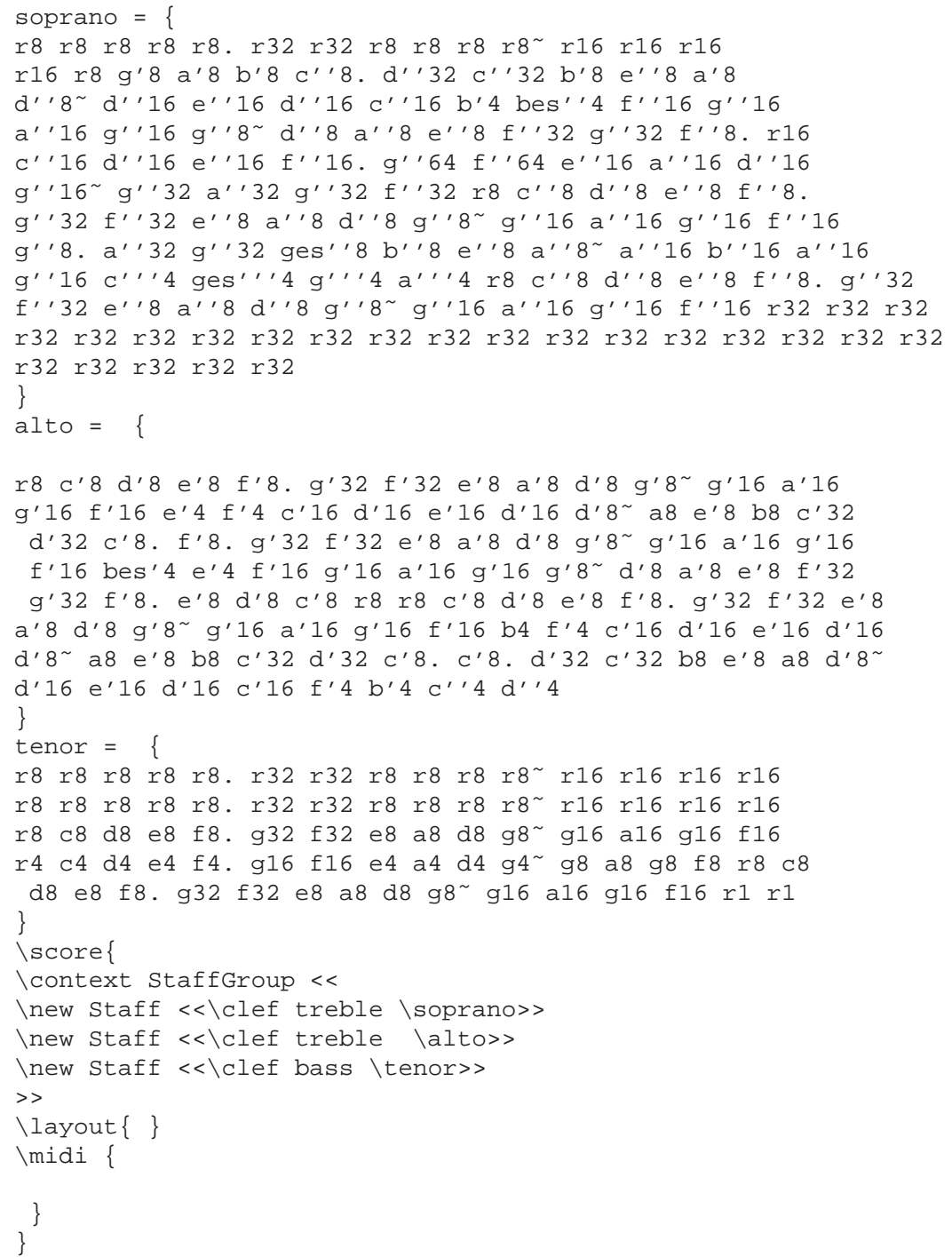

Código 7.1.1: Arquivo gerado pelo programa

\subsubsection{Partitura}



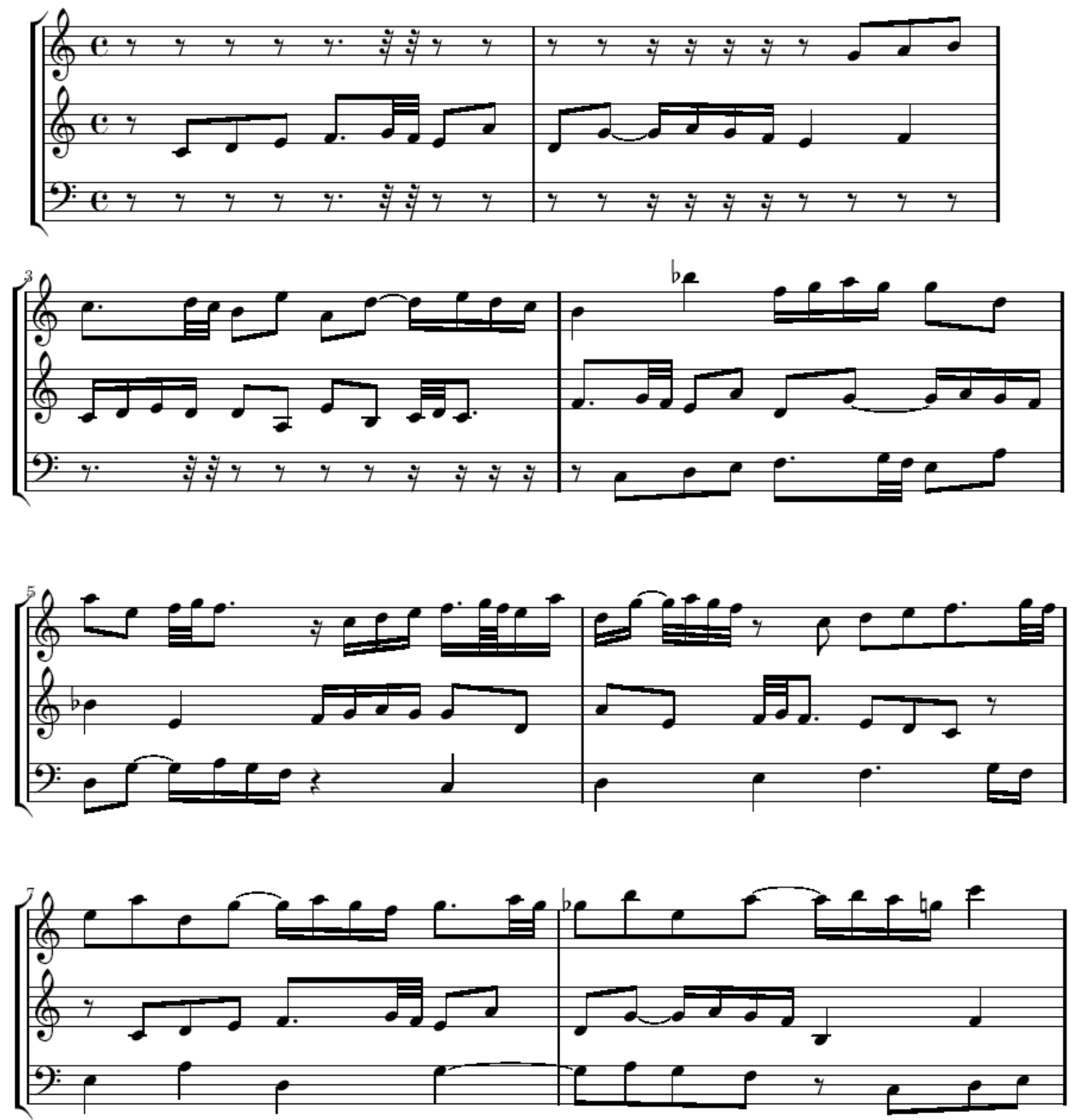

Figura 7.2: Partitura 

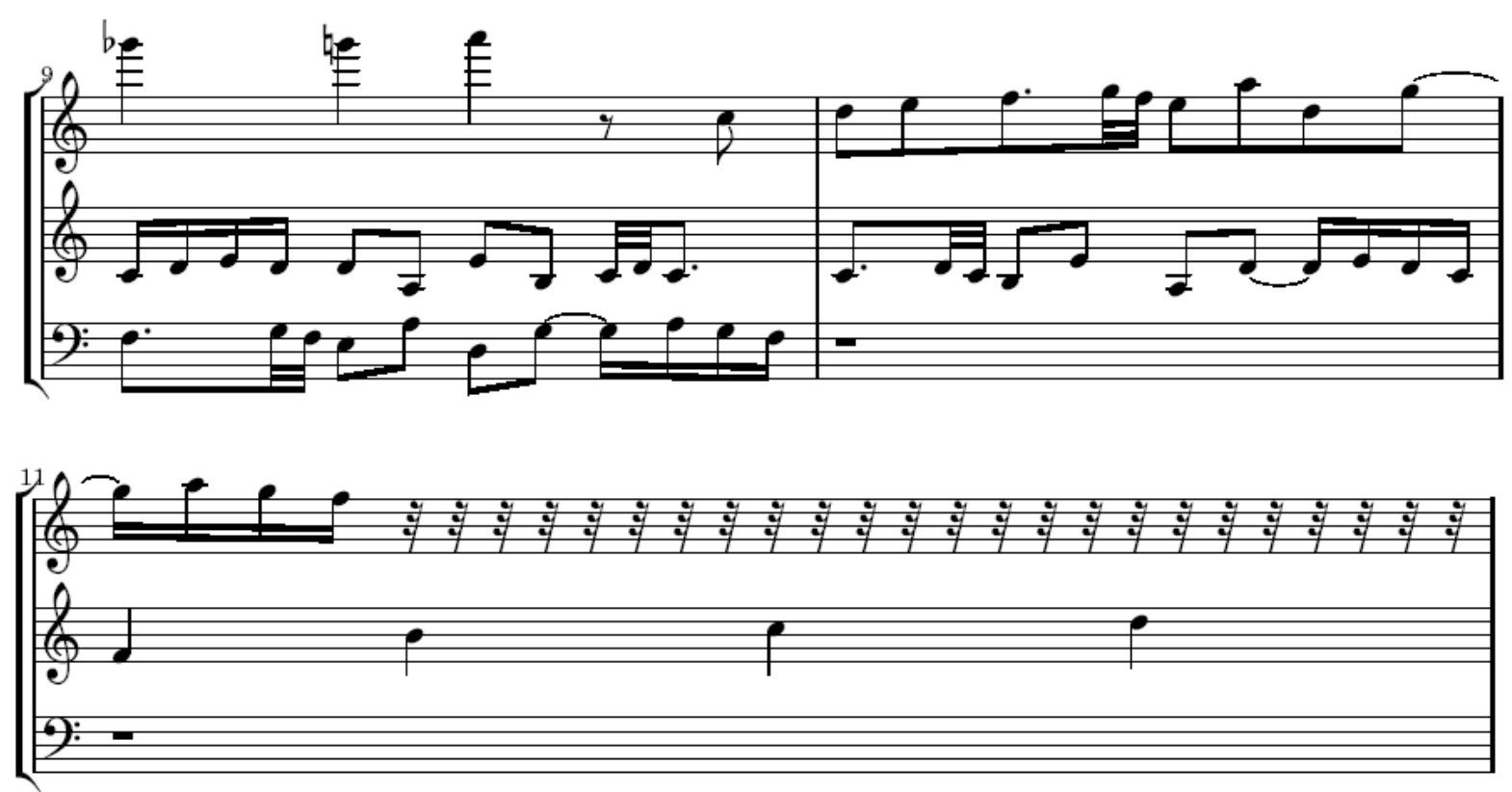

Figura 7.3: Continuação da Partitura

\subsection{Exemplo 2: O Cravo Bem Temperado, Fuga II em Dó Menor (BWV 847)}

\subsubsection{Sujeito ( entrada do programa )}

A notação para este sujeito é:

r8 c"16 b'16 c"8 g’8 aes'8 c"16 b'16 c"8 d"8 g’8 c"16 b'16 c"8 d"8 f'16 g'16 aes'4 g' 16 f' 16 ees'16

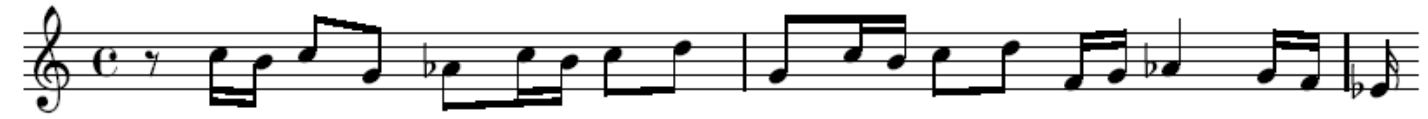

Figura 7.4: Sujeito da Fuga 


\subsubsection{Fuga ( saida do programa )}

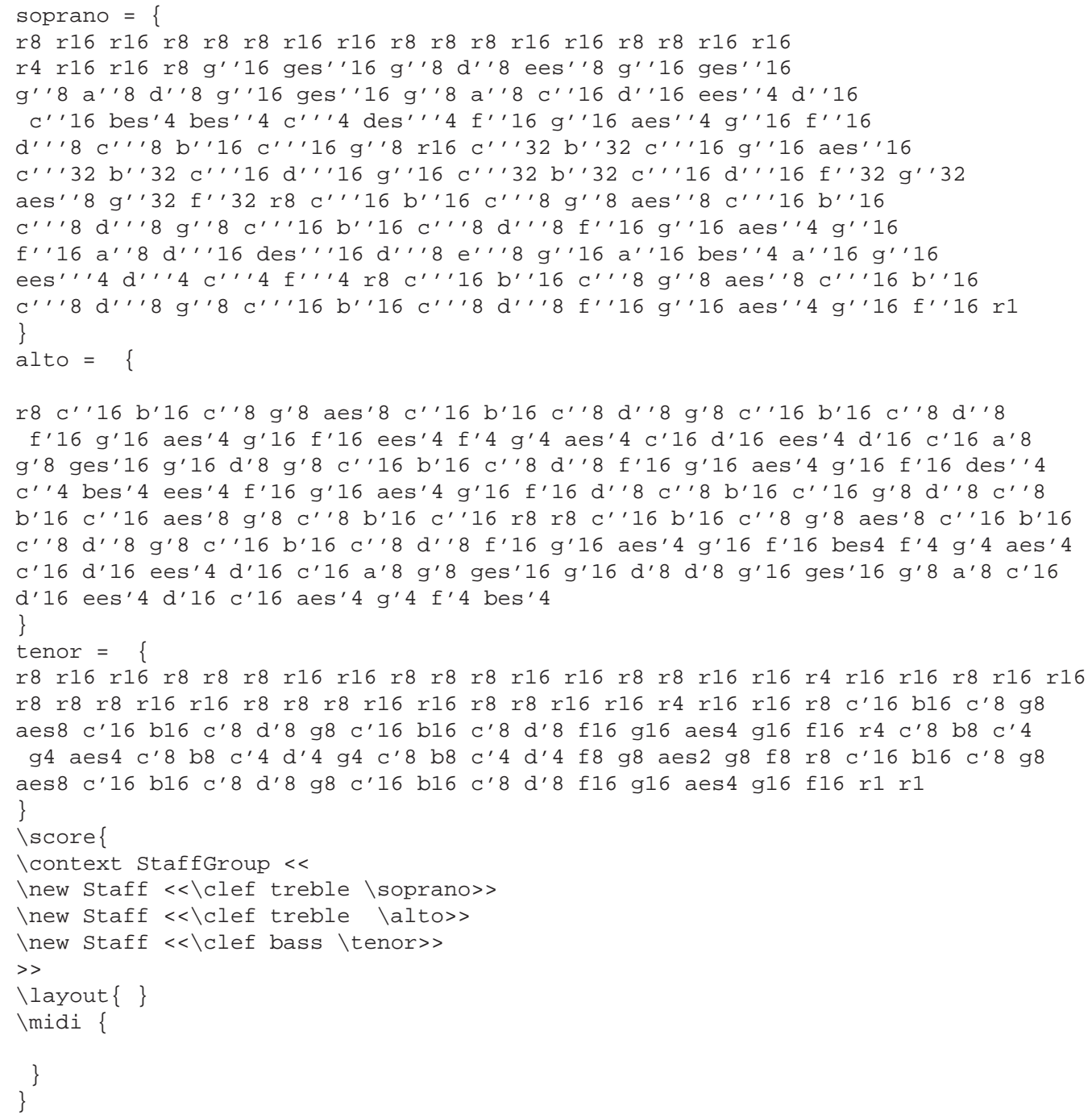

Código 7.2.1: Arquivo gerado pelo programa

\subsubsection{Partitura}



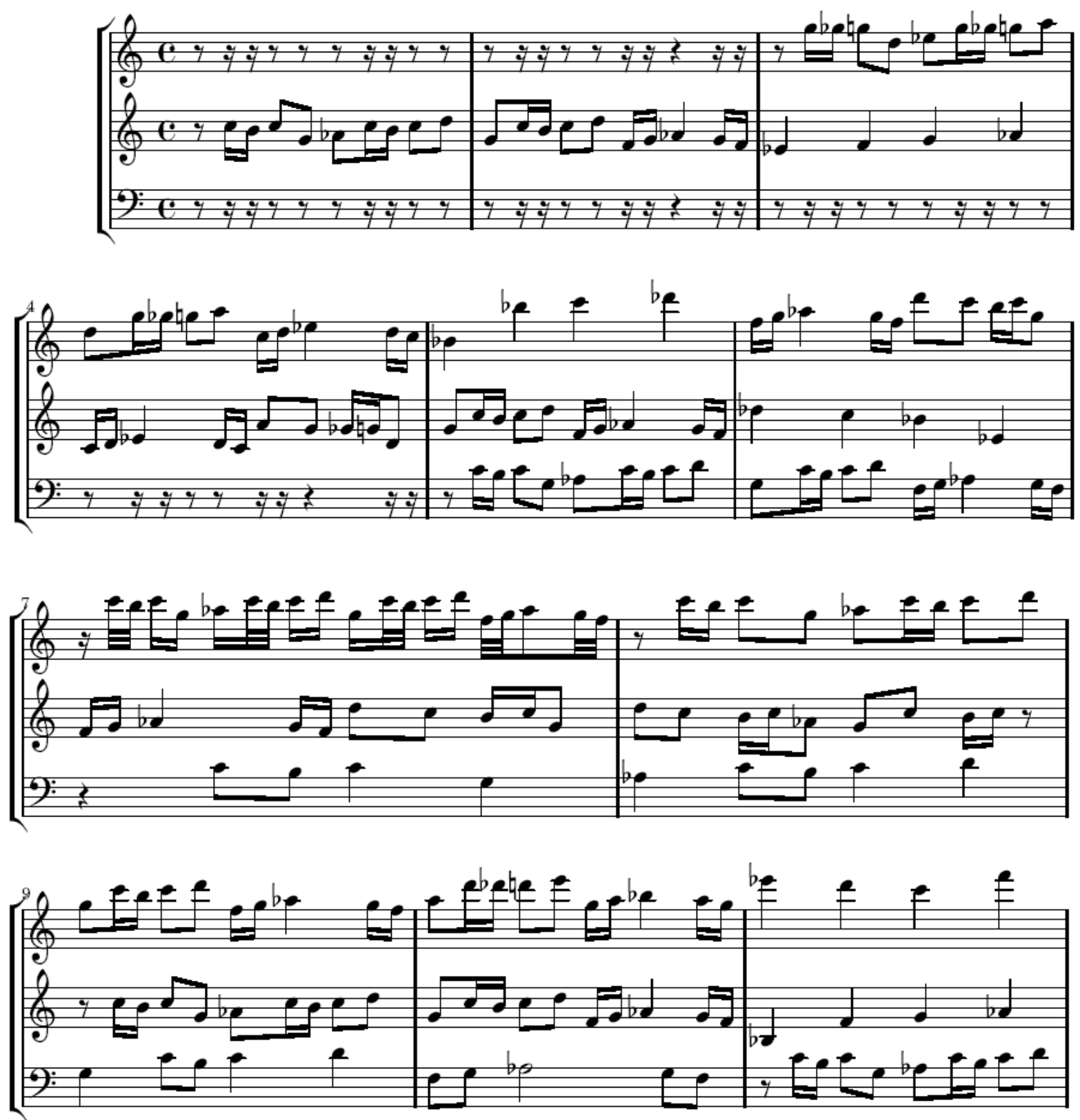

Figura 7.5: Partitura 


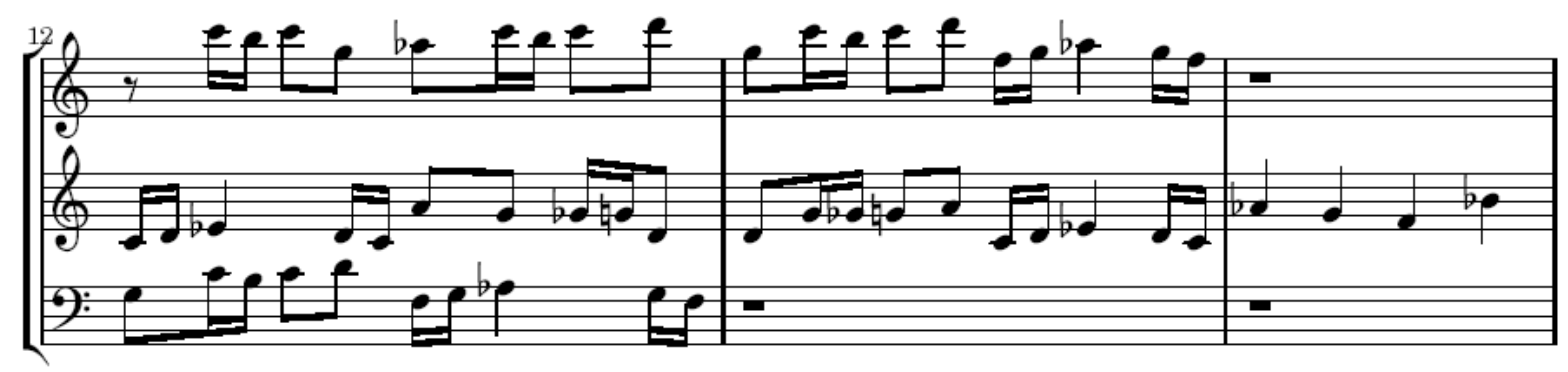

Figura 7.6: Continuação da Partitura

\subsection{Exemplo 3: A Arte da Fuga, Contrapunc- tus I em Ré Menor (BWV 1080)}

\subsubsection{Sujeito ( entrada do programa )}

A notação para este sujeito é:

d'2 a'2 f'2 d'2 cis'2 d'4 e'4 f'2 f'8 g'8 f'8 e'8 d'4

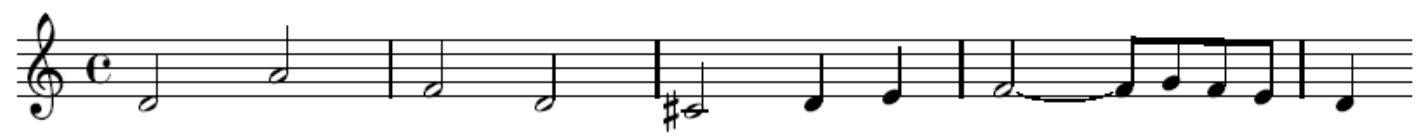

Figura 7.7: Sujeito da Fuga 


\subsubsection{Fuga ( saida do programa )}

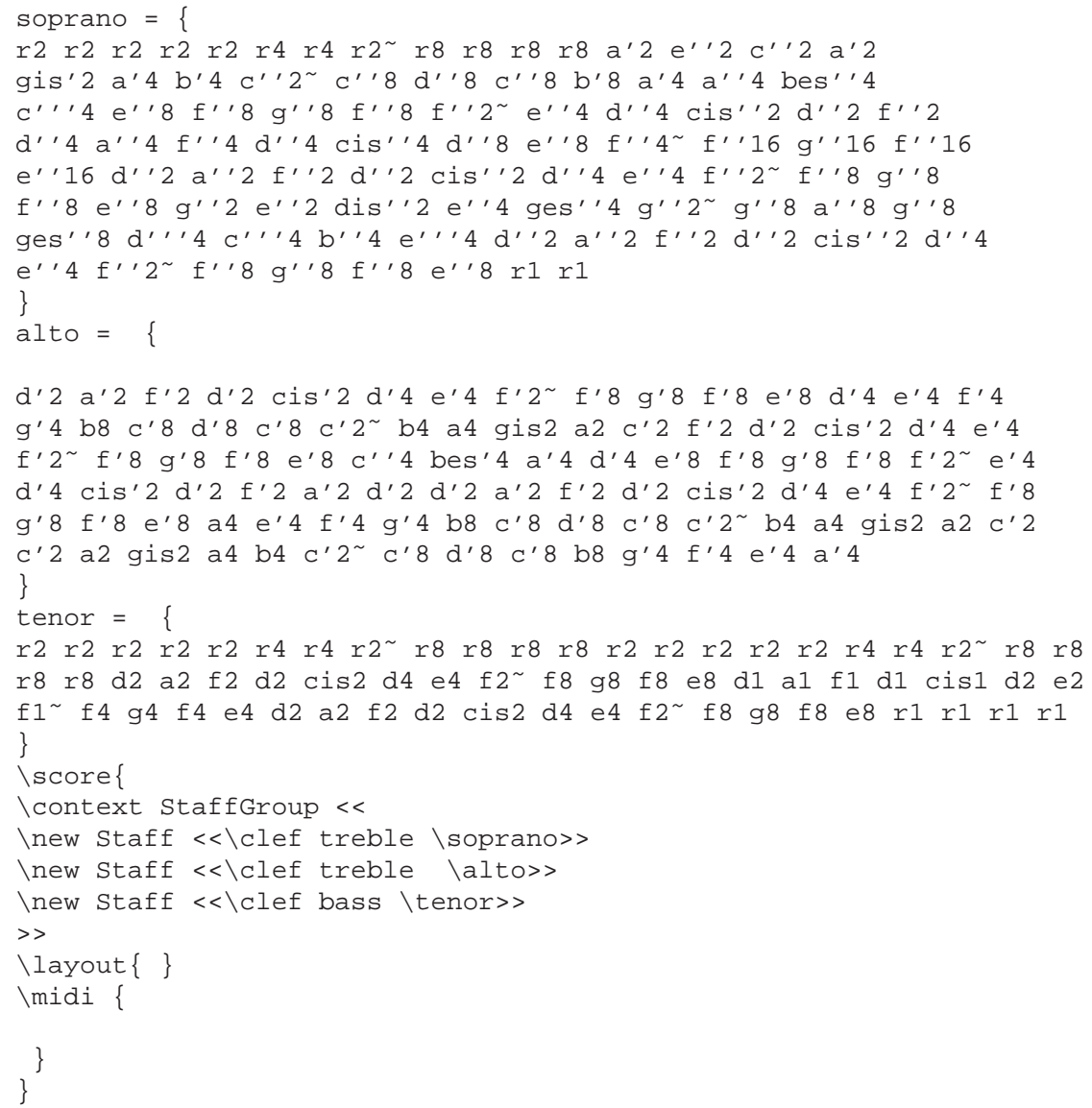

Código 7.3.1: Arquivo gerado pelo programa

\subsubsection{Partitura}



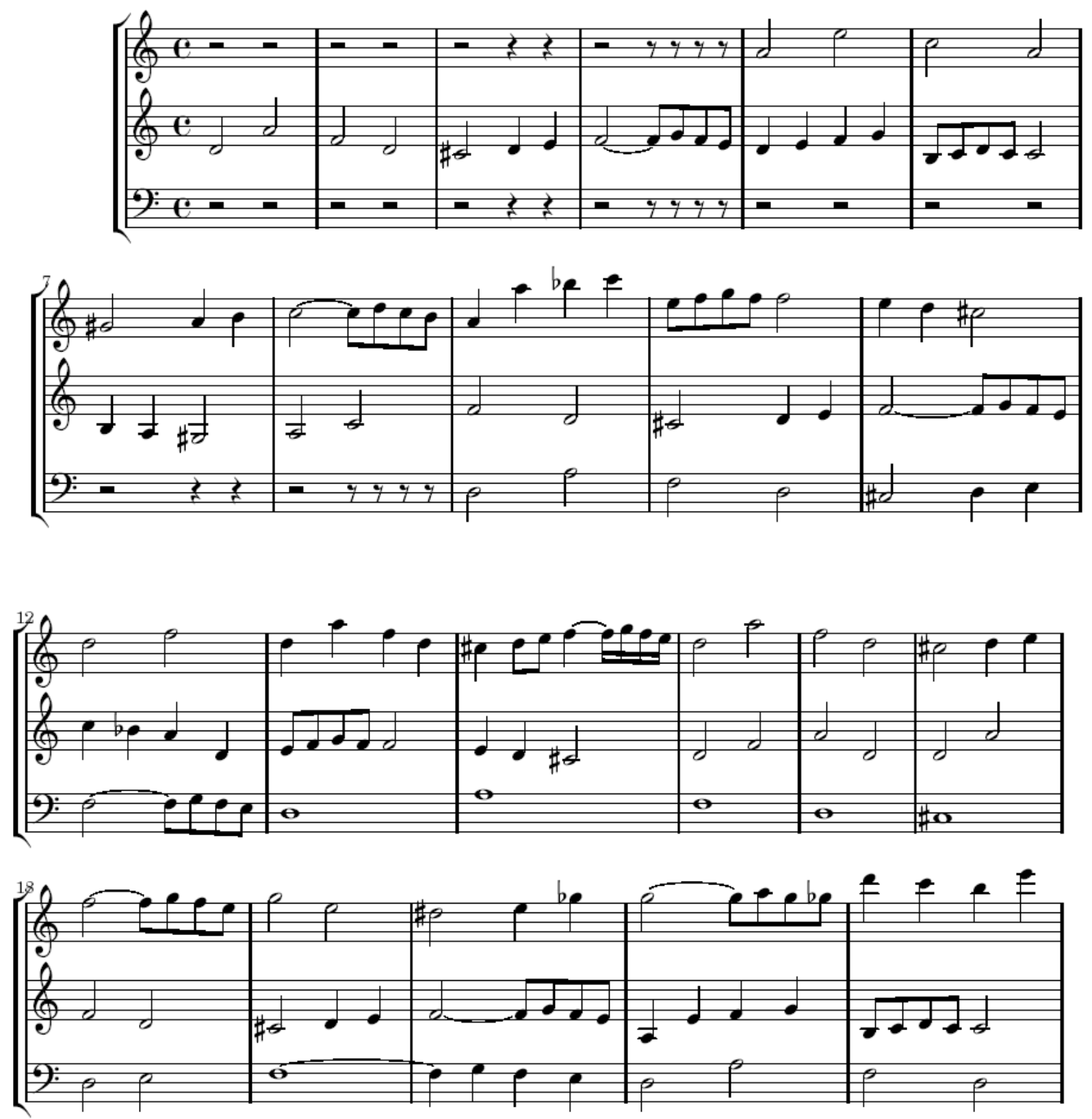

Figura 7.8: Partitura 


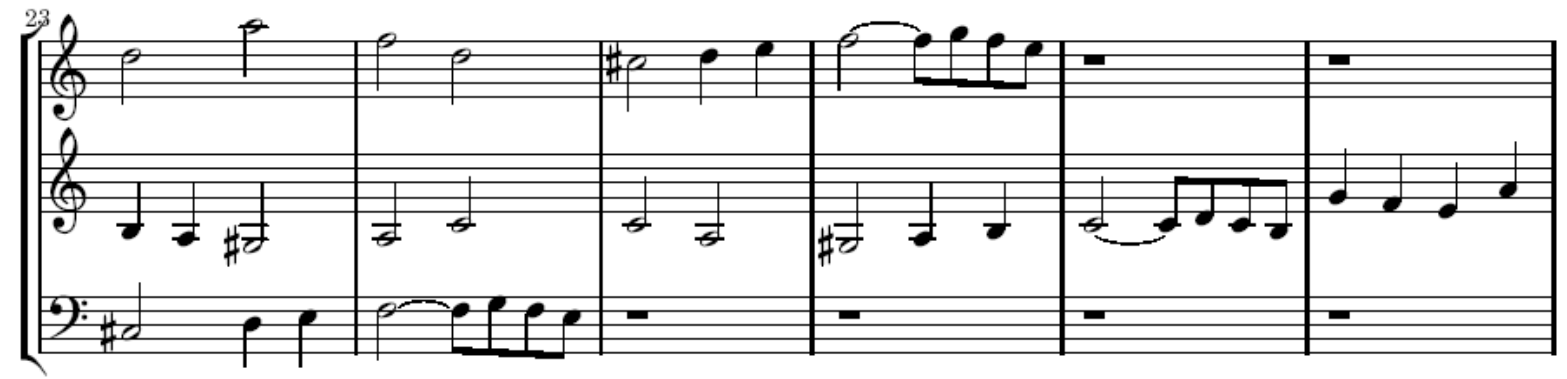

Figura 7.9: Continuação da Partitura

\subsection{Exemplo 4: Tema do Desenho Animado "Os Simpsons"}

\subsubsection{Sujeito ( entrada do programa )}

A notação para este sujeito é:

c'4. e'8 e'8 fis'4 a'8 g'4. e'8 r8 c'8 r8 a8 fis8 fis8 fis8 g8 g4

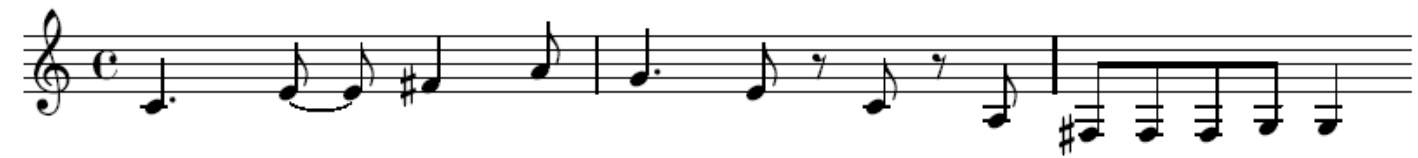

Figura 7.10: Sujeito da Fuga 


\subsubsection{Fuga ( saida do programa )}

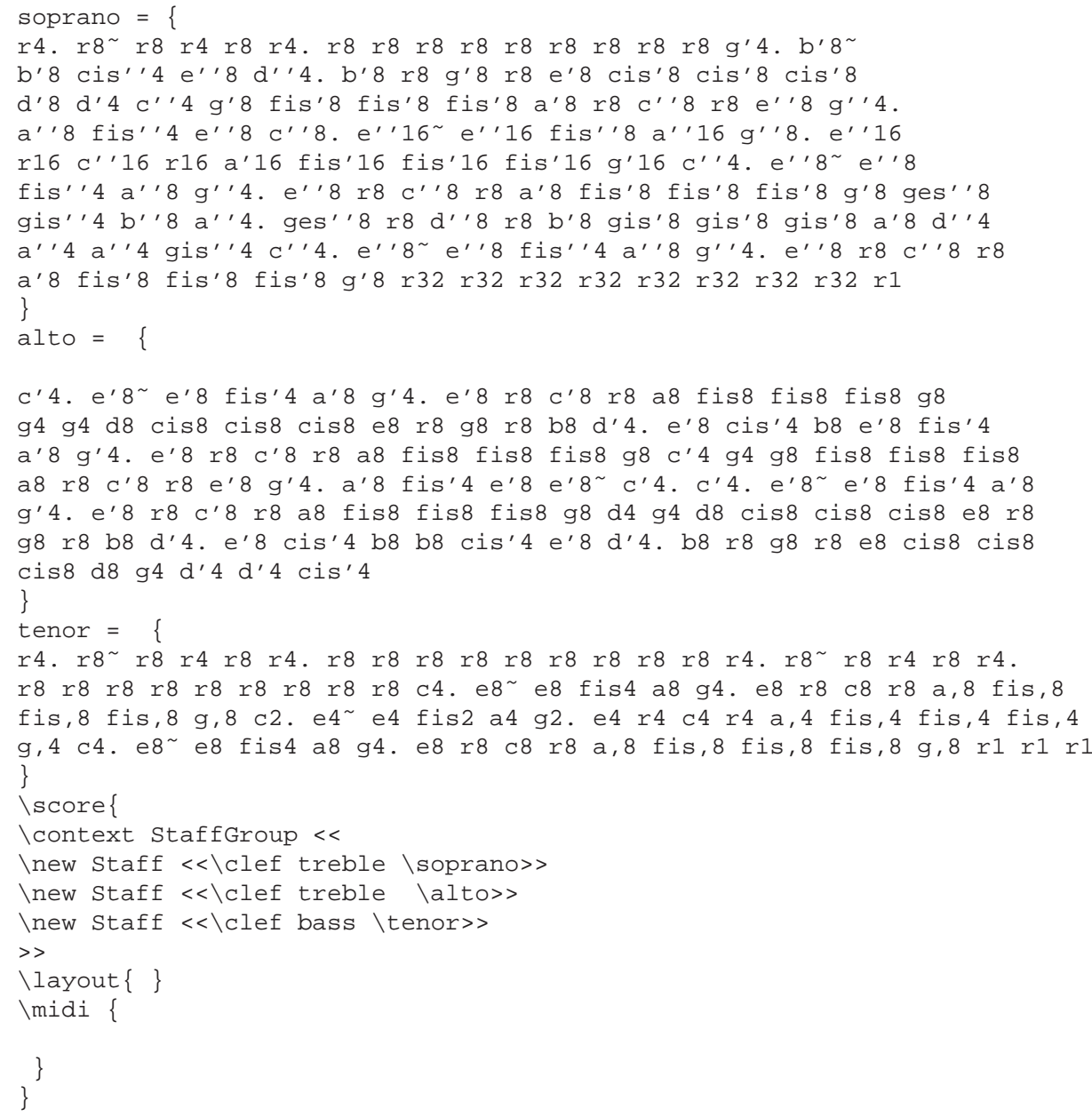

Código 7.4.1: Arquivo gerado pelo programa

\subsubsection{Partitura}



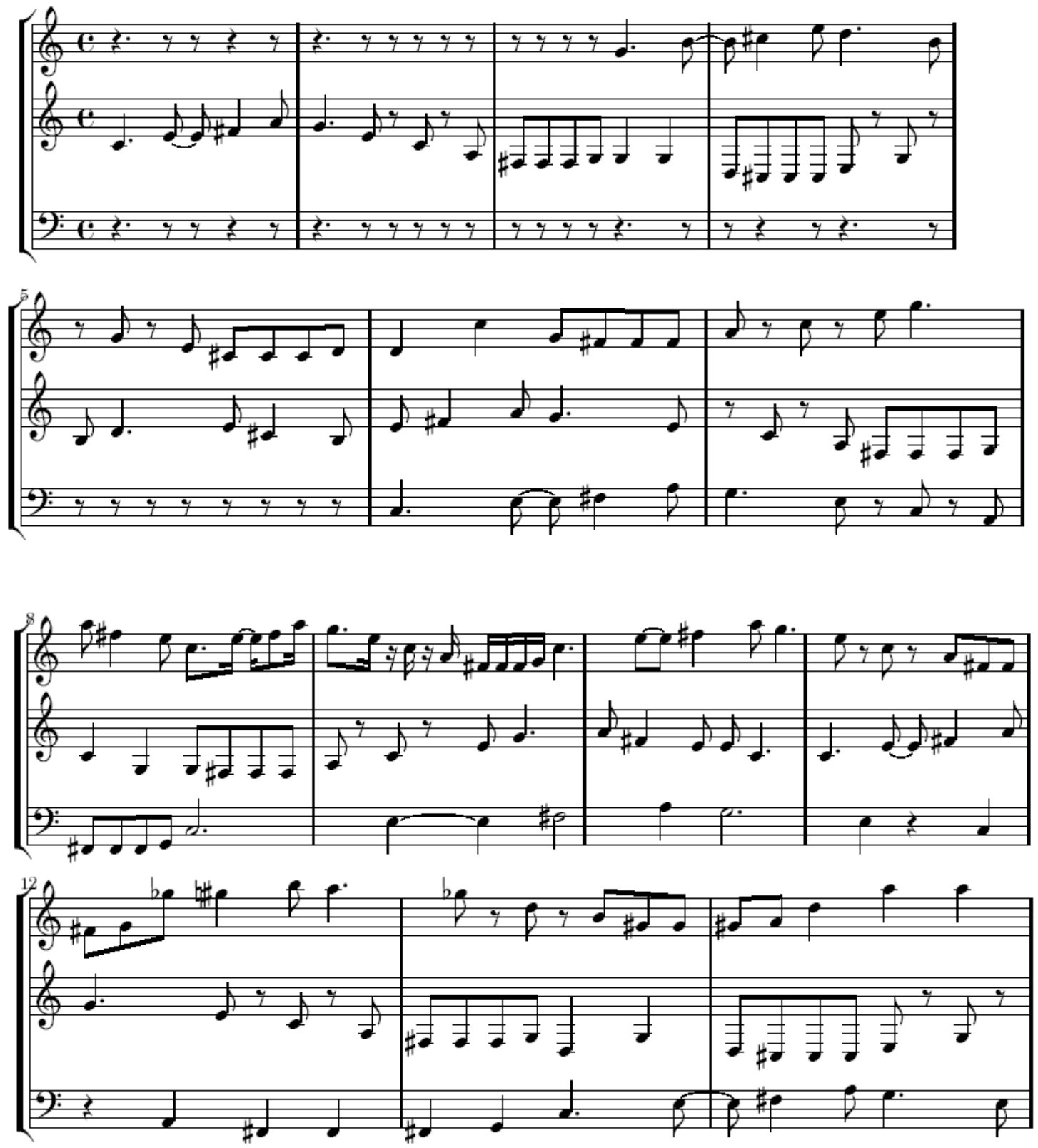

Figura 7.11: Partitura 


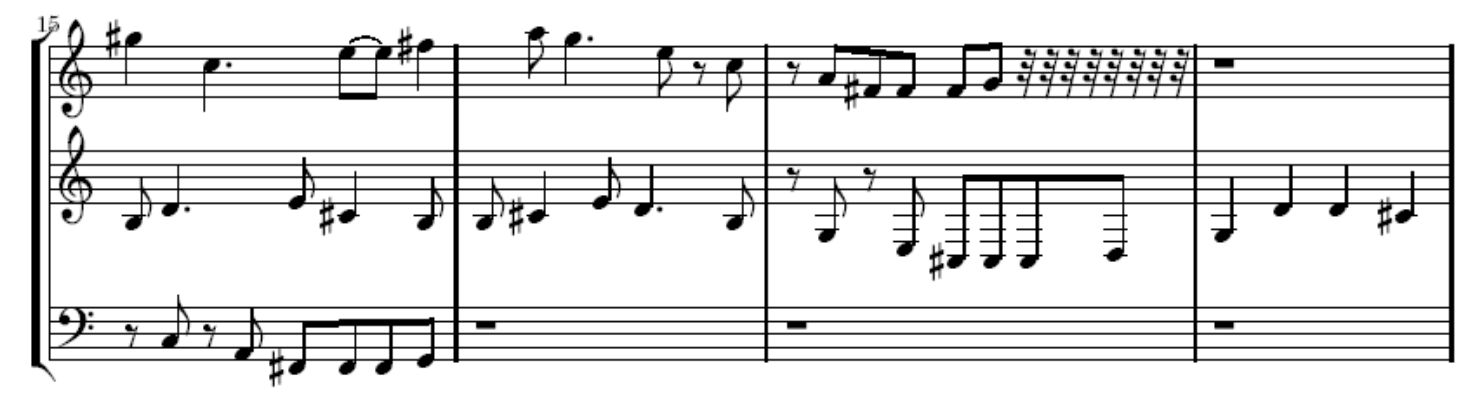

Figura 7.12: Continuação da Partitura 


\section{Capítulo 8}

\section{Conclusões e Trabalhos Futuros}

O presente trabalho mostrou-se satisfatório na composição de uma fuga usando uma implementação computacional de um algoritmo. $\mathrm{O}$ julgamento estético dos resultados fica a cargo dos ouvintes das fugas geradas.

O uso desse algoritmo, do modo como foi implementado, permitiu somente uma única estruturação para as músicas geradas, resultando, assim, em um aspecto intrínseco das composições [11], mas nem por isso perdeu-se a variedade nos resultados obtidos.

O próprio ato de implementar o algoritmo gerador de fugas tornouse uma forma de compor fugas. Mas uma vez pronto o programa, os resultados ficaram intimamente associados às entradas, ou seja, aos sujeitos.

Muitas modificações ainda podem ser feitas para aperfeiçoar o programa gerador de fugas, que ainda apresenta-se incompleto. Podese melhorá-lo para poder aceitar uma gama maior de sujeitos, ritmos ternários, entre outras coisas.

A parte de conclusão da fuga não foi implementada e seria o mais natural prosseguimento do trabalho. 


\section{Referências Bibliográficas}

[1] http://lilypond.org/doc/v2.10/Documentation/, 2008.

[2] http://pt.wikipedia.org/wiki/Altura(m\%C3\%BAsica), 2008.

[3] Andres Garay Acevedo. Fugue composition with counterpoint melody generation using genetic algorithms. In Computer Music Modeling and Retrieval. Springer, 2005.

[4] Harry B. Lincoln. The computer and music. Cornell University Press, Ithaca, New York, first edition edition, 1970.

[5] Johann Sebastian Bach. Das Wohltemperierte Klavier. G. Henle Verlag, München, 1960.

[6] Marcel Bitsch and Jean Bonfils. La Fugue. Éditions Combre, Paris, 1993.

[7] Amando Blanquer. Tecnica del Contrapunto. Real Musical S. A., Madri, 1975.

[8] Stephan Krehl. Fuga. Editorial Labor S. A., Barcelona, primera edición edition, 1930.

[9] Fred Lerdahl and Ray Jackendoff. A Generative Theory of Tonal Music. The MIT Press, Cambrige, Massachusets, 1996.

[10] Alfred Mann. The Study of Fugue. Faber and Faber, 24 Russell Square, London, 1958.

[11] Martin Supper. A few remarks on algorithmic composition. Computer Music Journal, pages 48-53, 2001. 